

\section{Propositions}

1. One cannot understand health worker motivation without immersing oneself in the health care environment.

(this thesis)

2. Health worker motivation is a complex phenomenon and a product of interpersonal and organisational processes in the work context.

(this thesis)

3. The media is a detraction of governance processes, yet political and communication sciences consider it as the fourth estate in democratic governance.

4. In certain cultures taking care of siblings is considered as training children to become responsible adults, yet child development theorists suggest that it is an abuse of children's right.

5. Rights-based approaches are being touted as progressive development strategies, but it is questionable the extent to which people living in conditions of material deprivation and social oppression can claim their rights.

6. Pursuing a PhD is like the work of a porter: patience, diligence and resilience are key to successful completion.

7. One of the greatest tragedies in life is for one to lose hope and resign oneself to fate.

Propositions belonging to the thesis, entitled

Frontline health worker motivation in the provision of maternal and neonatal health care in Ghana

Matilda Aberese-Ako

Wageningen, 9 November 2016 


\section{Frontline health worker motivation in the provision of maternal and neonatal health care in Ghana}

Matilda Aberese-Ako 


\section{Thesis committee}

\section{Promotors}

Prof. Dr J.W.M. van Dijk

Special professor Law and Governance in Africa

Wageningen University \& Research

Prof. Dr I.A. Agyepong

Research and Development Division

Ghana Health Service

\section{Co-promotor}

Dr G.J.E. Gerrits

Assistant professor, University of Amsterdam

\section{Other members}

Prof. Dr M.A. Koelen, Wageningen University \& Research

Dr B.P. Adongo, University of Ghana, School of Public Health, Legon-Accra, Ghana Dr M. Dieleman, Royal Tropical Institute, Amsterdam

Prof. Dr B.B. Bock, Wageningen University \& Research

This research was conducted under the auspices of the Graduate School of Wageningen

School of Social Sciences (WASS). 


\title{
Frontline health worker motivation in the provision of maternal and neonatal health care in Ghana
}

\author{
Matilda Aberese-Ako
}

Thesis

submitted in fulfilment of the requirements for the degree of doctor

at Wageningen University

by the authority of the Rector Magnificus,

Prof. Dr A.P.J. Mol,

in the presence of the

Thesis Committee appointed by the Academic Board

to be defended in public

on Wednesday 9 November, 2016

at 1.30 p.m. in the Aula 
Matilda Aberese-Ako

Frontline health worker motivation in the provision of maternal and neonatal health care in Ghana

177 pages.

PhD thesis, Wageningen University, Wageningen, NL (2016)

With references, with summaries in Dutch and English

ISBN: 978-94-6257-893-7

http://dx.doi.org/10.18174/387863 


\section{Acknowledgements}

I experienced a coach in you Han Van Dijk. I enjoyed every aspect of our interaction through which I benefitted immensely from your expert advice, counsel, teaching, coaching, mentoring and sharing your experience in your field work in Mali. I am greatly indebted to you for always being there for me and all the others. Like the father of the prodigal son, you love and respect each of your students in your own special way and make each of us see the good in us.

Prof. Dr. Irene Akua Agyepong, I say 'ayeekoo' to you for the expert supervision, mentoring and training; it was indeed a privilege to be supervised by you. The first time I encountered you was at Alisa hotel, where you made a presentation on health worker motivation on the Ghanaian-Dutch collaboration scientific dissemination. The second time your name came up was when you were made the Prince Claus Chair Professor in 2008 and a piece was written on you in the Ghanaian weekly mirror. I developed a yearning to learn from you and getting the opportunity to pursue a PhD under your tutelage became an answered prayer.

Dr. Trudie Gerrits, thank you for the supervisory support and for facilitating my studies at AMMA, both helped me to perfect my anthropological skills. I am very appreciative of that. Thank you Dr. Daniel Arhinful for the times that you offered me supervision, which helped me to improve on my research skills. Professor Emiritus Sjaak Van Der Geest, I say 'Ayeekoo' to you for your expert knowledge, which you freely shared with me. It was my privilege to encounter you and to be able to tap a little of your expert knowledge in anthropology. I am forever indebted to you for your help in getting me a supervisor and for linking me to other experts in the field of medical anthropology.

Lucie, Marielle, Diana, Coby and Enge, I appreciate the assistance you gave me, which helped me to find my way in the university. Dr. Patricia Akweongo, you knew my obsession to pursue a $\mathrm{PhD}$, so you forwarded the $\mathrm{PhD}$ call to me, which enabled me to apply for the position. You guided me in every stage and you still continue to offer me your sisterly support. I am eternally grateful to you. Thank you, Professor Fred Binka, for your support and encouragement. Dr. Abdallah Ibrahim, thank you for your support in reading portions of my thesis. My colleagues Augustina, Kayode, Lucy, Theresa, Mary, Modesta, Aku and Hilde, I appreciate your support and companionship. 
My dear Elizabeth Awine, I am eternally grateful for the sisterly love and support, you are the angel that is always on my path to pick up the pieces after me, to pre-empt and to anchor me. Thanks so much Dr. Kotoh and Gertrude for your encouragement, belief in me and for the privilege of being a friend and a sister. Dr.Akazili: 'fum mari fumia me paaa!!' Gifty Apiung, I am most grateful for your assistance and support throughout this $\mathrm{PhD}$ trajectory and I wish you the very best in yours.

Dr. Abraham Oduro, the director of the Navrongo Health Research Centre, the administrator Mrs. Sumbo, Dr. Cornelius Debpuur - 'my boss-slave', Dr. Williams and to Felix Kondayire for your immense help. To my colleagues Paulina, Kondayire, Thompson, Sebastian, Maxwell and Nathaniel, I am grateful for your prayers and support. Vida Kukula, Wing Commander Rtd Francis Anaman, Regina and Sebastian Bagina, I am very grateful for your prayers and support. Special gratitude to my family in Wageningen: Monica, Steven, Andre, Margaret, Samson and Family. Thank you my friends Nashiru, Theresa, the Sikaman community, Edem, Sebastian, Bizola and Fulera.

To my father the late Donald Aberese Akosenaba, my mother Mary Ann Mmeayem Ako and my siblings Mark Gordon, Justina, Theodora, Francis and Macdonald, I thank you for the different roles that you have played in my life and in this PhD trajectory. To Mr. Francis Avonsige, for your fatherly love and support, you have been our father since we lost our father thirty years ago. Sister Leticia Abiroduko, Solomon asked for wisdom and God gave him wealth as well. I asked for a cousin and God gave me a mother, a sister and a friend, thank you for being all that. Dr. Anthony Akunzule and Mrs. Akunzule, thank you so much for allowing Sukwene Naba-Ayine to use you to bless me so much. Without you I won't have had such a perfect academic place to stay for three years plus. Sister Agnes Abongo, thank you for your sisterly support and for linking me to the Akunzulis, your friends to help me. To my neighbours at Tse Addo Mavis, Francis, Mr Sawyerr and family and my friend Corporal Andrew, thank you for your support. I am also grateful to Rev. Frs. Abasi, Agana, Heap, Bangsiibu and Henry, the Tono Catholic community, St. Catherine Catholic community, Burmah Camp and the St. John the Baptist Catholic community of Wageningen for your prayers and support. To Aziks and Roland of the St. Anthony's guild, my childhood neighbour, Mrs Rose Boahene and Mathew Tabilba, your advices have taken me this far, may God richly bless you. 
I acknowledge with gratitude the greater Accra Regional Health directorate, the two districts and the management and staff of the study hospitals, many of whom became my friends, but for ethical reasons I will not mention their names. To the greatest of all I say Npuusiya Sukwene Naba Ayine! 


\section{Contents}

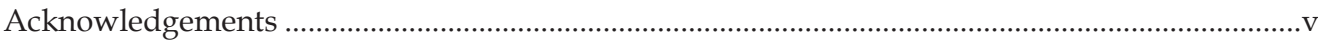

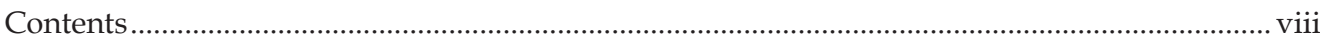

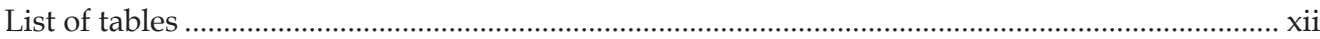

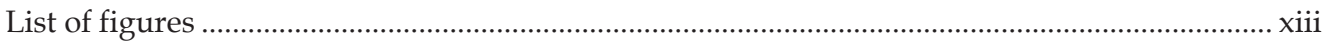

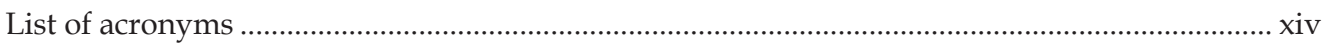

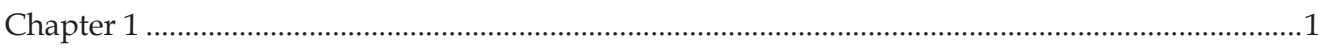

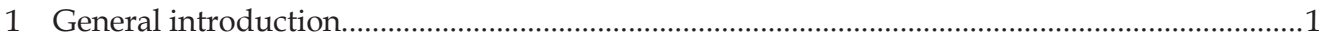

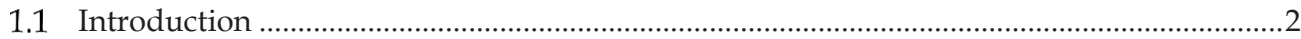

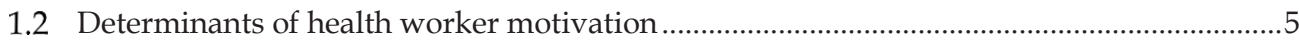

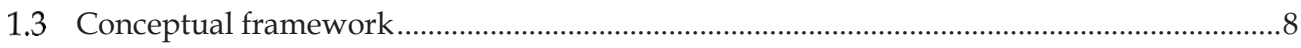

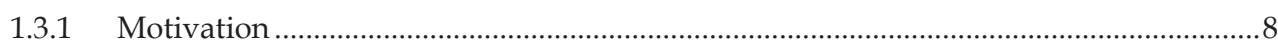

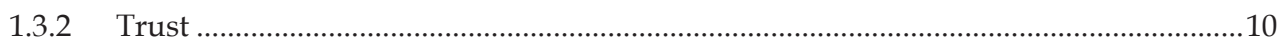

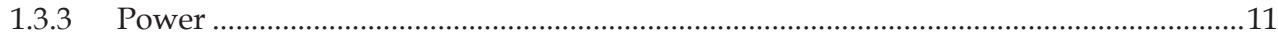

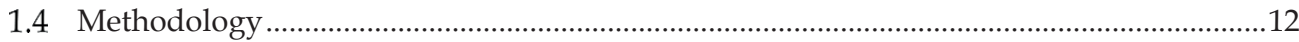

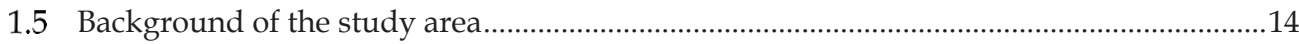

1.6 The Ghana health care system and health care arrangements..........................................14

1.6.1 Opportunities and challenges within the Ghana Health Service .................................17

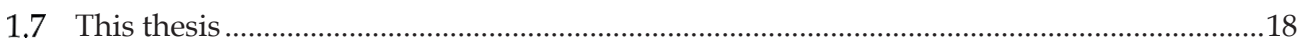

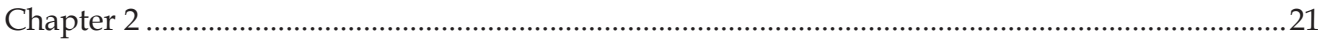

2 'I won't take part!' exploring the multiple identities of the ethnographer in two Ghanaian

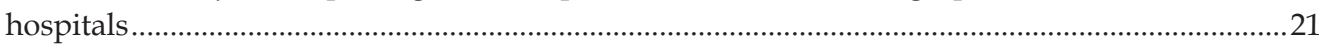

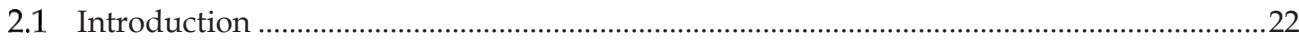

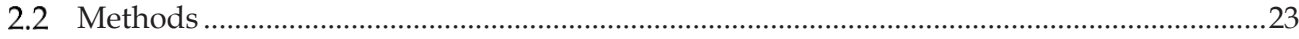

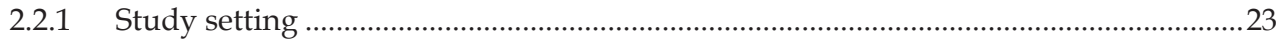

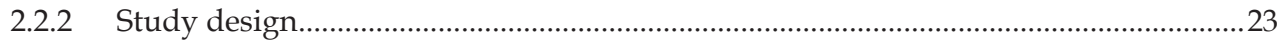

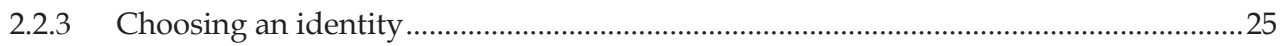

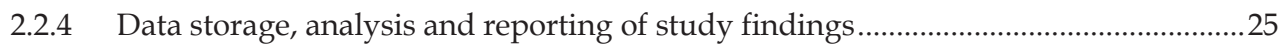




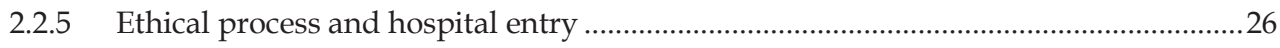

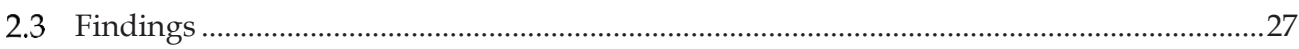

2.3.1 An interview with the head of Adom hospital ...........................................................2

2.3.2 My multiple identities in the eyes of research participants ..........................................27

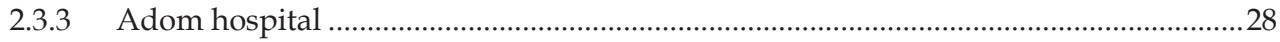

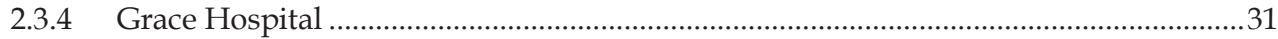

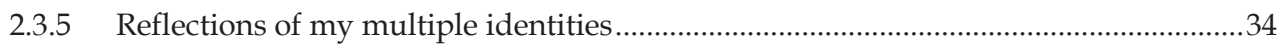

2.3.6 Making sense of my multiple identities in Adom hospital ...........................................35

2.3.7 Making sense of my multiple identities in Grace hospital ............................................36

2.4 Health worker motivation, identity and trust/distrust relations in the hospital

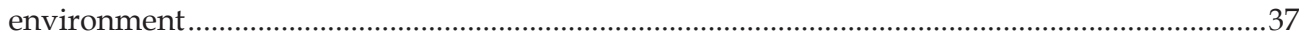

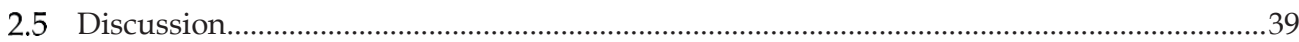

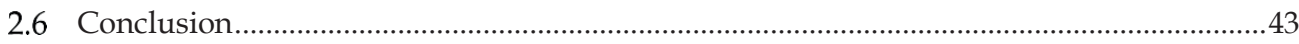

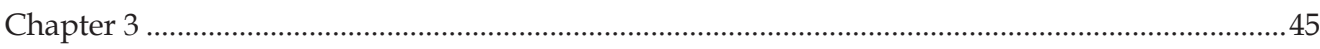

3 'Your health our concern, our health whose concern?' perceptions of injustice in organizational relationships and processes and frontline health worker motivation in Ghana ............................4 45

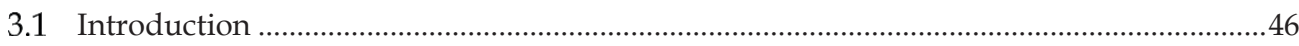

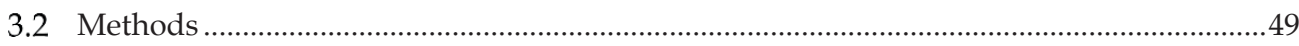

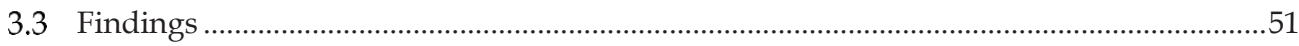

3.3.1 Perceived procedural and distributive injustice related to local hospital management53

3.3.2 Perceived distributive injustice related to wider health sector issues at national level58

3.3.3 Perceived interactional injustice related to hospital management................................63

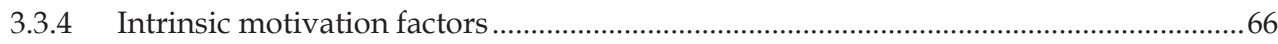

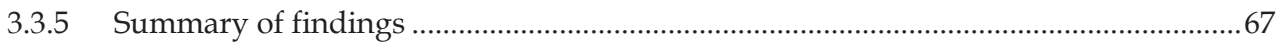

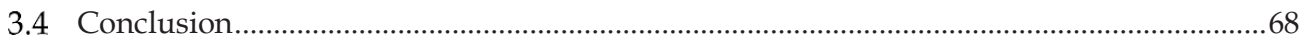

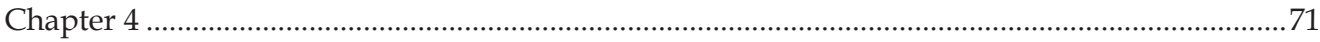

4 'I used to fight with them but now I have stopped!' Conflict and doctor-nurse-anaesthetists' motivation in maternal and neonatal care provision in a specialist referral hospital ....................71

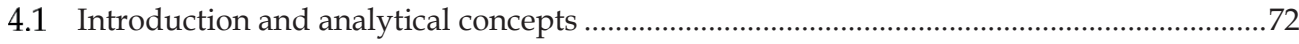

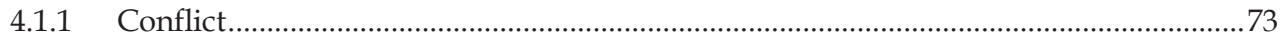




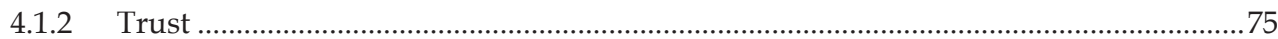

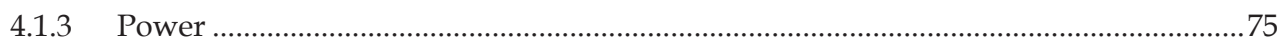

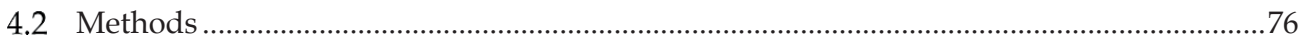

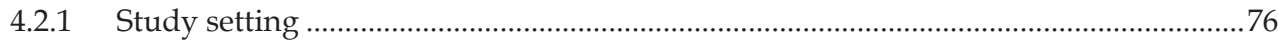

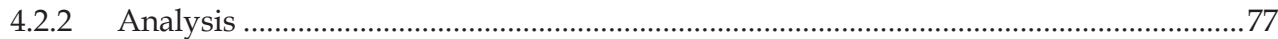

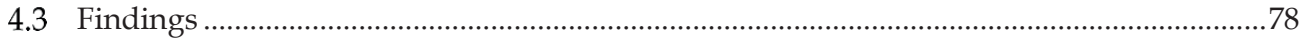

4.3.1 Unclear lines of authority at organisational level and perceived lack of recognition of nurse-anaesthetists

4.3.2 Different professional orientation resulting in different decision making pathways 84

4.3.3 Distrust of co-workers' professional competencies..... .86

4.3.4 Locum practice and illegal charges and the inability of the hospital to resolve such matters 87

4.3.5 Organisational arrangements inhibited frequent communication and the building of

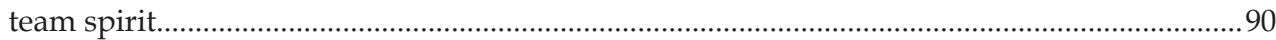

4.3.6 Distrust resulting from perceived distributive and interactional injustice ..................92

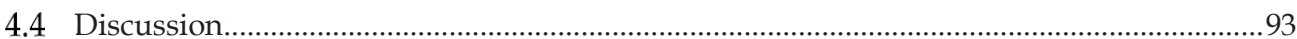

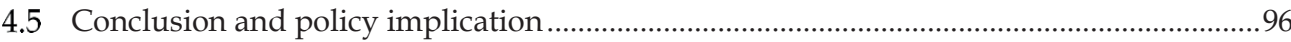

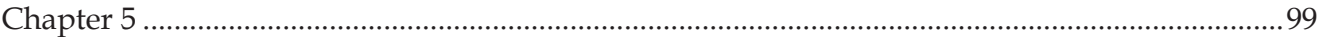

5 Even me, sometimes I get sick': Reflections on hospital managers' decision making power in

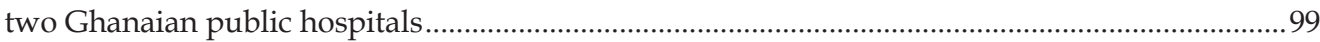

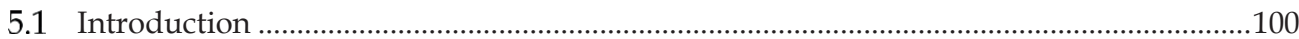

5.1.1 Power and trust relations in public hospitals................................................................101

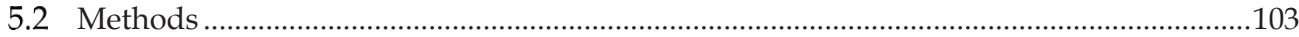

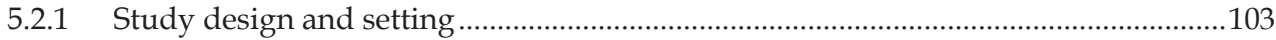

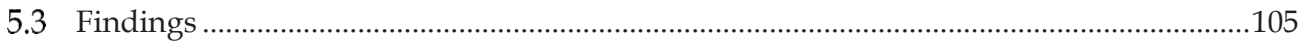

5.3.1 Managers' decision making power on human resource...............................................106

5.3.2 Managers' decision making power on health workforce financial and financial

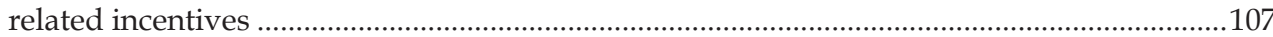

5.3.3 Managers' decision making power on infrastructure development, supplies and

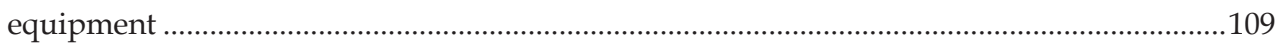

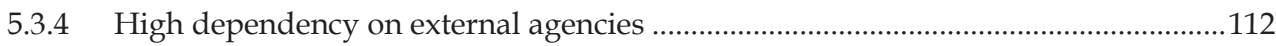

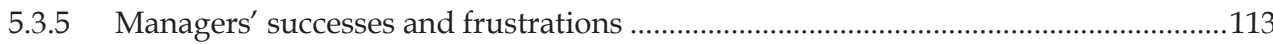


5.3.6 Recommendations from managers ...........................................................................114

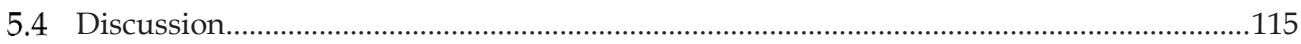

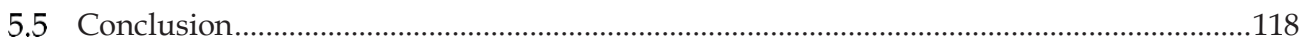

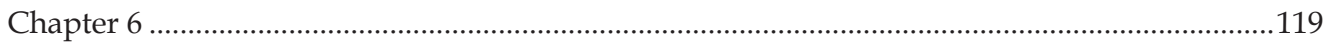

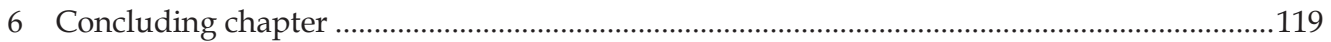

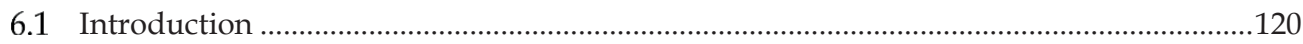

6.2 Interpersonal processes influencing health worker motivation .......................................120

6.3 Organisational and managerial processes influencing health worker motivation ...........121

6.4 Ghana wider health sector design and policies influencing health worker motivation ..123

6.5 Health worker motivation and response to clients' health needs ......................................125

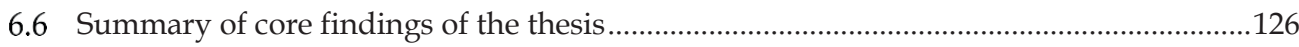

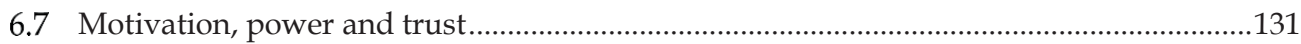

6.8 Implications of findings for MDG 4 and 5 in Ghana.......................................................133

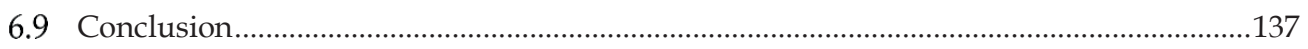

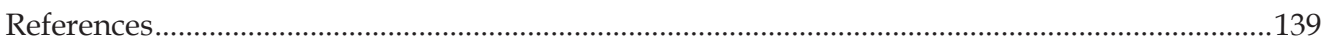

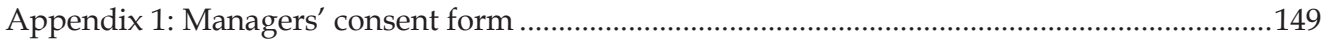

Appendix 2: Frontline health workers' consent form ................................................................151

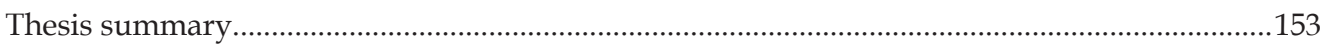

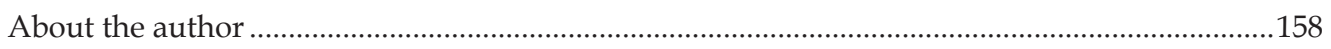

Completed Training and Supervision Plan …............................................................................159 


\section{List of tables}

Table 2.1 Categories of workers in Adom and Grace hospitals who I conversed with and participants who were interviewed .24

Table 3.1 Categories of workers in Adom and Grace hospitals who were included in the study and methods used in collecting data

Table 4.1 Categories of workers included in conversations and interviews.

Table 5.1 Data collection methods used and category of study participants who were contacted 


\section{List of figures}

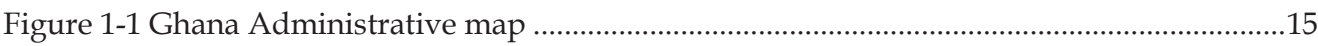

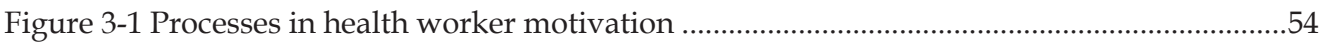

Figure 4-1 Framework of causes, management and consequences of conflicts in Adom hospital

.80

Figure 6-1 Complex set of extrinsic factors influencing worker motivation ................................129

Figure 6-2 Extrinsic and intrinsic determiners of health worker motivation and consequences on health worker responsiveness to clients' health needs 


\section{List of acronyms}

CQI

GHS

GSS

IMF

MDG

$\mathrm{MOH}$

NHIA

NHIS

SAPs

SDG

UNDP
Continuous Quality Improvement

Ghana Health Service

Ghana Statistical Service

International Monetary Fund

Millennium Development Goals

Ministry of Health

National Health Insurance Authority

National Health Insurance Scheme

Structural Adjustment Programmes

Sustainable Development goals

United Nations Development Programme 


\section{Chapter 1}

\section{General introduction}

This chapter presents an introduction to the thesis, rationale for the study, problem statement, the research questions, theoretical framework, and a definition of concepts. Also background of the study area and the state of the Ghana health care sector and arrangements are presented. Additionally the chapter presents a summary to all the chapters of the thesis. 


\subsection{Introduction}

The health of mothers and children determine the health and development of a nation, especially since mothers and children form a critical component of the population and the future of a nation (Ghana Statistical Service (GSS) et al. 2009). Consequently maternal and child health care are key priorities worldwide, which have been clearly enshrined in the Millennium Development Goals 4 (reduce child mortality by two thirds) and 5 (improve maternal health by three quarters) and also in the achievement of the sustainable development goals (Republic of Ghana 2012). To achieve the set targets of Millennium Development Goals (MDG) 4 and 5, the Ghanaian state and other collaborators initiated various intervention policies (Ansong-Tornui et al. 2007; Bosu et al. 2007; Koduah et al. 2015; Witter et al. 2007). The implementation of policies such as a fee exemption policy for pregnant women and children ${ }^{1}$ and the introduction of a national health insurance scheme $(\mathrm{NHIS})^{2}$ contributed to only a gradual improvement in the quality of maternal and child health care (Ansong-Tornui et al. 2007; Bosu et al. 2007; Witter et al. 2007). Maternal mortality and child mortality rates are key indicators of the quality of maternal and child health care in a country (Republic of Ghana 2012). Modelled estimates by the world bank indicates that there was a decrease in maternal mortality from about 630 per 100,000 live births in 1990 to about 350 in 2008 (Republic of Ghana 2012). Existing institutional data suggests that maternal deaths per 100,000 live births declined from 224 per 100,000 in 2007 to 201 per 100,000 in 2008 (excludes maternal mortality outside health care institutions). It is further suggested that if this trend continues, maternal mortality will be reduced to only 340 per 100,000 by 2015, instead of the MDG target of 185 per 100,000 by 2015 (Ministry of Health et al. 2011). Infant mortality rate (IMR) and under-five mortality rate (U5MR) are reported to have declined consistently between 1990 and 2010. The IMR declined by a third from 76.7 in 1990 to 51.3 per 1000 live births in 2009, while the U5MR declined by a third from 121.7 to 76.6 per 1000 live births over the same period. Despite these reductions,

\footnotetext{
1 The policy aims at ensuring that all pregnant women in Ghana utilise professional health care during antenatal health care, delivery and postnatal care for free. It also aims at ensuring that all unborn children and children less than five years are exempted from paying medical bills. (Ibrahim 2014)

2 The scheme aims at ensuring equity in health care in order to facilitate universal access to health care. It is designed such that health care institutions provide care to registered NHIS clients and the insurance authority reimburses them for the cost of the services provided. A new design where facilities are prepaid for services rendered known as per capita provider payment system (capitation) is being instituted, however primary care maternity services are excluded in the new scheme. (Koduah et al. 2015)
} 
it is reported that Ghana's child mortality levels are still relatively high compared with other middle income countries (Republic of Ghana 2012). Consequently maternal and child health continue to remain as key priorities in the national assessment report on the achievement of the sustainable development goals (Republic of Ghana 2012) .

Various studies have tried to explore the reasons for the slow progress in maternal and child health care (Agyepong and Nagai 2011; Ansong-Tornui et al. 2007; Bosu et al. 2007; Koduah et al. 2015). A recent study by Koduah et al. (2015), suggests that the fee exemption policy was not accompanied by an increase in budgetary allocation to the health sector. Additionally, other study findings suggest that health care institutions suffer from resource uncertainty due to erratic and unpredictable reimbursement from the central government and the National Health Insurance scheme (Agyepong and Nagai 2011; Ghana Health Service 2011; Koduah et al. 2015). These challenges complicate public health facilities' bid to provide quality maternal and child health care in Ghana.

Unfortunately, the managerial response to complaints on poor quality care has been to shift blame on mostly frontline health workers (Agyepong et al. 2004). Also public opinion has been that frontline health workers are unreceptive and exhibit negative attitudes in the provision of health care (Turkson 2009). However, studies suggest that frontline health workers provide care within a complex health system that is mediated by many factors including national and health policies, managerial and organisational processes, interpersonal relations between workers, and patient or client factors, all of which influence frontline health worker motivation and attitudes in the provision of health care (Agyepong et al. 2001; Agyepong et al. 2004; Andersen 2004; Bohmig 2010; Böhmig 2010; Senah 2003; Smits 2011).

Health care provision is dependent on the expert knowledge and skills of providers, and for that matter motivated frontline health workers with the right attitudes are crucial in ensuring that quality health care is provided to clients. Resultantly, various studies are beginning to investigate health workforce motivation in lower and middle income countries (Dieleman and Harnmeijer 2006; Dieleman et al. 2006; Franco et al. 2002; Franco et al. 2004; Kanfer 1999; Mbindyo et al. 2009b; Okello and Gilson 2015; Rowe et al. 2005). These studies conclude that a complex set of national, contextual, individual and client dynamics affect worker motivation. Equally in Ghana, various studies have 
investigated health worker motivation in public health care facilities (Adzei and Atinga 2012; Agyepong et al. 2001; Agyepong et al. 2004; Alhassan et al. 2013; Bonenberger et al. 2014; Dovlo 1998). These studies have focused on concrete set of influences and have improved our understanding of the complex and dynamic processes of worker motivation and offered policy recommendations. However these studies have not answered questions on the mechanisms by which multiple interactions at organizational level influence frontline health worker motivation and attitudes in public hospitals and the consequent effect on quality health care provision, in the midst of policy interventions aimed at achieving the set targets of MDG 4 and 5.

This thesis initially set out to study motivation focusing on motivation as an attitudinal and personal quality of health workers. However, motivation is a multidimensional phenomenon and is affected by all kinds of factors in the life-world of care providers, some of them under and some of them beyond their control. It is one thing to assess health workers' motivation, but quite another thing to explain why people are motivated or demotivated. So it was decided to shift focus and concentrate more on the processual character of motivation, as it is produced in interaction between people and their environment, and to try to determine the interactional mechanisms that cause health workers to be motivated or demotivated.

This study perceives motivation as both a process and a product of interpersonal and organisational processes in the work context. Thus issues of power, conflict, labour conditions, co-worker relations and organisational processes among others were noted to influence worker motivation. Also of interest was the consequent influence of worker motivation on workers' attitudes in their interaction with clients, which ultimately determined the level of responsiveness of health workers and the health care system to clients' health care needs.

To understand organisational and interpersonal processes in a natural work environment, ethnographic research was conducted in two public hospitals in the Greater Accra Region of Ghana. The methodological choice enabled the researcher to immerse herself in the hospital environment for twenty months to study, understand as well as to experience on the personal level, motivational processes in the hospital environment. This led the researcher to the following research objective and questions: 


\section{Research objective}

To explore the ways in which interpersonal interactions and organisational processes influence health worker motivation and the consequent influence on worker attitudes, in the provision of maternal and new born or neonatal health care in a Ghanaian hospital setting.

\section{Specific research questions were:}

- What are the interpersonal processes that influence health worker motivation?

- What are the organisational and managerial processes that influence health worker motivation?

- How does the setup of the Ghana health sector and its associated policies influence health worker motivation?

- How does health worker motivation influence worker attitudes and responsiveness to client health care needs?

\subsection{Determinants of health worker motivation}

Frontline health worker motivation, which determines worker attitudes and the responsiveness of the health care system to clients' health needs, is influenced by a complexity of national and health policies, managerial and organisational processes, interpersonal relations and patient or client factors. Within the health care system power and trust relations influence how these factors influence worker motivation, and managers are positioned within the hospital, to be able to ameliorate the influence of the varied determinants on frontline health worker motivation.

At a general level, national policies, health policies and directives shape decisions on terms and conditions of service and employment, which influence worker motivation and attitudes that may have a consequent effect on interpersonal quality health care provision. Studies suggest that national policies on labour conditions influence workers' motivation. Poor terms and conditions of service coupled with a weak economy can result in workers losing trust in national governments, which affect their motivation and attitudes in health care provision (Dieleman et al. 2003; Mbindyo et al. 2009a). The reverse is true, where health workers perceive favourable terms and conditions of service, they 
tend to trust the health care system, which motivates them and is translated into positive attitudes in worker-client relations (Purohit and Bandyopadhyay 2014).

Organisational and managerial determinants including worker promotion, transfers, terms and conditions of service including salaries, allowances, workload, monitoring and supervision, as well as organisational culture and climate, hierarchical power relations between workers and managers, values, norms, system of communication, organisational justice and trust relations influence worker motivation in the provision of health care (Agyepong et al. 2004; Franco et al. 2002; Mathauer and Imhoff 2006; Mbindyo et al. 2009a). Additionally, the work environment including appropriate infrastructure, availability of medical supplies, equipment and logistics influence worker motivation (Chandler et al. 2009). Other studies found that a favourable work environment and good organisational management foster trust relations between managers and frontline workers, which motivates workers and enhances their responsiveness to client care (Gilson 2003; Thu et al. 2015; Willis-Shattuck et al. 2008). The reverse is true, where health workers perceive that their work needs and concerns are not met, and that managers do not show interest in their welfare, they become frustrated and demotivated (Agyepong et al. 2004). Demotivation contributes to poor worker attitudes and interaction with clients that leads to poor worker response to client health needs, thus compromising with quality health care provision (Ansong-Tornui et al. 2007; Bosu et al. 2007).

Interpersonal processes including job-related determinants such as refresher training, competencies, co-worker relations and work experiences equally influence worker motivation and attitudes in the provision of health care. Where health workers benefit from refresher training, are competent, skilful and have the expertise, as well as receive support from co-workers, they find the environmental climate friendly and become committed to the organisation. This enhances their motivation and is translated into positive attitudes in their interaction with clients, which facilitates their response to client care (Donabedian 1980; Franco et al. 2002; Mathauer and Imhoff 2006; Mbindyo et al. 2009a). The reverse is true, where frontline workers do not perceive a friendly management and environmental climate, they lose trust in the organisation, which is then translated into poor attitudes in their interaction with clients, thus compromising their responsiveness to client health needs (Agyepong et al. 2004; Gilson 2003; Turkson 2009). 
Additionally self-related determinants including workers' personal disposition, temperament and past experiences, equally affect how workers respond to organisational processes (Franco et al. 2002).

Community and client level determinants also influence health worker motivation and attitudes in the provision of health care. Where health workers perceive a clientele that is responsive and cooperative, health workers become responsive to their needs. Additionally a supportive community that renders assistance to health institutions and a good rapport between health institutions and surrounding communities contributes to community - health institution trust, which motivates health workers. Where health workers perceive that community members do not show appreciation for their work, they lose trust in the community resulting in demotivation (Franco et al. 2002; Mbindyo et al. 2009a).

These four groups of determinants can individually or collectively militate or promote worker motivation and attitudes. Agyepong et al. (2004) referring to the frontline health worker as the internal customer of the health care system, argue that to ensure that health workers are well motivated to provide quality health care services, the complex inter-related factors that demotivate them need to be recognised and addressed adequately. Managers are entrusted with the responsibility of creating an environment that promotes positive work culture and climate that is motivating to workers, which will promote positive attitudes that will enhance workers' performance (Hartog and Verburg 2004; Mansour et al. 2005). When managers are able to exercise power positively in decision making, to communicate effectively with frontline workers, respect them, facilitate organisational learning and empower workers, as well as are transparent in decision making and fair in resolving workers' issues, workers develop trust in managers (Gilson 2003; Mansour et al. 2005; Okello and Gilson 2015). Workers who equally have power and can influence organisational processes reciprocate managerial decisions that foster favourable work climate with trusting behaviour including being committed, transparent and low absenteeism (Bowles and Cooper 2009; Lipsky 1980; Mintzberg 1983; Pfeffer 1981; Willis-Shattuck et al. 2008). This is then transformed into motivated workers who exhibit positive attitudes, which is translated into favourable worker interactions with clients that is responsive to clients' health needs and expectations. Conversely, when 
workers perceive that they are not being treated fairly, they lose trust in managers and in the organisation and become demotivated. Gathering their resources including their expertise and experiences, workers exercise power negatively by exhibiting negative attitudes in their interaction with clients, which can compromise their responsiveness to the health care needs of clients.

In order to investigate these processes in-depth and how in practice motivation is produced and perceived in the daily context of health work, it was decided to employ an ethnographic approach, to describe and analyse how and why organisational processes on a day to day bases influence worker motivation. The details of the methodological approach and its justification are further and extensively presented in chapter two.

\subsection{Conceptual framework}

The complex and dynamic processes of health worker motivation including national and health policies, managerial and organisational processes, interpersonal relations and patient or client determiners interact in a context of power and trust relations that influence worker motivation, which affects worker response to client care. Consequently concepts on motivation, trust and power play an important role in the analysis of the processual character of health worker motivation. The individual concepts and their interlinkages are discussed below.

\subsubsection{Motivation}

The provision of health care is dependent on the discretion and skills of people and for that matter their willingness to make prompt and timely clinical decisions that contribute to saving lives is core to quality health care provision. This makes the concept motivation in the health care organisation relevant in the analysis to help address the study objective as well as in answering the four study questions in chapters two, three, four and five of the thesis. Franco et al. (2002) define motivation in the work environment as '...an individual's degree of willingness to exert and maintain an effort towards organizational goals.' Franco et al. (2002), further argue that motivation is a transactional process between the individual and the work environment. 
This study conceptualized motivation as both an outcome and a process produced in interactions in the hospital context. Motivation is an outcome because it influences and results in part in the extent to which health workers are willing and energized to put in efforts to contribute to the achievement of organisational goals. It also contributes to the extent of workers' satisfaction, and personal fulfilment. It is process because it is not a one off event but a continuous process with variations over time depending on factors intrinsic and extrinsic to health workers and their work environment including the organizational culture and climate. As a process motivation, it is not static or something that the individual possesses. It is rather an outcome of interactions between people, the organisation and the context in which care is provided. Thus motivation is fluid and an individual can shift from motivation to demotivation depending on how the individual experiences organisational processes at a particular point in time. Franco et al. (2002), described the process of motivation as follows: '...an internal psychological process and a transactional process: worker motivation is the result of the interactions between individuals and their work environment, and the fit between these interactions and the broader societal context.'

Health managers exercise power in organising resources and in creating a conducive work environment that meets workers' personal and work needs. Where managers are able to exercise power, to meet such needs, workers tend to trust managers. Okello and Gilson (2015), suggest that workplace trust relationships with colleagues, supervisors and managers, employing organisation and patients directly and indirectly influence health worker motivation. This thesis agrees with this standpoint; however this thesis suggests that worker motivation is a complex process of interaction between the worker and the different processes and actors, which is imbedded in power relations. The consequence of positive power play is trusting relations between the worker, managers, co-workers and clients, which motivates the worker and it is translated into positive attitudes in the provision of health care delivery. The contrary is true, negative power play results in a distrustful worker, who is demotivated and exhibits negative attitudes in the provision of health care, resulting in a poor response to client care. 


\subsubsection{Trust}

The health care environment is an emotionally sensitive environment, where matters of life and death are experienced regularly, and people of different professions with different orientation and backgrounds have to interact and collaborate, to provide health care. For effective interaction and collaboration in the provision of health care trust must exist, which makes trust relevant for analysing and understanding interactions between frontline health workers and their managers, between frontline health workers and between frontline workers and clients. These experiences of trust contribute to shape and influence workers' motivation in the provision of health care (Okello and Gilson 2015). Even the researcher's experience and understanding of motivation in her interactions with her study participants, was influenced by trust relations between her and the research participants. Therefore trust appears repeatedly as a key factor in shaping workers motivation in the following chapters: two, three, four and five of the thesis.

Trust is defined as: '...to have faith or confidence that something desired is, or will be, the case' and distrust as: 'to have no confidence in, or suspect actions, intentions, motives of' (Fox 1974:66). Fox's (1974) definition suggests a two way relationship between a trustor and a trustee, where the former makes a decision to believe in the latter, based on the expectation that the latter will conduct herself in an expected manner. So trust is an important outcome and is related to the quality of interactions between a trustor and a trustee. How power is exercised in organisations affects workers' trust in their managers, their colleagues, the health care system, which ultimately affects trusting relations between workers and their clients (Gilson 2003; Okello and Gilson 2015). Managers' failure to meet frontline workers' personal and work needs, poor interpersonal relations between workers, as well as poor terms and conditions of service, contribute to workers losing trust in the health care system, their managers and the colleagues that they collaborate with in the provision of health care (Ferres et al. 2004; Fox 1974; Gilson et al. 2005; Okello and Gilson 2015; Zand 1972). Losing trust in such broad dimensions can contribute to a demotivated workforce, who can present negative attitudes in the provision of health care, which compromises with interpersonal quality care (Almost et al. 2010; Laschinger 2004; Gilson et al. 2005; Okello and Gilson 2015). The contrary is true, when health workers trust their managers, their colleagues and the health care system, they become motivated and so 
exhibit positive attitudes, which is translated into positive interactions with clients that enhances workers' responsiveness to clients' health needs (Dickin et al. 2011; Dieleman et al. 2003; Okello and Gilson 2015; Razee et al. 2012).

\subsubsection{Power}

The functioning of the hospital is influenced by various actors within and outside the hospital environment, who exercise power with the objective of influencing organisational processes and outcomes. Consequently power is ubiquitous in policy processes, directives, in daily interactions between managers and frontline workers, between frontline workers and between frontline workers and the clients who use the services of the hospital.

Thus power determines the decisions that people make, the policies that govern a public hospital, how managers make decisions at hospital level, as well as how frontline workers experience such processes, and how they translate it in their interaction with clients. Such processes no doubt influence frontline health workers' trust in managers, their colleagues and the health care system, which influences their motivation in the provision of health care. This makes power central to this thesis. Thus in order to have an in-depth understanding of the ubiquitous nature of power in organisational processes and in the daily lives of workers, and its consequent influence on worker motivation, this study used hospital ethnography in two public hospitals, with participant observation as a major method of data collection. This methodology allowed the researcher to observe and experience power in the process of interaction between workers and management in the hospital in the role of a participant in the day-to-day processes, and enabled observation, as well as first-hand experience of the role and meaning of power and its effects on motivation in the hospital setting.

There have been studies of motivation and power in organisations, which employ qualitative surveys and interviews. However, even these often start with observation and qualitative interviewing to gain enough understanding, to develop more quantitative instruments (Agyepong et al. 2004; Alhassan et al. 2013; Dieleman et al. 2003; Dieleman et al. 2006; Franco et al. 2004; Mbindyo et al. 2009a; Okello and Gilson 2015). Consequently, power was another focus in highlighting interactions in a hospital setting relevant for an 
understanding of processes of motivation and demotivation in the following chapters: two, three, four and five.

Power in a health care organisation is defined as '...the capacity to effect (or affect) organisational outcomes' (Mintzberg 1983:4). Mintzberg's definition leads us to a multidimensional, relational and processual approach to the study of power as exercised by actors outside and within organisational structures, with the aim of achieving desired outcomes. Subsequently, health workers exercise discretionary power in their capacity as agents of the health care system and they determine the kinds of treatment that clients receive, which influences the therapy of healing (Gilson 2003; Lipsky 1980; Mintzberg 1983; Ortner 2006; Pfeffer 1981). As subjects of power, frontline workers are under national policies and directives, which determine their conditions of service. Also workers are subject to managerial power play as managers' decisions and how they implement national and health policies and directives, create the kind of environment that determines workers' ability and willingness to translate their knowledge and skills into quality health care provision. Where health workers perceive that they are not being treated fairly and that they are not being provided with a conducive work environment, they feel disempowered and lose trust in managers and the health care system. Consequently they become demotivated in the provision of health care that is responsive to clients' needs (Chandler et al. 2009; Mathauer and Imhoff 2006).

\subsection{Methodology}

Though the entire process of participant observation and how the quality of the interactions of the researcher with the hospital environment in itself was an instrument to understand health worker motivation is extensively explained in Chapter 2, some additional information on the methodological choices made is provided here. The focus of this research was primarily on the processes of interaction between different categories of workers (such as nurses, doctors, nurse-anaesthetists, ward aids and managers at the different levels of the hospital), in order to be able to better understand the mechanisms that contribute to more or less motivation of health workers. The aim was not to assess motivation as such, based on the assumptions that motivation is an outcome of a process rather an intrinsic quality of the health worker. Therefore motivation was approached as a 
process outcome that is constantly created and negotiated in the daily work interactions at the work floor. It is difficult if not impossible to capture the mechanisms, interactions and daily realities that lead to more or less motivation in a survey type research or through extensive interviewing, as these methodologies take a single point in time. Therefore, participant observation was chosen as the core methodology for this study, supplemented with interviews to check and triangulate the observations made in the real-life situation. Participant observations also allowed first-hand experience of the researcher with the very interactions that produce (de)motivation (chapter 2).

Because of these choices a number of other choices were implicitly made. For example, choosing two hospitals as a research site meant that no explicit choice was made for a certain category of health workers, rather all the health workers attached to the maternal health units of these hospitals were in principle participants and informants in this research. For as far as possible all these people were also informed about the work going on and people who were interviewed were asked to sign a consent form. A further implication of this research method is that the people who were interviewed were not randomly selected, but rather asked, because they had a specific role or relation to the events observed in the hospital. In addition they were not systematically questioned with a prepared set of questions and survey, to assess motivation, but they were asked to reflect in general on working processes in the hospital, motivations and for additional information about certain events.

The choice for the two research sites was initially based on the idea that differences in size (small and big in the Ghanaian context: details in chapter 2) and setting (urban versus rural) would allow for a comparative analysis. However in the course of the research it appeared that the two sites were so unique in their organizational set-up and organizational issues that this comparison proved illusory. However, despite the differences there were also similarities, in the sense that the mechanisms leading to demotivation and lack of trust were fuelled by the same power differences and type of interactions, despite the qualitative differences between the two. Because of concerns of confidentiality and privacy of informants that are easily recognizable by their function, it is not possible to go into further detail here. 


\subsection{Background of the study area}

Ghana is a lower middle income country on the coast of West Africa (Figure1: Map of Ghana). Ghana gained independence in 1957 and became a republic in 1960. After a chequered history of brief periods of democracy interrupted by series of coup d'états, it has become a stable democracy since 1992 (Ghana Statistical Service (GSS) et al. 2009). Based on the 2010 population census, Ghana's population is about twenty five million, with a male/female ratio of 95/100 (Ghana Statistical Service 2012). The study was carried out in the Greater Accra Region - which contains the administrative capital of the country. With a total population of over four million people, it is the second most populated of the ten administrative regions of Ghana - after the Ashanti region (Ghana Statistical Service 2012). The Greater Accra region lies in the South East of the country along the gulf of Guinea (Error! Reference source not found.), (Ghana Health Service 2014).

\subsection{The Ghana health care system and health care arrangements}

Ghana's health care system has gone through various phases since independence. After independence the government of the day instituted a National Health Service scheme that sought to provide free health care to the population. However since the overthrow of the first democratically elected government in 1966 and the assumption of office of various military and civilian democratic governments, the health system has undergone various policy changes. Beside the political influences, another factor that has influenced policy directions in the health sector has been economic crisis leading to the International Monetary Fund (IMF) and World Bank stabilization and structural adjustment programmes (SAPs) from 1983 onwards. SAPs brought with them liberalization of the economy and reforms in the public services including the civil service, health and education (Larbi 2005). The health sector experienced a significant policy shift in 1985, due to a slow economic growth, which contributed to the introduction of a fee for service, also referred to as 'cash and carry' system that was instituted by the government of the day (Ibrahim and O'Keefe 2014). 
Figure 1-1 Ghana Administrative map

\section{GHANA ADMINIS TRATIVE MAP}

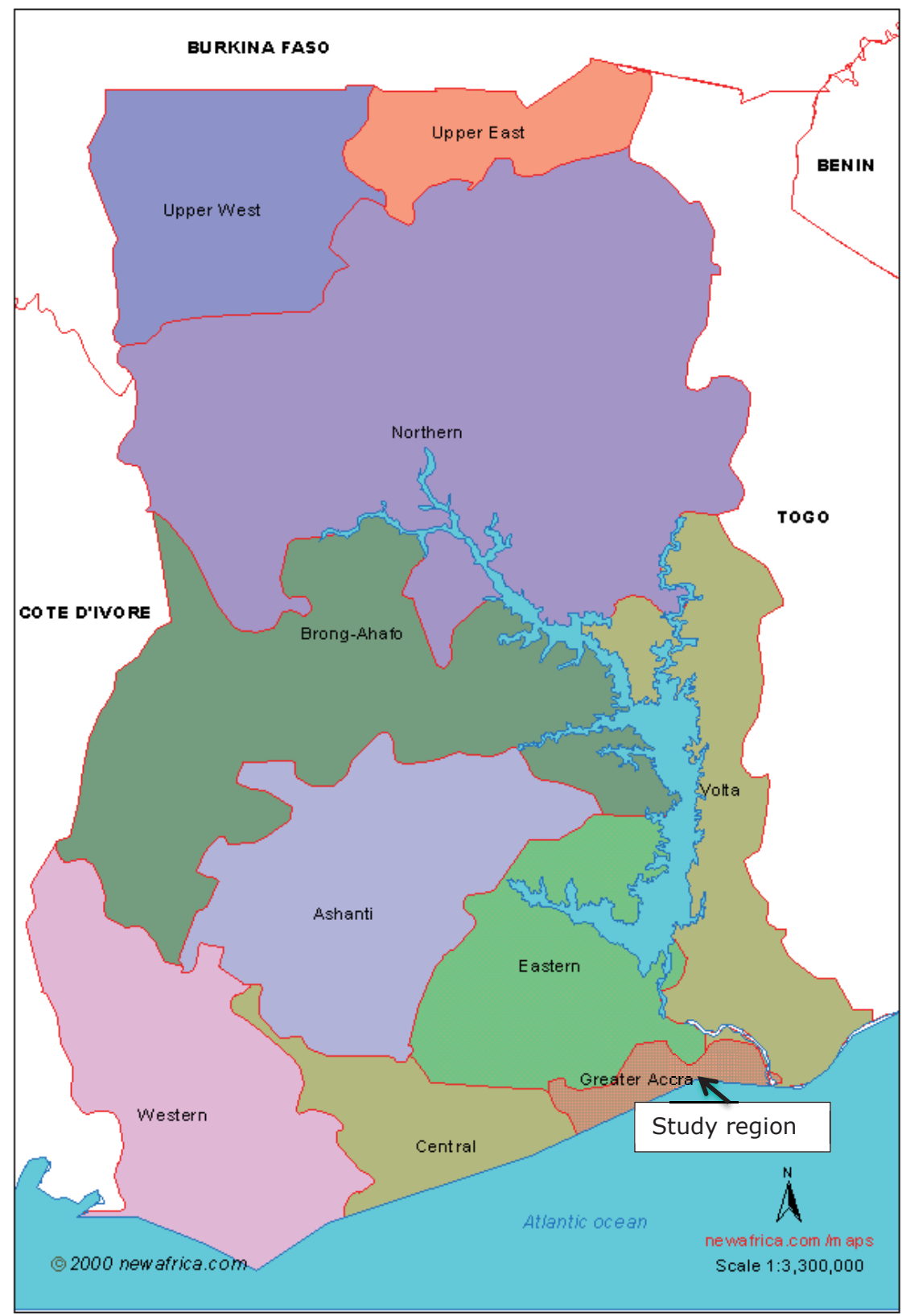


A significant shift in the administration of the public health service in Ghana was the passage of the Ghana Health Service and Teaching Hospitals Act $(525,1996)$, by parliament (Republic of Ghana Act 525 1996). Per the act, the Ghana Health Service (GHS) became the service implementing body, while the Ministry of Health $(\mathrm{MOH})$ remained the policy making body. The decentralisation has led to the transfer of power and decisions on the day to day management of health care services to the GHS, headed by a Director General (Agyepong 1999; Larbi 1998, 2005). Under the Director General are ten regional health directors presiding over service delivery in the ten administrative regional health directorates of the GHS. Under the regional health directors are district health directors who preside over the various districts in the ten regions of Ghana. The public hospitals, which are mostly headed by medical officers, are under the district health directorates. Nevertheless, the establishment of posts, recruitment, terms and conditions of service are directly controlled by central government agencies - therefore appointments, promotion and discipline, especially dismissal of core staff are beyond hospital managers' authority (Agyepong 1999; Larbi 1998, 2005). The private sector, consisting of for profit and nonprofit health care facilities, plays an important role in health care provision in Ghana, however it is subject to control of the Ghana Health Service system (Agyepong 1999).

A policy that has a bearing on hospital management and human resource management is the Public Procurement Act [663, 2003] (Government of Ghana 2003), which mandates all public institutions to go through a procurement system for reviews and approvals before procuring essentials and also before awarding of contracts (Ameyaw et al. 2012; Government of Ghana 2003). Also the Labour Act [651, 2003] (Parliament of the Republic of Ghana 2003), and the Ghana health services code of ethics (Ghana Health Service 2003), have a bearing on how health care is organised in health facilities. Additionally Ghana Health Service directives influence hospital management. Thus policies and directives provide opportunities as well as constraints for managers and frontline health workers in health care provision, which are discussed in chapters two, three, four, five and six of the thesis. 


\subsubsection{Opportunities and challenges within the Ghana Health Service}

The acquisition and retention of skilled labour is an important component for health care provision. However adequate doctor, nurse and midwife numbers to ensure equitable distribution nationwide continues to be a challenge, despite increased efforts by the $\mathrm{MOH}$ and the GHS to improve workforce numbers. Between 2009 and 2011, the doctor-patient ratio improved country-wide from 1 to 11,929 to 1 to 10,034 and that of the Greater Accra Region improved from 1 to 5,103 to 1 to 3,712. However, although the doctor/population ratios for both the Ashanti and Greater Accra regions appear to be good, about $50 \%$ of these doctors are in the two Teaching Hospitals in the regions. Consequently the GHS is seriously considering more sustainable strategies to increase the number of doctors nationwide (Ghana Health Service 2011:57).

The national nurse-population ratio has continued to improve from 1 to 1,497 in 2009 to 1 to 1,240 in 2011. The improvement in numbers has been attributed to a train and retain policy, which was adopted by the Ministry of Health that ensured that regions retained the personnel that were trained within their regions. However, the Greater Accra Region suffered a reduction in the nurse-population ratio from 1 to 1,069 to 1 to 1,255 in 2009 and 2011 respectively. The reason for the drop has been attributed to nurses leaving the region, to pursue higher education in other regions (Ghana Health Service 2011:58). The midwife-women in fertile age ratio improved from 1 to 1,538 in 2010 to 1 to 1,478 in 2011 nationally. Factors accounting for the improvement have been attributed to the setting up of midwifery schools in all the ten regions, which has contributed to a higher turnout of midwives. In the greater Accra region the ratio improved from 1 to 1,197 in 2010 to 1 to 1,160 in 2011 (Ghana Health Service 2011:58).

Coupled with the slow increasing numbers in the labour force is the challenge in sustaining the available staff numbers. Human resource management factors including a swelling health wage bill, inequitable distribution of the available staff, delayed promotions and high attrition rate of available staff continue to hamper service provision. Reasons given as accounting for these challenges include poor monitoring system to track disengaged staff contributing to a lack of up-to-date comprehensive human resource (HR) data. Regional and divisional directors of health have been blamed as not supporting the HR data base through updating and submission of nominal rolls on a quarterly basis. 
Others argue that outdated staffing norms for facilities, make re-distribution of essential health staff difficult. There are also concerns that there are inadequate resources for inservice training, fellowships and other management and leadership training (Ghana Health Service 2011:76).

Other challenges that the GHS faces include inadequate equipment and availability of blood banks in many hospitals, which hamper service delivery (Ghana Health Service 2011 \& 77). Preliminary findings of a survey that assessed the performance of health facilities in Ghana rated $77 \%$ of the facilities with grade C and D - where grade A+ is 90$100 \%$. Mission health facilities performed better than both private and public health facilities and the Eastern region was identified as the best performing region, while the Greater Accra region was one of the poorest preforming regions (National Health Insurance Authority 2013). The GHS suggests that accreditation rating through the National Health Insurance Authority (NHIA) inspection can be used as a proxy of the quality of care being offered in a particular facility (Ghana Health Service 2011:17). Thus the recent performance suggests that most public health facilities, especially in the Greater Accra Region are lagging behind in quality of care and therefore there is an urgent need to support them to improve their infrastructure, equipment and staffing gaps, in order to improve their ratings, as well as to improve the quality of care in public health facilities.

\subsection{This thesis}

This thesis comprises of six chapters. This general introductory chapter has presented the rationale for the study, problem statement, the research objective and questions, theoretical framework, definition of concepts, methodology, the state of the Ghana Health Service and background of the study area.

Chapter two of the thesis, which is entitled 'I won't take part!': exploring the multiple identities of the ethnographer in two Ghanaian hospitals, is a methodology chapter and has been accepted for publication and is currently being processed for printing in the journal Ethnography. The paper reflects on methodological considerations in ethnographic research in a Ghanaian hospital environment. It discusses how the ethnographer's approach to field entry, the topic of study, her use of ethnographic methods and contextual factors shaped her multiple identities that impacted on the 
research project. Concepts including power, motivation, trust, distrust and multiple identities are employed to discuss the findings.

Chapter three, 'Your Health Our Concern; Our Health Whose Concern?': Perceptions of unfairness in organizational relationships and processes and frontline health worker motivation in Ghana, has been published in the journal Health Policy and Planning. The paper draws upon motivation and organisational justice theories to explore how perceptions of justice influence frontline health workers' motivation and their resulting effects on workers' attitudes and responsiveness to clients' health needs. Additionally it explores intrinsic motivating factors and their influences on workers' response to clients' health needs and consequent effects on interpersonal quality maternal and neonatal health care in public hospitals.

Chapter four, 'I used to fight with them but now I have stopped!': Conflict and doctornurse-anaesthetists' motivation in maternal and neonatal care provision in a specialist referral hospital, has been published in the journal Plos One. It explores how health worker motivation and attitudes are affected by work floor conflicts, and the resulting effects on workers' response to clients' health needs and quality of health care provision. Concepts of power, trust and organisational conflict are drawn upon to inform the analysis.

Chapter five, 'Even me, sometimes I get sick': Reflections on hospital managers' decision making power in two Ghanaian public hospitals, has been accepted for publication by the International Journal of Health Planning and Management. It explores issues related to governance in public hospitals through a study of the role of hospital and floor level managers in organizing health care in two Ghanaian hospitals, and how empowered (or otherwise they are) to meet the needs of frontline health workers. Drawing upon the philosophy of Continuous Quality Improvement, frontline health workers are conceptualized as customers of the hospital and floor level managers. The ability of these managers to be responsive to health workers' needs can facilitate or inhibit the provision of quality maternal and neonatal health care. The findings suggest that hospital managers operate in a complex and dynamic environment, so they face various obstacles that make it challenging for them to promptly respond to frontline workers' personal and work 
needs. Consequently managers felt disempowered, which demotivated them in their line of work.

Chapter six is a synthesis of all the findings of this work, to draw conclusions on the extent to which the research questions of this thesis have been answered with the material presented in chapters one to five. It discusses the dynamics and complexities in health worker motivation, theoretical and methodological considerations and the limitations of the study. It concludes with a summary of the study findings, lessons learned and policy recommendations. The section draws on literature on motivation, power, and trust. 


\section{Chapter 2}

\section{2 'I won't take part!' exploring the multiple identities of the ethnographer in two Ghanaian hospitals}

The chapter presents an account of the researcher's fieldwork experiences in two Ghanaian hospitals over a period of twenty months. It describes and discusses how the identity of the researcher had to be negotiated in relation to organisational power structures and trust relations in the research setting. It discusses the paradox of the researcher's negotiation of her multiple identities of 'insider' and 'outsider' and their influence on the data collection process and analysis. In this way it shows how the researcher by positioning herself in the research field experienced the very subject that she went to study - that is worker motivation in the provision of health care and how these personal experiences were useful in understanding and analysing health worker motivation in an African context. Concepts including motivation, power, trust and multiple identities of the researcher are employed to discuss the findings.

This chapter has been accepted for publication in the journal Ethnography, and is currently in press. 


\subsection{Introduction}

The identity of the ethnographer plays an important role in the research process (Long et al. 2008; Van der Geest and Finkler 2004). Research participants' decision to cooperate in the research process is informed by their perceived identity of the ethnographer, which influences the level of trust between the two parties (Coumans 2011; Mullings 1999; Narayan 1993; Rosaldo 1989; Tsuda 1998; Wind 2008; Zaman 2008). So increasingly, as more anthropologists study their own societies their identity as natives and its influence on the research process come into question (Davies 2008; Wind 2008). Narayan (1993) contests the status of a 'native', questioning: 'how native is a native anthropologist?' She has rather advocated for multiple identities of 'insider' and 'outsider' positions. She argues that a prolonged stay and active engagement with her research participants can contribute to the ethnographer gaining their trust and becoming an 'insider', while certain times the supposed 'native' is naive of certain aspects of her own society, which can sometimes make her an 'outsider'. Yet still, van der Geest et al. (2012) argue that research projects give birth to the ethnographer - while learning about the 'other' the ethnographer identifies communalities between herself and her research participants, thereby qualifying herself as an 'insider' of the research project. Anne-Mei The (1999) takes these views further in her research experiences with cancer patients, where her emotional involvement with them earned her an 'insider' position.

The different views call for further exploration and understanding of ethnographers' experiences of multiple identities whether in their native countries or not. This paper contributes literature to this subject matter by reflecting on the author's experiences of multiple identities in her research work in Ghana - her native country.

The paper is part of my PhD study on health worker motivation in two Ghanaian public hospitals. The study reflects on how the approach to field entry, the topic of study, the use of ethnographic methods and contextual factors contributed to trust and distrust relations between me and my research participants that influenced my perceived multiple identities and the research project. The paper also discusses how I negotiated perceived identities; how participation offered me the opportunity to experience similar set of emotions that influenced frontline health workers' motivation, which served as a source of data collection, understanding and analysis of the study. 


\subsection{Methods}

\subsubsection{Study setting}

Two public hospitals were purposively selected: a specialist referral hospital located in an urban centre and a hospital that provides basic services in a peri-urban locality, anonymised as Adom* and Grace* hospitals respectively. Adom hospital, which has a bed capacity of 274 and a staff strength of seven hundred plus was selected to gain insight into the research questions in the context of a big specialist hospital. Grace hospital has a bed capacity of 20, a staff strength of 272 and was chosen to help understand the same issues in a smaller non-specialist hospital context.

\subsubsection{Study design}

The methodology of the study was hospital ethnography using participant and nonparticipant observation, conversations and in-depth interviews as data collection methods. To observe, experience, understand and represent the lives of subjects on the dynamics and complexities of health worker motivation, which are enacted on a daily basis in the health care environment, I needed to immerse myself in the field of research as recommended in anthropological studies (Emerson et al. 2005; Geertz 1973; Van der Geest and Finkler 2004). I conducted twenty months of ethnographic fieldwork in two Ghanaian public hospitals. In the first phase of the study, I spent ten months in the Obstetrics and Gynaecology [O\&G] department of Adom hospital, which is a bigger facility and so required more time to study worker motivation. I spent less time - six months in the O\&G department of Grace hospital. In the second phase, I spent two months in Grace hospital and another two months in Adom hospital, to clarify gaps in the data collected by conducting interviews and conversations with study participants [see Table 2.1].

The use of participant observation enabled me to experience, understand and capture deeper meanings of interactions and relationships between various actors (Eriksen 2004; Spradley 1980). I conducted non-participant observation by engaging in activities including participating in staff meetings, training workshops, having lunch with frontline health workers and sitting in the O\&G outpatient department, theatre, consulting and delivering rooms and other locations within the two hospitals, to observe interactions 
between managers, frontline workers and clients. I also actively participated in health care provision by assisting midwives and ward aids to do urine and blood-sugar tests. I assisted in deliveries by recording time of delivery and weight of babies and giving medical supplies to nurses as they conducted deliveries.

Table 2.1: Categories of workers in Adom and Grace hospitals who I conversed with and participants who were interviewed

Category of workers $\quad$ Data collection methods

\section{Conversation Interviews}

\section{Adom hospital $^{a}$}

Nurses and midwives

62

House officers

5

2

Senior doctors

11

4

Anaesthetists

5

3

Ward Aids

2

Orderlies

Doctors who left Adom hospital

6

6

6

Laboratory officials

- 2

Departmental supervisors

- 2

Hospital managers

\section{Grace hospital ${ }^{b}$}

Nurses and midwives

Nurse who left the facility

Doctor

Ward Aids

Departmental supervisors 4

Hospital managers

aIn Adom hospital observation was carried out in the antenatal and postnatal clinics, labour, lying in and the gynaecological wards and the maternity theatre. Additionally, the ethnographer participated in meetings, doctors' ward rounds, training and workshops for workers. bIn Grace hospital observations were done in the antenatal and postnatal clinics, the labour ward and the hospital pharmacy. Also, the ethnographer participated in the district annual performance review meeting and a party for five retirees. 
Conversations are defined as casual talk in everyday settings or a talk or spoken encounter (Heritage 1990). Conversations are an important data source in anthropological enquiry, as they enable the researcher to obtain first-hand information on social phenomena (Patton 2002). I conversed with department and hospital managers, as well as the different categories of frontline health workers such as nurses, doctors, nurseanaesthetists and ward aids. Conversations helped me to gain a better understanding of organisational practices and interactions among the different actors.

Face-to-face unstructured interviews in English language were conducted with selected frontline workers and managers on decision making processes, staffing norms, values, perceptions and practices, hospital management, decision making, power and trust relations. The method was appropriate for this study, because it enabled an exploration of real life experiences of people in research settings (Yin 2009). It also helped to explain, clarify and confirm actions and occurrences that were not readily understandable (Patton 2002).

\subsubsection{Choosing an identity}

Ethnographers have assumed various identities in the field of research depending on the aim of the study (Long et al. 2008; Mulemi 2010; Van der Geest and Finkler 2004; Wind 2008). Since this study aimed at understanding frontline health worker motivation, having no medical background, I chose the identity of a research student. Such an identity offered me the freedom to interact with the different categories of frontline workers.

\subsubsection{Data storage, analysis and reporting of study findings}

Notes from observations and conversations were refined and expanded at the end of each day in line with standards in ethnographic studies (Emerson et al. 2005). Interviews were recorded and later transcribed verbatim by a research assistant. The data was typed, grouped and saved in two data sets: 1) interviews 2) observations and conversations. Subsequently the data was transferred into a qualitative software programme, Nvivo [version 8]. The different data sets were then individually coded systematically - first into broad codes, then specific codes alongside topic coding. The codes were then triangulated and common patterns were put into various themes for further interpretation. The 
findings and reporting of this article is based on key themes that emerged from the analysis.

\subsubsection{Ethical process and hospital entry}

I followed the protocol required for conducting research in public health facilities in Ghana. Firstly I received ethical clearance from the Ghana Health Service Ethics Review board [approval number GHS-ERC:06/01/12], and from the University of Wageningen. Secondly I presented an introductory letter from the University of Wageningen to the regional health directorate requesting permission to conduct anthropological studies in the two public hospitals. The regional health directorate approved the study and offered letters, which introduced me as a research student, to the respective district health directorates that have oversight responsibility over the study hospitals. At both district directorates the introductory letters were approved and I was given duplicate copies to present to the hospitals. In Adom hospital I presented the approved letter to the head of the hospital, who welcomed me warmly and introduced me to some of the senior managers as a PhD research student. The head then delegated one of the senior managers who introduced me to the O\&G department managers and frontline health workers, where I was scheduled to work.

In Grace Hospital I presented the approved letter to the head of the hospital, who referred me to the administrator. The administrator delegated an administrative intern to introduce me to the acting head of nursing. Subsequently the acting head of nursing delegated a junior nurse who introduced me to the various departments including the O\&G. However I could not interact with the frontline workers that we met in the departments, as the junior nurse indicated that she was in a hurry to go for an outreach programme.

Verbal consent was obtained for conversations. Written informed consent was obtained from all interview participants prior to conducting interviews. The initial plan was to issue written consent forms to interview participants. However, when I faced challenges of distrust with my research participants, the consent forms became credible evidence that I fell on to establish my student identity. The consent forms contained the purpose, confidentiality, anonymity of the study and my identity as a PhD student of the 
Wageningen University. Additionally my mobile phone number and the phone number of the administrator of the Ghana Health Service ethics review board, were included for further inquiry from study participants.

All names used in this article are anonymised to protect the facilities and study participants. Also it is important to note that the ethnographer's supervisor, the regional health director was not privy to some of my experiences in the research field, especially on matters that linked me to the regional health administration as a spy. She was brought into the picture after the data had been anonymised and I submitted a draft manuscript to her for her advice and approval. However I held in-depth discussions with my Dutch supervisor, since he was perceived as a neutral person. I also consulted the administrator of the Ghana Health Service ethics review board for guidance on how to maintain my neutrality.

\subsection{Findings}

\subsubsection{An interview with the head of Adom hospital}

The head of Adom hospital had earlier agreed to my request for an interview. As we were going through the consenting process and we arrived at the voluntariness of the study she said to me: 'I was not aware that it is voluntary. I thought it was mandatory, but if this is the case, then I don't want to take part [in the interview].' I concealed my state of surprise and confusion and appealed to her to allow me to interview her. She responded: 'I don't care, you can take me anywhere, I won't take part!' After repeated resistance amid persuasion she finally agreed to be interviewed. ${ }^{3}$

\subsubsection{My multiple identities in the eyes of research participants}

The head of Adom hospital's dismissive response of 'I won't take part!' and her subsequent responses in the interview helped me to gain further insights into the dilemmas and complexities of the multiple identities that I had experienced among research participants. I had transformed from a research student in the eyes of the head of Adom hospital into a spy. My experiences with the heads and frontline workers in the two hospitals are presented in the rest of the finding.

${ }_{3}^{3}$ Adom hospital, field notes, 04/12/2013. 


\subsubsection{Adom hospital}

The Adom hospital head's perception of my identity was transformed from a neutral research student to a spy, who was in the hospital to spy and report activities to the GHS authorities. Most of the frontline workers on the other hand perceived me in three different identities: a spy for a higher authority, an 'Anas' [investigative journalist] and a research student linked to power structures in the hospital and the national level.

\section{The head of Adom hospital's perception of my identity as a spy}

Prior to the onset of the study, I had met the head of Adom hospital at a different forum, where I was introduced to her as a student of the then regional director of health of the region that the hospital is located in. My Ghanaian supervisor being the regional director of the region that the hospital is located in, was administratively the Adom hospital head's superior. So I took the opportunity to inform her that her hospital had been selected for a research study, and she encouraged me to come over to conduct the study. Thus on the onset of the research I enjoyed a good relationship with her. She had been very receptive and even agreed to my request to sit in management meetings, which was a close-door meeting of senior hospital managers. However my identity as a student eroded with time, as I continued to conduct interviews and conversations with workers that was reported to her, which she described as gossip. A comment she made with regards to illegal charges bore credence to this perception: 'You see, me I am somebody I don't like gossip. That is why when you came I said I wasn't going to take part [in the interview]. Because I knew all the things you were going to say, anyway. I have heard about it.'4

Her perception that I was a spy came out strongly in the interview when I sought clarification on administrative issues. She repeatedly became defensive by suggesting that the administrative questions that I posed could better be responded to by the regional director of health - my supervisor - her superior.

After the interview with her, I left the hospital crushed and demotivated. Being distrusted and perceived as one who engaged in gossip and a spy for a higher authority, shocked me. I felt humiliated, embarrassed and misunderstood. This development was a stark contrast to the warm reception that I received on the onset of the research.

\footnotetext{
${ }^{4}$ Interview with the head of Adom hospital, 04/12/2013.
} 


\section{Frontline health workers' perception of my identity}

So it is clear that some research participants like the head of Adom hospital perceived me as a spy, planted in the hospital by the regional and national health authorities, to observe and report workers' activities to them. As a result, some frontline workers were very strategic and cautious in conversations and interviews, as the following conversation reveals:

Ethnographer: ... so what motivates you?

Midwife: I don't want to talk to you. I do not want you to write down my name and be observing what we are doing and go and write bad things about us, write good things about us.

Ethnographer: How can you say something like that?

Midwife: That is what our superiors have made us to believe. They told us that you are here to observe what we are doing and to find out our faults and report us to the authorities. ${ }^{5}$

Additionally, some ward and department managers who perceived me as a spy of the regional and national health authorities sometimes explained to me why they had to take certain disciplinary actions against particular workers. This was to ensure that I gave a favourable report about the hospital to the regional and national authorities.

The perceived identity as a spy was exploited by some of the ward and department managers, who used my presence as a confirmation to their subordinates that their work was being observed and reported to the regional and national health authorities. So they admonished their subordinates to put up positive attitudes and to work hard, for such managers by giving such information, helped to strengthen their power and control over their subordinates. Accordingly, such managers drew me into the local power struggle between them and the frontline workers.

Some research participants perceived me as an 'Anas' [an investigative journalist Anas is the name of a popular investigative journalist whose name has become synonymous with investigative journalism in Ghana], who was in the hospital to spy on

\footnotetext{
${ }^{5}$ Adom hospital, conversation with a midwife, 20/09/2012.
} 
their activities in order to report to media houses and the general Ghanaian populace. This suspicion was played out in conversations with research participants as some openly called me 'Anas'. Also, some demonstrated their suspicion through their body language [some midwives stopped conversing with their colleagues when I appeared in the ward or went into the nurse's room]. In one of the wards that I worked in it was common for the midwives to discuss in my presence that 'Anas' could be visiting the hospital. It was also common for the ward manager to say to clients in my presence during routine health education talks: 'Some of you are journalists, but because you are not in uniform, we do not know.'6

Some of the research participants also perceived me as a student researcher, who had links to the hospital, the regional and national health authorities. They felt that they could use me to convey their concerns to their superiors in the hospital, at the regional and national levels. They demonstrated this perception especially in times when there were challenges that needed to be addressed. For instance on one occasion I was sitting in one of the specialist wards and the workers were overwhelmed with a high client turnout. The doctor on duty appearing frustrated asked me to include this occurrence in my report, so that I could draw the attention of their superiors at the hospital and national levels to address it. ${ }^{7}$

Initially I brushed these perceived multiple identities off, however when I realised that research participants' perceptions of such identities influenced their interaction with me, I felt frustrated and demotivated. So I resolved to negotiate my identity by sometimes addressing workers' fears and distrust. I reassured them that I was a research student and the motive for the research was academic and for national policy interest. I also assured them that I was bound to abide by the ethical guidelines of protecting the identity of my informants. As additional proof, I gave out copies of the study's consent forms to most of the research participants, whether they were scheduled to be interviewed or not. Such negotiations helped to allay the fears of some of the workers, but others remained evasive in their responses during conversations and interviews.

\footnotetext{
${ }^{6}$ Adom hospital, field notes, 24/05/2012.

7 Adom Hospital, observation notes, 06/03/2012.
} 


\subsubsection{Grace Hospital}

In Grace hospital I experienced two opposing identities. To the head of the hospital I remained a research student throughout the period of research. To the frontline workers I transformed from being perceived as a spy of the hospital management authority to a research student.

\section{Grace hospital head's perception of my identity as a research student}

During the research period I met and interacted with the head of Grace hospital on a few occasions. She rarely came to the O\&G department, where I conducted most of the research. Also, the general impression I got from frontline workers was that she was difficult to approach. However, unlike her subordinates who distrusted my identity as a research student and so refused to grant me recorded interviews, the head was very welcoming and appeared to trust my identity as a research student. She readily signed the consent forms prior to the interview, agreed to be tape recorded and had an open interview with me. For instance when I asked her about the illegal sale of items, which I had observed in the O\&G department, she admitted them and sought confirmation from me as follows: 'When you [ethnographer] were at maternity [O\&G department], didn't you notice that they were selling mats for mothers and those things?'8 Her openness suggested that she did not see any need to conceal information that appeared damaging to her hospital, since she perceived that my interest was purely academic. Her admission that she believed that the $O \& G$ department engaged in illegal sales, and so she distrusted them, also helped me to understand why the $\mathrm{O} \& \mathrm{G}$ department workers perceived me as a spy of the hospital management and thus had distrusted me at the onset of the research.

\section{Frontline workers' perception of the identity of the ethnographer}

Initially frontline workers in Grace hospital believed that I was an 'Anas' [a spy-not necessarily a journalist] of the hospital management authority, who had been planted in the O\&G department, to spy and report perceived malpractices of workers. So I was identified as an 'insider' of the hospital management authority, which informed their

\footnotetext{
${ }^{8}$ Interview with the head of Grace Hospital, 05/03/2014.
} 
interactions with me. The midwives, ward aids and the only doctor in the O\&G department interacted with me very cautiously - they gave me monosyllabic responses and some avoided me, while others closely monitored my interactions. Certain spaces like the labour ward and department meetings were closed to me.

In the third week of the research I met a midwife [Pearl], who became my closest friend. One day Pearl asked me how I entered the hospital and I explained to her about the process. Pearl responded: 'You know, a lot of people here think you are some sort of Anas!' She said that the midwives were suspicious that I had been planted in the $O \& G$ department to spy on workers' activities for the hospital management authority. She further explained that the workers in the O\&G department probably believed that I was a spy, because I had not been directly introduced to them. So the midwives had decided to conceal their activities from me and they including Diamond, a senior midwife - who I worked closely with, had advised her to be cautious of me. ${ }^{9}$ Later, a senior midwife confirmed Pearl's assertion in an interview, when she mentioned that the hospital management intimidated them and set spies on them:

Ethnographer: Who are those other people who ask clients about you people and report to the head?

Senior Midwife: Those in-charge of the hospital [hospital management authority] told them. Someone told us to be careful, because there are journalists around.

These experiences helped me to understand that I was the spy that Diamond and a few of the other midwives had repeatedly mentioned to me that the hospital management authority had set to trap them, in order to victimize them. This accounted for the cold reception that I experienced from them. Thus I became cautious in my interactions with them and so I used my phone's text messaging function to take down notes, as I could no longer use my notebook. I also refrained from asking direct questions and stuck to conversing with them about their motivation for becoming health workers and the challenges they faced. However, the midwives even including Pearl continued to perceive me as a spy and thus they distrusted me. For instance on one occasion, while I was in the labour ward with Pearl, a midwife who was on leave visited and Pearl introduced her to

\footnotetext{
${ }_{9}^{9}$ Grace Hospital, conversation with Pearl, 06/09/2012.
} 
me. She appeared to be friendlier than the other midwives, consequently I sensed that she was not privy to the rumours of my perceived identity as a spy, hence I started conversing with her. However, Pearl cautioned her in a local Ghanaian language, which she knew I did not understand that I was an Anas and therefore she should be careful not to divulge any information to me. Though I do not understand the local language, I was able to decipher from the conversation that Pearl was telling her colleague I was a spy. Consequently, I confronted Pearl over the comment and gave copies of the consent form to each of them. This seemed to convince Pearl that I was a research student, as Pearl asked me why I had not given them copies of the consent form earlier on and had made them to believe that I was some sort of an 'Anas'.10

I also broke off from time to time from the hospital, but maintained communication with Pearl through the mobile phone. Hence on one occasion she said that she had had an argument with her colleagues, who insisted that I was a spy and that I had obtained the information that I sought to spy on, thus I was not returning to the hospital. Afterwards, I visited the hospital and interacted with all the midwives who were on duty to convince them of my student identity. Several of them were surprised to see me and a senior midwife confirmed their argument with Pearl: 'Oh, we thought you had finished with your work and you had left, but your friend or is it your sister [referring to Pearl] told us that was not the case. She said you will be returning!'11

Continued efforts to reach out to the frontline workers, having to explain repeatedly my research to each of them, as well as the hostile environment that I experienced wore me down. I felt I meant well and was working in the interest of frontline workers, yet my good intention was being received with such distrust. Consequently, I felt desperate, frustrated and demotivated. I resented the hospital and dreaded the days that I had to spend there and looked forward to the end of the research.

Out of desperation I went back to the acting head of nursing, to appeal to her to reintroduce me to the O\&G workers. I explained to her that it appeared some of them were not aware of my study and my student identity. However she assured me that the initial introduction that was done by the junior nurse was enough. Thus I rationalised that I had to renegotiate my student identity on my own. So I intensified my visits to the

\footnotetext{
${ }^{10}$ Grace hospital, field notes, 07/09/2012.

${ }^{11}$ Grace hospital, conversation with a senior midwife, 26/09/2012.
} 
hospital, I continued to explain my research to the workers and also distributed copies of the consent form to the other midwives, whether they were slated to be interviewed or not. Pearl also helped by countering her colleagues' frequent arguments that I was a spy and insisting that I was genuinely pursuing a PhD abroad, so my interest in the hospital was purely academic. My Dutch supervisor visited Grace Hospital, which was a serendipitous occurrence, as this helped to confirm my status as an international student.

Subsequently, in the second phase of the research, Diamond and several of the midwives begun to see me as a research student. This new identity positioned me as an 'outsider' and a neutral observer, who could be trusted with sensitive information, which would not be divulged to their immediate superiors, thus workers felt safe interacting with me. Hence they showed interest in my work and shared with me the issues that motivated as well as those that demotivated them. They also revealed their frustrations and distrust of the hospital management and the GHS authority structures, which had contributed to workers becoming resentful and demotivated.

\subsubsection{Reflections of my multiple identities}

Having to constantly negotiate my identity and position in the research field relates well with Wind's (2008) experience of having to daily negotiate her position as a participant observer, in order to observe on-going activities and events in her study of how rheumatoid arthritis people manage chronic diseases in two Danish health facilities.

I had naively assumed that by following the national protocol for field entry and my identity as a Ghanaian female research student, was enough to qualify me as an 'insider', which would position me strategically and facilitate the research process. However in my attempt to understand determiners of worker motivation I experienced both trust and distrust relations, as I negotiated between multiple identities, so I had to rely on my emotions. In reflecting back on my research experiences I agree with Fetterman's observation (Zaman 2008): 'The ethnographer is a human instrument . . relying on its senses, thoughts, and feelings, the human instrument is a most sensitive and perceptive data gathering tool.' With hindsight I realise that similar to Feterman's observation, by using my thoughts and feelings as data gathering tools and by positioning myself in different spaces, I went through various emotions, which made me to experience motivation and 
demotivation like my research participants. This draws me to Evans-Pritchard's observation many years ago:

I wonder whether anthropologists always realize that in the course of their fieldwork, they can be, and sometimes are, transformed by the people they are making a study of that in a subtle kind of way and possibly unknown to themselves they have what used to be called 'gone native' (Evans-Pritchard 1976:245).

I experienced methodological advantage when I got emotionally involved with my research participants. The (1999), equally alludes to this methodological advantage when she got emotionally involved with her research participants in her study of cancer patients, which afforded her a better understanding of their lived experiences.

\subsubsection{Making sense of my multiple identities in Adom hospital}

In Adom hospital I negotiated between perceived identities of a research student, a spy and a journalist among my research participants. The head of Adom hospital and the frontline workers were very subtle in exhibiting their distrust of my identity as a research student, as most of them were friendly towards me. Hence I initially assumed that I had been accepted and thus I could trust them. My prolonged stay revealed that for some of them I continued to be a distrusted 'insider' of the regional and national Ghana Health Service power structures, which informed their interaction with me. This contrasts with Mulemi's (2010) experience in Kenya - having assumed the role of a neutral visible observer, his continued stay in the hospital gradually made him a part of the cancer ward and clinic and the staff saw him as 'one of them'.

Overtime I realised some of my study participants including the head of Adom hospital accepted me, because of the power position that they perceived that I occupied as one connected to the GHS regional and national authorities. Resultantly at the onset of the research in Adom hospital, majority of the research participants communicated with me strategically. They gave me only favourable accounts of the hospital and its workers, which they perceived will be presented to a higher authority. As I prolonged my stay I observed that some of the conversations I earlier had with study participants, which indicated that certain workers were dedicated and hardworking, were not true. 
The use of ethnographic methods including conversations, participation and interviews were interpreted by the head of Adom hospital and some of the workers as gossip and spying for a higher authority, which they silently disapproved. The details of the interview with her suggested that she had only tolerated me, because she did not want to offend her superior - the regional director - my supervisor. So once the consent form indicated the voluntariness of the interview, she realised that I was on my own and that she could prevail over me. Also her continued reference to her superior in the actual interview on issues of administrative decisions on worker motivation, revealed her belief that I was spying on hospital management issues for the GHS regional authority. Based on this account I agree with Wind's (2008) suggestion that '...the ethnographer is an important audience for the informants. At least some if not all of an ethnographer's informants will watchfully scrutinise all her actions, attitudes, comments and questions.' Thus my presence and activities were equally observed, scrutinised and discussed by research participants.

\subsubsection{Making sense of my multiple identities in Grace hospital}

In Grace hospital I had to constantly renegotiate my position as one perceived as a distrusted 'insider' to a trusted 'outsider' in order to be accepted. This draws me to Wind's suggestion of ethnographers having to constantly negotiate their position in the field of research:

In the best of ethnographic worlds the ethnographer locates a place from where she can participate in the lives of the people studied; she finds a credible role that gives her the best opportunity for building trust and rapport so that she can join in different situations and activities (Wind 2008).

The very cursory introduction to the O\&G department workers by a junior nurse created the impression that I was a junior intern from one of the local universities. Also it did not show any seriousness of my research and made me appear a mystery woman to the workers. I initially accepted such an identity with the belief that it would endear me to the research participants and I also hoped it would help distance me from the GHS authority structure, which I had been linked to in Adom hospital. However, I was wrong. That position rather made frontline workers to perceive me as a distrusted 'insider' of the hospital management authority, who could easily convey their views to their immediate 
superiors, who had power to punish them. Also research participants perceived that I did not fit into the category of students that they were used to, which were nursing and medical students. A management arrangement that had created an atmosphere of distrust in the hospital prior to the onset of the research, was that a worker had been placed close to the pharmacy to enquire from clients who were exiting the hospital whether workers had charged them illegal fees. So the workers found my mysterious presence in the department as a confirmation of their suspicion that the hospital management wanted to intensify its decision to monitor workers' activities by planting a spy in the O\&G department. Later interviews with some of the hospital managers confirmed the fears of the O\&G department workers. The hospital managers however explained that there had been previous incidences of illegal deals at the hospital, which was why management made the decision to improve accountability and transparency by placing a worker close to the pharmacy to check on illegal deals. Thus, managers equally felt frustrated and resentful that the O\&G department workers did not seem to understand their motives.

I had initially developed similar distrust, bitterness and resentment for the hospital and its workers, so I had felt demotivated in conducting the research. However toward the end I enjoyed the friendliness and warmth of my research participants, which made me to feel motivated to continue the research.

Thus among the O\&G workers I was in Wind's (2008) words: 'an object for the Others' interpretation and social engagement, including their friendliness, cheerfulness, aggression, irritation and indifference.' My presence presented to them an image of the hospital management's power and authority in the $O \& G$ department. So the frontline workers resisted me, because they saw me as part of the power struggle between the hospital management and the O\&G department. Thus their reaction towards me was merely their lived experiences of an environment filled with a culture of distrust, resentment and their fear of control from the hospital management.

\subsection{Health worker motivation, identity and trust/distrust relations in the hospital environment}

This study suggests that like Evans-Pritchard's (1976) observation, the instrument of the research became 'native'. That is in my effort to understand worker motivation, I had to 
rely on my emotions to negotiate multiple identities within the research environment. Consequently in the process of interacting with my research environment and research participants, I experienced acceptance, rejection, distrust, trust, power struggle, resentment and frustration, which influenced my motivation as well. Thus I became subject to factors, which Franco et al. (2002) suggest also affect worker motivation: '...worker' motivation is affected by internal psychological as well as transactional processes and interactions between individuals and their work environment, as well as the broader societal context.' This raises the question - why was my identity and position that complex in a hospital environment?

Eriksen defines identity, which he also refers to as social identity as '...which groups a person belongs to, who he or she identifies with, how people establish and maintain invisible but socially efficient boundaries between us and them' (Eriksen 2004:157). Eriksen (2004) refers to Barth's argument that identity is both imperative and situational - that is, identity is both chosen by an individual as well as enforced on the individual by powerful groups such as nations and societies. The ethnographer's identity can be influenced by various social and contextual processes within and beyond the research environment. Consequently, the individual can have multiple identities, and so can negotiate her identity by choosing to play down on some aspects, while emphasising others - depending on the time and space (Eriksen 2004; Narayan 1993; Wind 2008). Similarly anthropologists have had to negotiate between multiple identities of 'insider' and 'outsider' positions during research (Chege 2015; Merriam et al. 2001; Narayan 1993; Tsuda 1998; Wind 2008).

In Grace Hospital the perception of my identity as an 'insider' of the hospital management created fear and distrust among frontline workers, who were unwilling to interact with me. The identity of an international $\mathrm{PhD}$ student made me a neutral observer and an 'outsider' who was not feared and could be trusted with intimate information on factors affecting workers' motivation. In Adom hospital the perceived identity of a journalist made me an 'outsider' of the health care system, who wished to find faults and report to the media and the general public, so frontline workers did not trust me. My perceived identity as someone linked to the hospital and the GHS power structures made me a supposedly powerful 'insider' of the health care system. So the head and frontline workers distrusted me and sought to present a perfect image of themselves and their 
environment. Consequently in order to understand worker motivation, I had to negotiate between multiple identities of 'insider' and 'outsider' positions with their concomitant influence on distrust and trust relations.

These feelings of trust and distrust relations between me and the research participants influenced the research process and were thus central to understanding worker motivation in the hospital environment. Fox (1974) defines trust as 'to have faith or confidence that something desired is, or will be, the case' and distrust as 'to have no confidence in, or suspect actions, intentions, motives of.' Research participants' considerations to trust or to distrust me were based on their own lived experiences of trust in their relations with the hospital and the larger Ghana Health Service structure. Where research participants perceived me as a representative of the health service authorities, they transferred their distrust, fear and lack of confidence in their superiors onto me. On the other hand where they perceived me as an 'outsider' of the health care system, they perceived less risk in trusting me. Additionally those who perceived me as an investigative journalist, transferred their fear of the consequences of public opinion of negative reportage of their hospitals onto me.

\subsection{Discussion}

The study using the experiences of the researcher reflects on how contextual, field entry process and organisational factors influenced the identity of the researcher and the research project.

Organisational structures and arrangements influenced my identity in both hospitals. Some of the research participants in Adom hospital easily related to the study and accepted me as a student, because being a relatively large specialist referral hospital, the workers were used to different categories of local and international students frequently conducting various studies and internships. Also the large size of the hospital helped to minimise my visibility. Grace Hospital on the other hand, had few structures and offered basic services, so few nursing and medical students came on internship. Consequently, the workers were not used to seeing and interacting with diverse categories of students, hence once I did not fit into the known categories, they distrusted my identity as a student. Similarly, Tsuda (1998) experienced distrust among the indigenous Japanese 
workers in his study of factory workers, because they were not used to experiencing students conducting ethnographic studies in their work environment.

Another contextual factor that influenced my identity is the onset of democracy and the passage of the Whistleblower's act - ACT 720, in Ghana, which encourages and protects informants in the public interest as follows:

An ACT to provide for the manner in which individuals may in the public interest disclose information that relates to unlawful or other illegal conduct or corrupt practices of others; to provide for the protection against victimization of persons who make these disclosures; to provide for a fund to reward individuals who make the disclosures and to provide for related matters (Government of Ghana 2006:3).

These two developments have facilitated access to information and as a result there has been a proliferation of the media in public and private spaces and public hospitals are of high interest. This is because public hospitals provide essential services and are patronised by a majority of the populace. Thus my perceived identity as an 'Anas' seemed to have come from Anas Aremeyaw Anas' pioneering work in the field of investigative journalism in Ghana, which has contributed to his name becoming synonymous with investigative journalism (Anas 2015). His most recent finding and perhaps the most significant is a two year film documentary that exposed widespread corruption in the Ghanaian judicial sector. Thirty-four judges and magistrates and over hundred court workers were caught on hidden cameras taking bribes. Some of the officials involved have been dismissed after being found guilty by a judiciary disciplinary committee constituted by the Chief Justice of Ghana (Mensah-Tsotorme 2015). The investigative piece has consequently created a deep and destabilizing crises of conscience as well as fear in the Ghanaian society (Wikipedia 2015). So democratization and open access to information in Ghana has paradoxically led to a culture of distrust and attempts at misinformation in public institutions. Similar studies on hospital ethnography in a teaching hospital in Ghana and another in Bangladesh suggest that local contextual factors play an important role in the daily routine of the hospital, reflecting the culture in which it is embedded (Bohmig 2010; Böhmig 2010; Zaman 2004, 2008). 
The power game that was exercised between me in negotiating my identity and the research participants, who decided to be strategically selective in their communication with me is not new in anthropological research. Therefore this study agrees with Long et al. (2008) and Wind's (2008) observation that the ethnographer's position in the research space is a constant negotiation and a delicate and sensitive process. Similarly Bohmig (2010), reports of how the nurses that she understudied in a Ghanaian teaching hospital had the power to conceal or to hide information from her to produce enriching or misleading data, however they could not prevent her from accessing the ward space or writing about them. Merriam et al. (2001) equally report of power play between researchers and research participants in their study of Chinese immigrants in the USA and business women in Botswana respectively. Davies (2008), Merriam et al. (2001) and Mullings (1999) further argue that both the researcher and research participants are vested with power. Hence research participants like the researcher can be selective with the information they choose to provide, which ultimately affects the research project.

Using participant observation, conversations and interviews to explore health worker motivation, which is a sensitive topic for the government, managers and frontline workers in Ghana (Agyepong et al. 2012; Alhassan et al. 2013; Dartey-Baah and Amoako 2011), contributed to the rumours that fuelled the belief among the research participants that I was spying on them. I also experienced tensions when I raised questions on motivation and financial incentives. Managers presented defensive responses and frontline workers blamed managers and the government for poor and lack of financial incentives. Details of these findings have been reported in other studies (Aberese-Ako et al. 2014; Aberese-Ako et al. 2015). Thus I was caught in the middle of the power struggle between the Ghanaian government, hospital managers and health workers. Likewise, Mullings (1999), based on her experience in conducting interviews with managers and workers in information processing companies in Jamaica, argues that the choice of methodology in organisational settings can position the researcher in the middle of the quiet or disguised conflict between the different power brokers, such as managers and workers. This can contribute to neither group perceiving the researcher as a trustworthy 'insider'. Similarly, Wind's (2008) suggestion that the ethnographer's work often appears trivial or as if she is watching, monitoring or policing staff inappropriately, helps to 
explain why research participants developed the perception that I was spying on them for a higher authority.

The position of the native 'insider' as a distrusted spy and the native 'outsider' as a trusted research student though surprising to me, confirms Van der Geest and Sarkodie's (1998) assertion that in Ghana foreigners are often treated more courteously than Ghanaians. Also, Bohmig's (2010) study in a Ghanaian teaching hospital suggests that as a woman, nurse and a non-native, she gained an 'insider' position as one of the nurses, who are women. Also her identity as an expatriate endeared her to the young nurses, who saw her as one who could give them information on migration to the West. Similarly my position as a foreign-based student garnered me more respect and trust than my initial position as a native research student. A second explanation for the contradictions of the 'outsider' and 'insider' identities and their links to trust and distrust relations could be the following: an 'outsider' identity positions the researcher outside the hospital and the GHS power structures and for that matter research participants felt safe that they could trust me with information that would not be relayed to their superiors, so they would not suffer some backlash effects. The contrary is true.

Negotiating my multiple identities between trust and distrust relations as well as cooperation and lack of cooperation from research participants were important sources of data, as they enabled me to gain knowledge and a better understanding of determiners of worker motivation. The findings suggest that high levels of distrust relations between frontline workers and managers created a poor organisational climate that demotivated workers. These findings have been reported in other papers (Aberese-Ako et al. 2014; Aberese-Ako et al. 2015). Nonetheless the finding contradicts with Mullings' (1999) argument on positional spaces, which suggests that trust resulting in cooperation between the researcher and the research subject are the only avenues that the researcher gains knowledge.

My emotional experiences of motivation, demotivation, trust/distrust and power struggles in my interactions with research participants and the research environment, reflects the experiences of frontline health workers in the provision of health care. This observation could not have been gotten without the use of ethnographic methods. The finding buttresses research experiences in Kenya (Mulemi 2010; Long et al. 2008). In the 
same manner this study of health worker motivation goes beyond earlier studies that relied on interviews and self-reported factors influencing motivation of health workers (Agyepong et al. 2004; Bonenberger et al. 2014; Dieleman et al. 2003; Dieleman et al. 2006; Jack et al. 2013; Mbindyo et al. 2009a; Purohit and Bandyopadhyay 2014; Thu et al. 2015).

\subsection{Conclusion}

This paper explored my research experiences in my native country, Ghana. The hospital entry process, contextual factors and the ethnographic methods used shaped my perceived multiple identities among research participants, which influenced the research project. Various lessons have been learned.

Contextual factors and the ethnographer's approach to field entry can affect the research project. Therefore the ethnographer needs to be conscious, sensitive and reflective of her position in the research environment.

The perceived identity of the ethnographer can be multiple and transformative even for natives, which can affect the research project. Thus the ethnographer gaining an 'insider' or 'outsider' position is not necessarily advantageous or disadvantageous. Rather the ethnographer's ability to understand and explore the different positions contributes to obtaining knowledge from the different perspectives.

The ethnographer's observations and emotions are important sources of data. By relaying on her emotions the ethnographer can gain a deeper understanding of the study subject.

Both trust and distrust relations between the ethnographer and research participants are important sources of data. As even in a position of distrust the ethnographer can gain knowledge and a better understanding of the context of her research.

Having the right introductory letters can enable ethnographers to gain entry into public hospitals, but it does not necessarily lead to acceptance and winning the trust of research participants. It behoves on the ethnographer to negotiate her identity in the hospital environment in order to win the trust of her research participants, which

enhances her chances of accessing knowledge. Also participation in the activities of 
research participants contributes to building trust relations, which can facilitate the research process.

The hospital is a place that relationships are intense, because it is about life and death, so the fact that emotional distrust pops up is understandable. Thus managers should be sensitive to their environment and should ensure that researchers are properly introduced and the objectives of their research well discussed with health workers, before the onset of field work. This would help to allay workers' fears and unnecessary suspicions. 


\section{Chapter 3}

\section{3 'Your health our concern, our health whose concern?' perceptions of injustice in organizational relationships and processes and frontline health worker motivation in Ghana}

This chapter uses motivation and organizational justice theories to illustrate how perceptions of justice influence frontline health workers' experiences of motivation and demotivation and their consequent effect on workers' attitudes and responsiveness to clients' health needs. Additionally it explores intrinsic motivating factors and their influences on workers' responsiveness to clients' health needs and consequent effects on interpersonal quality maternal and neonatal health care in public hospitals. The chapter concludes that for health workers to be able to respond to the needs of the clients who visit their facilities, it is pertinent that frontline health workers' personal and organizational needs are adequately addressed.

The chapter has been published as Aberese-Ako, M., vanDijk, H., Gerrits, T., Arhinful, D. K. \& Agyepong, I. A. 2014. 'Your Health Our Concern, Our Health Whose Concern?': Perceptions of injustice in organizational relationships and processes and frontline health worker motivation in Ghana Health Policy and Planning, 29, 15-28 (Supplement 2). 


\subsection{Introduction}

Policy-makers and other agents responsible for reforming African health institutions and systems have often blamed health workers for a poorly responsive health system, suggesting that health workers interact and communicate poorly with clients (Agyepong et al. 2001; Andersen 2004; M.O.H. 2001, 2007). Interventions to improve quality and responsiveness in healthcare have centred on professionals and frontline workers without recourse to a total system reform (Agyepong et al. 2001; Agyepong et al.2004). Yet, low health worker motivation and discontent continue to be cited as major causes of poor healthcare quality and outcomes in Sub Saharan Africa including Ghana (Adzei and Atinga 2012; Agyepong et al. 2004; Agyepong et al. 2012; Alhassan et al. 2013; Chandler et al. 2009; Faye et al. 2013; Luoma 2006). Worker motivation can be defined as the degree of willingness of the worker to maintain efforts towards achieving organizational goals (Franco et al. 2002; Kanfer 1999). Extrinsic motivation factors including contingent rewards such as salary, policy reforms and organisational factors, and intrinsic motivation factors that embody the individual's desire to perform the task for its own sake, which is selfgenerated and non-financial such as interpersonal factors, have been cited as influencing worker motivation in Africa including Ghana (Agyepong et al. 2004; Andersen 2004; Ansong-Tornui et al. 2007; Bosu et al. 2007; Chen et al. 2004; Mutale et al. 2013; Prytherch et al. 2012; Rowe et al. 2005; Songstad et al. 2011; Willis-Shattuck et al. 2008; Witter et al. 2007). Thus worker motivation is an important indicator of the quality and responsiveness of an organization towards its frontline health workers.

Continuous Quality Improvement (CQI) is a management philosophy as well as approach. It is a philosophy in that it has underlying beliefs, ways of thinking, concepts and attitudes about quality improvement. From a CQI philosophical perspective, quality is the product of a chain in which each person is a customer (client) of the people in the process preceding theirs (Agyepong et al. 2001; Agyepong et al. 2004; McLaughlin and Kaluzny 1994). The external users of the services of a particular organization for example the mother who brings her child for an immunization or the woman who comes to deliver at a health facility, who in the health system are called clients or patients are the last in the chain. The quality and responsiveness of the service they receive will be influenced by the quality and responsiveness of the whole customer chain, which starts at the top of the 
organization and ends with them. In this conceptualisation, the workers in an organization are seen as internal customers or clients and the clients at the end of the chain are the external customers or clients. For example if the administration office has delayed a nurse's request for better conditions of service or supplies, she may become irritated and frustrated and the chances that she will have a negative attitude towards her work increases, which in turn will influence her response to her clients' needs (external customers of the organization). The Continuous Quality Improvement (CQI) philosophical concept of internal and external customers of an organization may be a more inclusive concept to use in thinking through how to make health systems people centred. The nurse in our illustrative example has not received 'people-centred care' from her organization, which may negatively affect her ability to deliver 'people-centred care' to the clients (external customers) who have come to her. People-centred-care has been defined as:

....care that is focused and organized around people, rather than diseases. Within a people-centred approach, disease prevention and management are seen as important, but are not sufficient to address the needs and expectations of people and communities. The central focus is on the person in the context of his or her family, community, and culture (WHO 2011).

Drawing upon the CQI philosophy related to internal and external customers, if quality is the end result of a linked chain from internal through to external customers; then for an organisation to function well and provide quality care to its clients, it has to take care of the quality needs of its workers or internal customers. This study sought to explore frontline health worker experiences and perceptions of justice in national and organizational policies, processes and procedures relevant to their work; and how these issues influence their motivation and responsiveness to clients in the provision of maternal and neonatal health care. The study answered the questions: how do frontline health workers perceive justice (fairness) in the support they receive from the organization they work for and how does that influence their motivation to respond to their clients' health care needs? To explore the various dimensions of workers' experiences organisational justice theory has been employed.

Organisational justice theory is one of the critical theories in studying worker motivation (Latham and Pinder 2005; Songstad et al. 2011; Zapata-Phelan et al. 2009). 
Justice and fairness are concepts with similar meanings and in this paper will be used interchangeably. Both concepts have to do with impartiality, reasonableness, justice and equity (Agyepong 2012). Organisational justice is used to pinpoint the individual's belief that the distribution of outcomes, or procedures for distributing outcomes such as pay and other opportunities are fair and appropriate when they satisfy certain criteria (Bell et al. 2006 ; Leventhal 1976). The theory is relevant to this study, because perceptions of justice have been known to elicit different behavioural reactions including positive or negative attitudes in workers' response to work demands and performance within organisations (Colquitt et al. 2006; Greenberg 1993; Konovsky 2000; Laschinger 2003; Zapata-Phelan et al. 2009). When workers perceive injustice they may become demotivated and repay the organisation with negative attitudes, which affects organisational climate. Where they perceive fairness they are more inclined to be motivated and repay the organisation with positive attitudes including trust and positive response to organisational and clients' needs (Cropanzano et al. 2002).

We theorized that a frontline health worker's judgement of fairness in policy and organisational processes elicits reactions that influence motivation and response towards work, which affects the worker's desire to perform tasks that contributes to the achievement of organisational goals. This makes organisational justice an appropriate concept for exploring processes that shape health worker motivation and response to clients' needs in a hospital context.

The idea of organisational justice is based on Leventhal's two dimensional distinction of procedural and distributive justice (Leventhal 1976), and interactional justice (Colquitt et al. 2001; Konovsky 2000). Procedural justice is defined as an individual's belief that allocative procedures or decision making processes, which satisfy certain criteria are fair and appropriate (Cropanzano et al. 2002; Gergen et al. 1980; Leventhal 1976). Distributive justice is perceived as the individual's belief that it is fair and appropriate when outcomes or rewards such as salary, punishments, or resources are distributed in accordance with certain criteria (Colquitt et al. 2001; Cropanzano et al. 2002; Leventhal 1976; Stinglhamber et al. 2006). Interactional justice has been defined as the quality of interaction between individuals (Cropanzano et al. 2002; Stinglhamber et al. 2006). Interactional justice contains two aspects, informational and interpersonal justice. 
Informational justice is defined as the extent to which individuals are provided with information or rationale for how decisions are made (Almost 2006; Greenberg 1993; Laschinger 2003). Interpersonal justice is defined as the extent to which individuals are treated with respect and dignity (Almost 2006; Greenberg 1993; Laschinger 2003).

All three dimensions of justice distributive, procedural and interactional justice, will be used in this study to explore workers' perceptions of justice in policy and organisational processes within the hospital context, as they were evident in worker narratives. While distributive justice focuses on the final outcome, procedural justice deals with the processes involved in arriving at the final outcome (Leventhal 1976). The line between the two can be very thin and in our findings some of the issues presented had both procedural and distributive justice complexly interrelated, so the two dimensions of justice will be discussed concurrently.

\subsection{Methods}

For purposes of anonymity the hospitals are referred to as Adom and Grace hospitals and pseudonyms are used for all names used in this paper. Adom hospital serves a metropolitan area with a population of about half a million. It has specialist units, services, as well as workers including Obstetrician Gynaecologists, Anaesthetists and Paediatricians. It provides comprehensive inpatient care with a bed complement of 294. It has a theatre that permits major surgical operations and the full range of emergency obstetric services in addition to routine delivery services. Grace hospital serves a periurban population of about two hundred thousand inhabitants. It has a bed capacity of twenty and provides only basic maternity services. It had no theatre for major surgical operations during the period of study, but efforts were being made to set up one. The facility refers complicated obstetric and gynaecological cases needing specialised services to better-equipped facilities outside the district. Its doctors are general practitioners.

Adom hospital was selected to help gain insights into the study questions in the context of a big specialist hospital. Grace hospital was chosen to help understand the same issues in a smaller non specialist hospital. Data was collected in two phases. MA collected data in the maternity and new-born units of Adom hospital from January to September 2012 and in the maternity department of Grace hospital from October to December, 2012. 
In the second phase, she collected data in Grace hospital in July and August 2013 and in Adom hospital in October and November, 2013. Table 3.1 gives a breakdown of categories of workers and the methods used to obtain data. Data were collected on task agreement, relationships between professional groups and management, challenges and benefits in health care provision, trust relations and motivation. Attitudes and workers' responses to clients' needs were observed by the researcher as well as crosschecked with health care providers.

Table 3.1 Categories of workers in Adom and Grace hospitals who were included in the study and methods used in collecting data

\begin{tabular}{lcc}
\hline Category of workers & \multicolumn{2}{c}{ Data collection methods } \\
\cline { 2 - 3 } & Conversation Interviews & \\
\hline Adom hospital & 62 & 12 \\
Nurses and midwives & 5 & 2 \\
House officers & 11 & 4 \\
Senior doctors & 5 & 3 \\
Anaesthetists & 2 & 2 \\
Ward Aids & 6 & 6 \\
Orderlies & - & 2 \\
Doctors who left Adom hospital & - & 2 \\
Laboratory officials & 9 & 1 \\
Departmental supervisors & 3 & 4 \\
Hospital managers & & \\
Grace hospital & & 7 \\
Nurses and midwives & 23 & 1 \\
Nurse who left the facility & 1 & 1 \\
Doctor & 1 & - \\
Ward Aids & 4 & 4 \\
Departmental supervisors & 3 & 4 \\
Hospital managers & 2 & \\
\hline
\end{tabular}

Notes from observation of events, participation in workshops among others and conversations were jotted down in field note books. The notes were reconstructed and expanded at the end of each field visit in line with standard ethnographic studies 
(Emerson et al. 2005). Interviews were tape recorded and transcribed verbatim by a neutral researcher. The aim of employing a neutral researcher was to preserve interviewees' original expressions and to enhance validity of the study. Observation notes, conversations and transcribed interviews were typed and transferred to qualitative analysis software Nvivo (version 8), which was used to generate a coding list on common themes that arose from the data. Subsequently, the data were systematically analysed to identify patterns, differences and contradictions. Secondary data including institutional reports, policy guidelines and circulars were used to support and crosscheck the findings.

Main themes identified were related to distributive, procedural and interactional justices at local hospital management and the wider health sector decision making levels. These three dimensions of justice form the basis for interpreting and reporting on study findings at the two levels. Additionally intrinsic motivating factors were found and they are also discussed. While different categories of frontline workers were studied, the findings focus on doctors, nurses and anaesthetists' experiences, because these three categories of frontline workers are tasked with the core responsibility of providing maternal and neonatal health care.

This is part of the PhD work of the first author MA referred as the researcher or ethnographer'. The study was conceptualised by all the authors (MA, HD, TG, DA and IAA), referred to as 'the team'. MA collected the data. Coding and analysis of data were done by MA under the supervision of HD, TG, DA and IAA. The findings were then discussed with the other authors and quotes crosschecked for scientific rigour. The manuscript was drafted by MA with inputs in all phases from HD, TG, DA and IAA.

\subsection{Findings}

The researcher participated in a workshop that was organised by the management of Adom hospital for selected health workers (administrators, doctors, nurses, paramedics) in the facility. The objective of the workshop was to improve workers' knowledge on legal issues concerning the rights of workers and clients. Towards the close of the workshop workers were given the opportunity to ask questions. The excerpts below of a question a nurse-administrator asked a facilitator who is a doctor and also a frontline worker and the response shows in a nutshell perceived policy and organisational injustice issues 
encountered by nurses, doctors and anaesthetists in everyday health care provision in Adom hospital, as indeed was also the case in Grace hospital, where subsequent fieldwork was conducted.

Nurse: We have been talking about how to attend to clients for two days, what do you have for us, health workers?

Facilitator: It is shameful that companies pay for their workers who we take care of. But in health institutions we who take care of them pay our own medical bills. 'Your health our concern, our health whose concern?' That is why they believe health workers steal things. In those institutions they reimburse health bills. Why do you think you should use all the internally generated funds (IGF) for services and not to take care of yourselves? You think VALCO and Electricity Company of Ghana use all their money to buy steel and electricity! They use some to take care of their workers. ${ }^{12}$

The interaction suggests that health workers perceive that the values they are being asked to hold for their clients are not the values they feel are being held for them as people in the health system by their employers.

Firstly, the nurse's question suggests perceived neglect of frontline workers, who are yearning for attention. Secondly, the facilitator presents layers of perceived injustices confronting health workers. He suggests injustice in policy regarding conditions of service of health workers compared to their colleagues in other establishments. He also brings out organisational matters including interactional injustice regarding a common negative perception that health workers are thieves who steal medical supplies from public hospitals to sell to private hospitals. Additionally, he brings out issues of distributive injustice on how monies generated by health workers within their facilities are used. He suggests that the electricity company that supplies most parts of the country electric power and VALCO company, which produces aluminium derived from bauxite of worldclass quality to meet local demand and for export, are 'people-centred', because they use their companies' revenue to purchase raw materials for production to meet their external customers' electric power needs and equally use part of it to take care of their 'internal customers' health needs. He juxtaposes the Ghana Health Service logo: 'Your health our

12Adom hospital, observation notes, 24/05/2012. 
concern', which suggests that the health of the external customer is the responsibility of the health worker with 'Our health whose concern?': implying that the health worker's health needs are not the responsibility of anyone.

Thus health workers who are the custodians of health care of the general public perceive that they do not receive 'people-centred' care. This interaction fits Ntim's assertion in his article on economic governance and social accountability in Ghana: 'The moment there is a perception of unfairness-that others are having more than their due, this de facto precipitates agitation' (Ntim 2013). This goes to support other findings in this study that suggest that majority of frontline health workers perceive distributive, procedural and interactional injustice to be operating at local hospital management and the wider health sector decision making levels. By the wider health sector decision making level, we are referring to the Ministry of Health as well as its national directorate; the Ghana Health Service and the regional level directorates, which have the responsibility for making decisions that become authoritative for the lower levels (districts, hospitals and below). In the rest of this section the findings will present narratives of frontline workers based on Figure: 2 as follows: distributive, procedural and interactional injustice at hospital management and the wider health sector decision making levels. Factors influencing intrinsic motivation of frontline workers and consequences on workers' response to clients' health needs will also be discussed.

\subsubsection{Perceived procedural and distributive injustice related to local hospital management}

Frontline workers perceived distributive injustice by hospital management in the provision of incentives and response to equipment, tools and supplies to work with and their infrastructure needs, which are discussed below.

Workers in Adom hospital said in past times they were given incentives such as a monthly transport allowance and a Christmas package. However in recent times management had failed to provide these incentives, which they considered unfair. ${ }^{13}$ They suggested that it had contributed to a reduction in worker motivation to respond to clients' needs. In the words of a frontline worker:

13 Adom hospital: conversation with a doctor, 05/07/2012; conversation with a midwife, 27/07/2012; interview with a nurse, 20/09/2012; observation notes, 24/05/2012. 
Figure 3-1 Processes in health worker motivation

Factors influencing worker motivation Outcomes

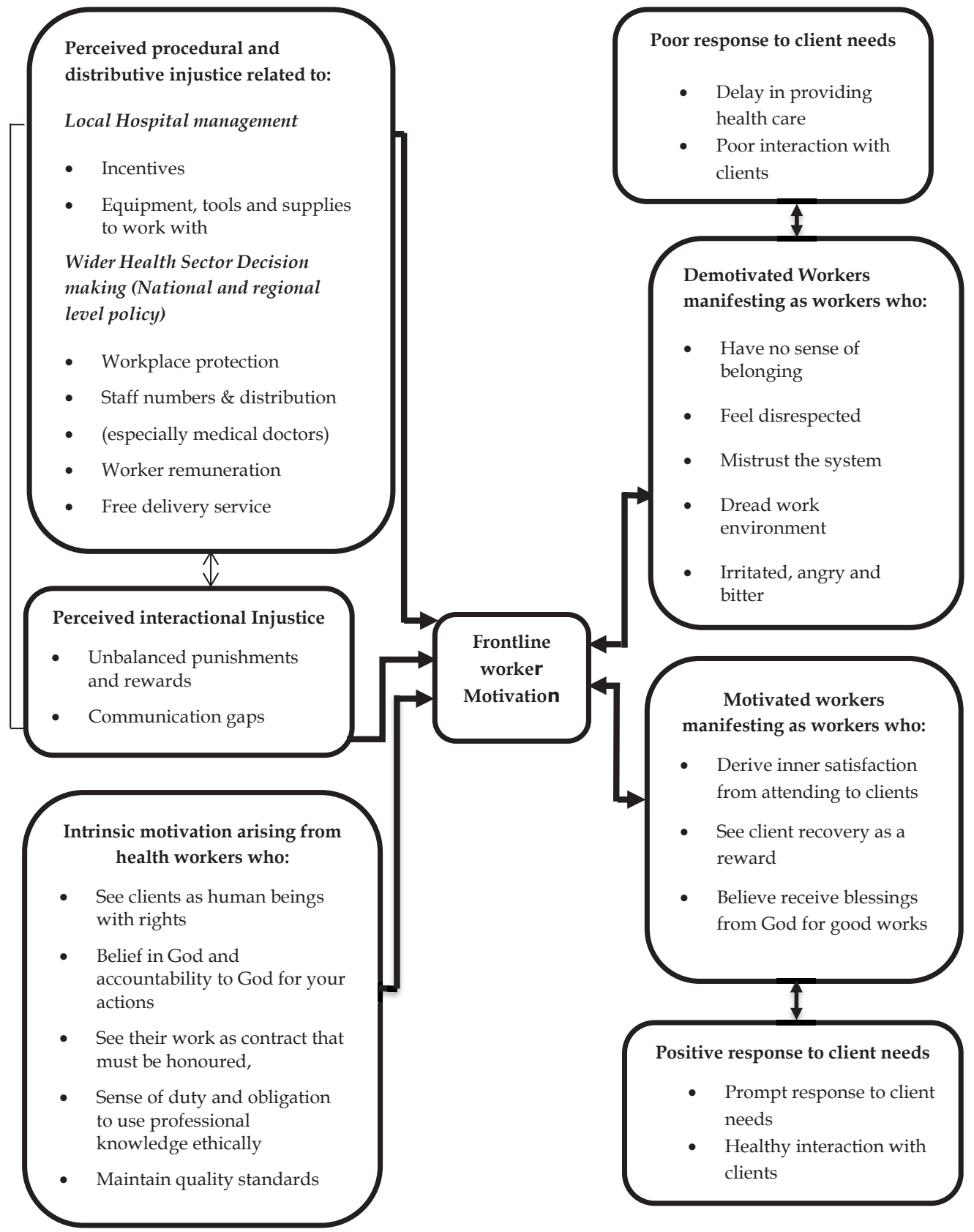


I think the problems are coming from here. Last two years when they decided not to motivate us at Christmas, they thought we will talk, so the director quickly went on leave....People are not complaining because they are all smart and finding their way around by doing their own things. ${ }^{14}$

Additionally, interviews and conversations with nurses, anaesthetists and doctors including some doctors who had left Adom hospital, suggested that they perceived that management did not treat doctors posted to the maternity department fairly. So they were not motivated to stay. One of the doctors who left the facility stated: 'I thought "I will be given accommodation at Adom hospital", but they denied me. I thought after that "they will give me some allowance for fuel"; no they denied me.'15

In response, a management worker said that the facility stopped providing incentives to workers because a directive from the director general's office in 2008 ordered all facilities to stop issuing incentives. ${ }^{16}$ Some frontline workers indicated that they were aware of the directive. Nevertheless they argued that their output is high, which enables the hospital to generate a lot of revenue. So it was only fair that they should be appreciated for their efforts by being given monetary incentives. ${ }^{17}$ On the issue of doctors leaving Adom hospital, the hospital's manager responded that they had recently introduced an incentive package specially for doctors in the maternity department to help maintain the few doctors that were in the department. ${ }^{18}$

In Grace hospital, midwives complained of lack of incentives including the provision of drinking water, infrequent allocation of Christmas bonuses and stoppage in providing night cups (coffee, tea and biscuits) for workers on night duty. ${ }^{19}$ In response, two management workers explained that management in consultation with frontline workers agreed to sacrifice all incentives to workers and rather use the money to buy essential items, which were required for a peer review ${ }^{20}$ exercise. They said that all

\footnotetext{
14 Adom hospital, conversation with an anaesthetist, 05/07/2012.

15 Interview with Dr. *Bill, former staff of Adom hospital, 09/09/2013.

16 Adom hospital, interview with an accountant, 17/08/2012.

17 Adom hospital, conversation with a senior midwife, 08/06/12.

18 Adom hospital, interview with a hospital manager, 04/12/2013.

19 Grace hospital: conversations with a nurse, 03/09/201, 29/07/2013; conversation with a nurse, 22/08/2012; conversation with two night nurses, 11/08/2013.

20 An annual activity that has been instituted in the study region. It involves health staff of other public facilities within the region assessing the performance of sister facilities. The aim is to encourage public facilities to step up quality health care provision.
} 
frontline workers agreed to sacrifice and were happy about it.21 Conversations with midwives on night duty however, suggested that they were not aware of this arrangement. 22

Some workers in Adom hospital bemoaned deteriorating conditions of the hospital's infrastructure resulting in some injuries to workers. For instance during a maternal audit meeting a senior nurse and a senior doctor narrated how a theatre door fell on a nurse. No compensation was provided to the nurse afterwards. They suggested that it was not fair that though their efforts brought in money, management did not provide them with a conducive work environment. ${ }^{23} \mathrm{~A}$ frontline worker summed the situation up:

All that we are asking is every day we work, but where does the money go? Look at the air conditioners and the fans in the wards, they are not working! But when you go to their offices [management workers] you will see that everything works. ...Yet, those of us who do the real work and bring in the money, you come to our offices and we are crammed and nothing works. ${ }^{24}$

In both hospitals, frontline workers perceived procedural injustice in their respective hospitals' management response to their equipment and basic medical supplies needs. Some added that sometimes they were not involved in decisions to acquire supplies and equipment, for which they are the end users. Also whenever they were involved their views were not taken into consideration. ${ }^{25}$ They felt that the hospitals delayed in providing them with basic supplies and sometimes they were given substandard products to work with. They perceived these acts as unfair to frontline workers who have to improvise on such occasions to provide health care to clients. They argued that this contributed to delays in providing services to clients. Some said using substandard products contributed to the provision of poor quality care to clients. They indicated that managers' poor response in providing them with their work needs was demotivating. ${ }^{26}$

21 Grace hospital: interview with two management members, 06/08/2013; conversation with two nurses, 11/08/2013.

22 Grace hospital, conversation with two night nurses, 11/08/2013.

${ }^{23}$ Adom hospital, observation notes, maternal audit meeting, 16/03/2013.

${ }^{24}$ Adom hospital, conversation with an Anaesthetist, 5/07/2012.

25 Adom hospital, conversation with a nurse-anaesthetist, 03/10/2013; Grace hospital, conversation with a nurse, 26/09/2012.

26 Adom hospital, conversations with two nurse-anaesthetists, 03/10/2013, 26/09/2013; Grace hospital, interview with a senior nurse, 30/07/2013. 
Management workers on the other hand responded that the seemingly poor response to supplies and equipment needs was because facilities are required to follow procurement laws for bulk purchases. Unfortunately, the procurement process takes some time and that accounts for the delay. ${ }^{27}$ For substandard medicines and other supplies, they admitted that this was a challenge to management as well. Facilities are by law not allowed to buy supplies and equipment from the open market, if the Central or Regional Medical stores have some in stock. Yet, sometimes medicines issued to facilities from the Central medical stores were expired or fake. To support this assertion, two management members cited an occasion that Grace hospital returned quantities of oxytocin, ${ }^{28}$ which the medical stores supplied to the hospital, because they were discovered to be fake. ${ }^{29}$

The majority of workers indicated that management's inability to provide incentives, the needed medical supplies and failure to maintain safety standards was demotivating and a sign of management's lack of appreciation of their work. Thus they did not trust that management was working in workers' interests..$^{30}$ This supports Adzei and Atinga's (2012) study, which suggests that resources to work with and the quality of hospital infrastructure are significant determining factors of health worker motivation and retention in district hospitals in Ghana. Other studies equally suggest that health workers' inability to pursue their vocation due to lack of means and supplies is a demotivator (Mathauer and Imhoff 2006). Also related to this finding but in a contrary direction, procedural justice has been found to lead to increased job satisfaction, organisational commitment and organizational citizenship behaviour (Konovsky 2000). Thus, workers' perception of injustice was observed to have contributed to a lack of commitment and anticitizenship behaviour that was counterproductive to the achievement of organisational goals. We observed that in part at least, as a consequence of these perceptions that the organization was not interested in their welfare as people, there was low worker motivation that had led to attitudes that created tensions and contributed to poor organisational climate and poor worker collaboration in health care provision. Ultimately,

\footnotetext{
27 Adom hospital, interview with a hospital manager, 31/07/2012.

28 Ocytocin is a drug commonly used in induction and argumentation of labouring clients. (Freeman and Nageotte 2007)

${ }^{29}$ Grace hospital, interview with two hospital managers, 06/08/2013.

${ }^{30}$ Adom hospital, conversation with a nurse-anaesthetist, 05/07/2012.
} 
it affected worker response to clients' needs. Some workers had adopted strategies including doing locum ${ }^{31}$ in private facilities, charging clients illegal fees or reporting to work late or leaving work early. ${ }^{32}$ Sometimes such attitudes led to delays in responding to clients' needs, due to poor collaboration among different categories of professionals providing services such as caesarean sections (C/Ss). An illustration is a junior doctor who had to wait for nurses, orderlies and an anaesthetist on afternoon shift to arrive to work with him to perform a caesarean section on a client, who was admitted the previous day and needed an emergency C/S. In response to a question on factors demotivating him, he expressed his frustration as follows:

Look at that woman lying there [a pregnant woman set with infusion is lying on a bed in the walkway], she has been in labour since Sunday [this was a Monday afternoon], but now we cannot perform C/S on her, because it is $1.30 \mathrm{pm}$ and the morning shift people say they have to close. ${ }^{33}$

Ideally the morning shift should have worked with the doctor till the afternoon shift took over at 2.00pm. This kind of situation has been observed elsewhere (Galer et al. 2005; Heponiemi et al. 2010). Still related to these observations, but in the contrary direction, other studies have found that where workers had trust in management, it reflected in a positive relationship between workers and their clients (Atinga et al. 2011; Bruce 1990; Koenig et al. 1997; Westaway et al. 2003).

\subsubsection{Perceived distributive injustice related to wider health sector issues at national level}

Folger (1993), suggests that when employees perceive that their organisation cares about them as human beings, they are more likely to trust the organisation, exhibit greater loyalty and commitment to work and the contrary is true. Many of the frontline workers in this study perceived injustice at a wider health sector level that is the central Ministry of Health $(\mathrm{MOH})$, the Ghana Health Service (GHS) and its regional health service directorates. They suggested that the sector was not responsive to their health care needs, work related injuries and providing them with a conducive work environment. Frontline

\footnotetext{
${ }^{31}$ Locum is working in private facilities in addition to being permanent workers in public hospitals.

32 Grace hospital: conversation with a nurse, 18/07/2013; interview with Dr. Job, 03/08/2013.

${ }^{33}$ Adom hospital, conversation with a junior doctor, 23/07/2012.
} 
workers' perceptions of injustice at sector level sometimes intersected with their perceptions of injustice at hospital management level.

Frontline workers suggested that the Ministry of Health, the Ghana Health Service and their facility managers did not care about their welfare. Consequently they did not trust that GHS and their facilities would take care of them if they risked their lives in the line of duty. Frontline workers' lack of trust was sometimes exhibited in worker-client interaction. The observation below is an illustration of one of such incidents in a maternity ward. A mentally challenged client was in labour, but she was not cooperating with a senior nurse, who wanted to conduct a vaginal examination. A junior nurse discouraged the senior nurse from continuing her efforts by saying:

If she will not agree.... leave her....If you force to examine her and she resists, you could injure yourself.... Ghana Health Service will not do anything for you. You will even have to take care of yourself, buy your own drugs, treat yourself and no one will compensate you. ${ }^{34}$

Interviews with management workers suggested that there was a work policy guideline for adverse events to ensure that workers who got injured were catered for. ${ }^{35}$ However workers who were injured or exposed to HIV/AIDs and Hepatitis B in the process of providing health care, said they had to bear the cost of treatment. A doctor in Adom hospital who experienced needle pricks on three occasions while performing surgery on HIV/ AIDS clients said he had to pay for the cost of treatment. ${ }^{36}$ A nurse in Grace hospital also narrated her experience as follows:

If a worker is sick even paracetamol [a pain killer usually administered as first aid] you have to buy ...Last year I was doing delivery and had to do episiotomy. While I was suturing, I suffered a needle prick. Unfortunately, the client was hepatitis B positive....I had to do some tests... I also had to go for hepatitis B vaccination and the disease control officer charged me 15 Ghana Cedis (US\$7) for each of the three shots. ${ }^{37}$

\footnotetext{
${ }^{34}$ Adom hospital, observation notes, 14/09/2012.

35 Adom hospital, interview with a hospital manager, 31/07/2012; Grace hospital, interview with two hospital managers, 20/09/2013.

36 Adom hospital, interview with a junior doctor, 14/09/2012.

${ }^{37}$ Grace hospital, interview with a senior nurse, 30/07/2013.
} 
The researcher interviewed a legal expert to understand whether workers had a right to demand treatment for injuries at work and better conditions of service. He said that the Ghana labour act stipulates that the health of the employee is the concern of the employer. So workers had the right to demand better conditions of service. He added that it was more rewarding to the organisation to provide such basic services to their frontline workers, because it served as a booster to worker performance. ${ }^{38}$

Frontline workers in Adom hospital perceived distributive injustice from the regional health directorate and hospital management in the allocation of frontline workers especially doctors to the maternity department of Adom hospital. Adom hospital conducts over 200 deliveries in a week. At the time of the field work, it had three specialist obstetrician gynaecologists and three general doctors. Additionally, an average of three house officers [newly qualified doctors on internship] were posted to Adom hospital's maternity department periodically to do three to six months internship under the supervision of specialists. Doctors complained of unfair distribution of doctors and work between them and their colleagues in the teaching hospitals. hey suggested that in comparison, the teaching hospitals attended to only a slightly higher number of maternity cases than they did, yet had about seventy doctors in their maternity departments, compared to the six in Adom hospital's maternity department. ${ }^{39}$

Some suggested that the regional health directorate was unresponsive to their need for doctors, despite efforts put in by the maternity department to bring their predicament to its notice. Conversations with some doctors in the maternity department and an interview with a doctor who left the facility suggested that an assessment of the quantum of work by the regional health directorate recommended that the maternity department be staffed with twenty five doctors. But the regional health directorate did not provide the recommended number of doctors. They perceived this development as unfair, because the six doctors available had to take on the work of twenty five doctors. ${ }^{40}$

The consequences of unfair distribution of doctors included work overload, doctors feeling overused, complaints of ill health, tiredness and waning motivation. Some devised coping strategies including switching their phones off when off duty and refusing

\footnotetext{
38 Interview with a legal expert, 08/09/2013.

${ }^{39}$ Adom hospital, observation notes, 23/11/2012.

40 Adom hospital: conversation with two gynaecologists, a junior doctor and a house officer, 30/04/2012; interview with Dr. Job*, 03/08/2013.
} 
to visit some of the wards in the maternity department during ward rounds. Some placed quotas on the number of clients they would attend to in a day. ${ }^{41}$ The finding supports Manongi et al.'s (2006) study, which suggests that health workers give quotas when they are overwhelmed with work. Some doctors in Adom hospital coped with the workload by performing only emergency $\mathrm{C} / \mathrm{Ss}$ and skipped elective $\mathrm{C} / \mathrm{Ss}$. Other doctors who experienced burn out left the hospital, giving the $\mathrm{O} \& \mathrm{G}$ department a relatively high doctor turnover. An interview with Dr. Job* who was described as a good doctor, but left Adom hospital depicts the process from feelings of injustice, to demotivation and to attrition.

I got tired...It gets to a point you begin to feel that those managing the system don't really care about those who are busily doing the work. So whether you go to work and there is no water or whether you go to work and the laundry is not functioning, whether you go to work and the unit that sterilizes the equipment is not functioning, whether you have enough medical officers or house officers to support you do the work or not, nobody seemed to be finding permanent solutions to these problems. So once in a while we run into different forms of crisis...and then you find out that you are getting more and more irritated with everybody who work with you. You snap at nurses, you snap at patients. You get up in the morning, particularly on the days that you are going on calls, you are not happy to be going to work. 42

A senior nurse manager explained that the limited number of doctors in the maternity department of Adom hospital was a national problem. She explained that there are quotas imposed on the number of workers that the Ghana Health Service can employ at a given time. Secondly the teaching hospitals, which are the training institutions that feed public hospitals with doctors, retain most of the doctors they train. ${ }^{43}$ The skewed distribution of doctors in low resource countries including Ghana has been noted elsewhere (Agyepong et al. 2001; Chen et al. 2004; Dovlo 1998; Faye et al. 2013; Mbindyo et al. 2009a; Mutale et al. 2013; Snow et al. 2012). Unfortunately, in many countries the establishment of posts, recruitment, terms and conditions of service are beyond the authority of public hospitals and regional managers. They are directly controlled by central government agencies

\footnotetext{
${ }^{41}$ Adom hospital, interview with a junior doctor, 31/10/2012.

${ }^{42}$ Interview with Dr. Job*, 03/08/2013.

43 Adom hospital, conversation with a senior nurse, 26/11/2013.
} 
(Appiah-Denkyira et al. 2011; Larbi 1998, 2005). Secondly per the Ghana Health Service and Teaching Hospitals' Act 525 (Government of Ghana 1996), the regional health directorate and the Ghana Health Service, have no authority over doctors in the teaching hospitals, which are a major source of recruitment of doctors and other frontline workers. These gaps are translated into skewed distribution of doctors in public health facilities as was the case is Adom hospital.

Frontline workers in the maternity department of both facilities perceived distributive injustice in national policy related to worker remuneration. They suggested that since they were attending to higher client numbers than their colleagues in other departments, they should be given incentives to make up for the low remuneration from government. ${ }^{44}$ A senior doctor in the maternity department of Adom hospital presented this view:

Dr. Kofi*: The Ghana Health Service system is such that the physician specialist and the gynaecologist receive the same salary. But the physician specialist will come in the morning, do the prescriptions and by afternoon he is done... But our work is different; you can be called at any time. ...sometimes they call me at 2.30am.

Researcher: So do you think your midwives have a case when they complain that they are not being treated fairly?

Dr. Kofi*: Yes, their complaints are right. Because they work a lot, but are not given much...the problem is a national one. For instance workers of the same rank are given the same salary across the country. So a nurse of the same rank whether the fellow is in the labour ward, the out patients department or wherever receives the same salary. ${ }^{45}$

A management member in Adom hospital agreed that the quantum of work in the maternity department was comparatively higher than in the other departments, so the workers in the maternity department should be compensated for the extra work. ${ }^{46}$ However a senior nurse manager in Adom hospital and two management workers in

\footnotetext{
${ }^{44}$ Adom hospital, conversation with two nurses, 20/04/2012.

45 Adom hospital, conversation with a senior doctor, 05/07/ 2012.

46 Adom hospital, interview with a physician specialist, 31/07/2012.
} 
Grace hospital held the view that all departments are important, so they should be treated equally. The priority should be on using the internally generated funds to run the hospital and any surpluses could be used to provide incentives to motivate all workers. ${ }^{47}$

Another national policy issue cited by workers as unjust both from a distributive and procedural injustice perspective was the implementation of the fee exemption policy, which involves universal exemptions from payment of user fees for delivery services (Ansong-Tornui et al. 2007). Frontline workers in Adom hospital suggested that the policy had led to an increase in client load in the maternity department, without a corresponding increase in staff numbers, basic equipment, tools and supplies, worker remuneration and expansion of infrastructure. To use the words of one of the senior doctors:

I am disgruntled and angry but we have to work. They refused to give us our conversion difference [salary adjustment]. ...Look at the clients; some are sitting on benches. Adom hospital, two thirds of the land has not been used, we have a large plot of land and what is being done with it! Look at the small thing they are putting up as the maternity block and look at how long it has taken. ${ }^{48}$

Workers perceived that the fee exemption policy had been implemented without taking into consideration the ability of facilities and workers to manage excess client numbers or how to compensate workers for the extra work. The increase in numbers put a strain on workers and facilities, which was demotivating. Similar finding has been reported (Ansong-Tornui et al. 2007). Other studies have documented frontline workers' perceptions of unfair remuneration with agitations for better remuneration in Ghana (Agyepong et al. 2012). Songstad et al. (2011) also noted the influence of policy and political developments on worker remuneration and perceptions of injustice in Tanzania.

\subsubsection{Perceived interactional injustice related to hospital management}

In Grace hospital many frontline workers perceived interactional injustice from hospital management in meting out punishments and rewards and in communicating with workers. Frontline workers suggested that the head of the hospital did not commend them

47 Adom hospital, interview with a nurse, 20/09/2012; Grace hospital, interview with two hospital managers, 06/08/2013.

48 Adom hospital, conversation with a senior doctor, 03/10/2013. 
for good work done, but was quick to reproach (insult) workers who made mistakes. They found her approach to interacting with them unprofessional and demotivating. ${ }^{49}$ An interview with two management workers confirmed frontline workers' perceptions about the head. The management workers added that if a worker made a mistake, the head of the facility insulted the worker and his or her entire family. Also if the worker in question ever made another mistake in future, the head always referred to her previous mistakes. ${ }^{50}$ A senior nurse said she had indicated in a staff survey questionnaire in 2013 that they were not commended for their good work, but were always reproached by the hospital management for their short comings. ${ }^{51}$

The management workers as well as the frontline workers who were interviewed admitted that the head of the hospital had the right to discipline workers. However, they said they would have preferred an approach to discipline with the head appropriately investigating reported offences first, then dealing with the offences in a professional way, instead of making discipline seem like a personal attack on workers. They argued that dealing with offences in a professional manner could help bring long term solutions and prevent recurrence of similar offences. ${ }^{52}$ In an interview with the researcher, the head of Grace hospital said that she follows the Ghana Health Service code of ethics ${ }^{53}$ to discipline offending workers. This entails: she first gives a verbal warning to an offender, followed by a written warning and the third time she hands the offender over with the compiled evidence to the district health directorate or the regional health directorate for action. On the issue of workers complaining that she reproaches them for their offences, she explained that once a worker commits an offence, she reprimands the worker in her office in the presence of the worker's department head, who serves as a witness. However, if the fellow repeats a similar offence she refers the worker to the previous offence, because the

\footnotetext{
${ }^{49}$ Grace hospital: interview with a doctor, 29/07/ 2013; interview with two nurses 30/07/2013; conversation with a nurse, 29/07/2013.

50 Grace hospital, interview with two hospital managers, 06/08/2013.

51 Grace hospital, interview with a nurse, 30/07//2013.

${ }^{52}$ Grace hospital: interview with two hospital managers, 06/08/2013; interview with a doctor, 29/07/ 2013; conversation with a nurse, 29/07/2013.

53 The Ghana Health Service code of conduct and disciplinary procedures stipulates how matters of workers' discipline should be handled by health service managers. (Ghana Health Service 2003)
} 
worker would have probably promised to be of good behaviour, but might have forgotten and committed a similar offence. 54

Some workers suggested that existing channels for communicating concerns to management were not helpful. A former management worker said they had durbars, 55 which were not useful channels for communicating their concerns to management. He said frontline workers complained that in previous durbars when they raised their concerns, the head of the facility responded in an unfriendly manner. Consequently, very few workers attend durbars. 56 The head of Grace hospital said in an interview that she did not see her responses at durbars as a confrontation, this was probably the perception of some workers. She stated that she and her core management team members make efforts to address workers' concerns at durbars. ${ }^{57}$

Thus ironically workers felt that the professional work ethics that they were being espoused to hold for their clients, were not being reciprocated to them by the hospital management. Perceived interactional injustice contributed to feelings of bitterness, sorrow and anger, which affected some workers' self-confidence, interest and desire to perform their duties. ${ }^{58}$ Consequently some workers did not take initiatives to facilitate health service provision to clients and sometimes counterproductive behaviours were observed. On one occasion women who had completed their antenatal visit could not leave the facility, because they had to take their drugs from the antenatal pharmacy. However there was no dispensary attendant, so the women sat waiting for another hour. The junior nurse who provided them with the antenatal service got worried and asked her superior if they could do anything about the women's plight, since there was no dispensary attendant at the dispensary to attend to them. The superior responded: 'I don't care what happens. If I talk then they will report me to doctor [head of Grace hospital]. So I won't bother myself.'59 Subsequently, the women who overheard her comment left the facility without waiting any longer to receive their routine antenatal drugs.

\footnotetext{
54 Grace hospital, interview with hospital manager, 05/03/2014.

55 Open air meetings that brings together managers and frontline workers to interactive freely to discuss organisational issues.

${ }^{56}$ Grace hospital, interview with a former hospital manager, 07/08/2012.

57 Grace hospital, interview with a hospital manager, 05/03/2014.

58 Grace hospital: interview with a medical doctor, 29/07/2013; interview with two nurses, 30/07/2013; conversation with a nurse, 29/07/2013.

${ }^{59}$ Grace hospital, observation notes, 18/07/2013.
} 
Workers' perception of being treated with disrespect and in an insensitive manner contributed to poor organisational climate and lack of job satisfaction and the desire to leave the facility. Similar findings have been noted elsewhere (Almost et al. 2010; Laschinger 2003, 2004). Also, Mathauer and Imhoff (2006) found that appreciation of their work and recognition among others, were important ingredients to worker motivation and a perceived sense of justice. Fonn and Xaba (2001), infer that when health system managers treat workers fairly, respecting their rights, empowering them and creating a conducive work environment, workers become motivated and exhibit positive attitudes towards work.

\subsubsection{Intrinsic motivation factors}

Most frontline workers perceived injustice at hospital management and policy levels, which they suggested affected their motivation. However, interestingly some of these workers demonstrated a high sense of motivation and responded positively to clients' needs in spite of this. In-depth interviews and conversations with some workers who were observed to exhibit a high sense of motivation suggested that the factors motivating them were intrinsic. Intrinsically motivating factors were similar in both facilities. Sources of workers' intrinsic motivation included perceiving clients as human beings with rights and the desire to maintain standards and accountability to God for one's actions. Others were a perception of their work as a contract that must be honoured, a strong sense of duty and the obligation to use their professional knowledge ethically. Some intrinsically motivated workers suggested that the greatest incentives to them included successful client recovery, which gave them an inner sense of satisfaction and others believed they received blessings from God, for responding positively to clients' health needs. Below are illustrative excerpts from two workers. The first is a doctor in Adom hospital, whose motives were clients' rights, a high sense of duty and a desire to maintain standards. The second is a nurse in Grace hospital whose motives included professional ethics and deriving inner satisfaction from successful outcomes.

I don't want to mismanage anyone. I don't want to give half-half treatment to anyone. I don't want to see someone and it is like you are experimenting, no. If I see you, I want to give you the very best I can and standard treatment that you 
deserve. Not because you are in Ghana, so you don't have this, no. ... I don't want to cut corners. ${ }^{60}$

You see, I believe that when you are doing a job you have to do it well. When I came here [Grace hospital] the first time, I realized that there was no oxygen and I said I won't work without oxygen. The then matron... had to get it before I became comfortable to work here. You know, when you are working, the inner satisfaction is very important. How can you deliver a mother and the baby needs resuscitation and you cannot do so and you watch the baby die. ${ }^{61}$

These two workers and several others like them who were intrinsically motivated exhibited positive attitudes including sacrificing to stay back to attend to clients past their scheduled times. In emergencies, some used their personal resources including going to other hospitals to beg for supplies for their hospital. Some improvised in the absence of critical supplies to save lives. ${ }^{62}$ The influence of intrinsic motivation on worker performance is consistent with Lin's (2007) finding that workers' attitudes and intentions to perform tasks are strongly associated with their intrinsic motivation. Studies in Benin suggests that vocation, professional conscience, job satisfaction and the desire to help clients are strong motivating factors for health workers (Mathauer and Imhoff 2006). Studies carried out in India found that intrinsic factors had a higher influence on doctors' motivation in the provision of health care than extrinsic factors (Purohit and Bandyopadhyay 2014).

\subsubsection{Summary of findings}

Our findings support studies that suggest that workers' motivation is influenced by extrinsic and intrinsic factors. We found that perceptions of distributive, procedural and interactional injustice at organisational and policy levels had a strong influence on workers' motivation and response to clients' health care needs. Frontline workers had the feeling of being let down by the health system, as they perceived that they did not receive 'people-centred care' from their employers, despite being asked to provide 'peoplecentred care' to the clients that come to their hospitals. They perceived that the values they

\footnotetext{
60 Adom hospital, interview with a Junior doctor, 14/09/2012.

61 Grace hospital, conversation with a nurse, 05/09/2012.

62 Adom hospital, observation notes, 03/07/2012, 17/09/2012; Grace hospital, observation notes, 01/11/2012.
} 
are being asked to hold for their external customers are not being held for them by the health system within which they work. This considerably weakens the credibility of the message they are being given to treat their clients in a responsive manner. Furthermore, perceived injustice in policy and organisational processes, made them distrust their leadership. Some became apathetic and less motivated to respond to external clients' needs.

Despite perceived injustice in policy and organisational processes, some workers demonstrated a high sense of motivation and responded positively to clients' health care needs. We found that intrinsic motivation factors including perceiving clients as human beings with rights, the desire to maintain standards and accountability to God for one's actions among others, played a key role in workers who demonstrated a high sense of motivation. Intrinsically motivated workers suggested that they derived inner satisfaction from performing tasks and others believed that they received blessings from God for responding to clients' needs. Nevertheless, even intrinsically motivated workers such as Dr. Job burned out with time. This shows that worker motivation is a dynamic process.

\subsection{Conclusion}

Our methodology of a participatory approach through participant observation, conversations and in depth interviews in studying frontline worker motivation in a biomedical environment provides insights on organisational justice in the hospital environment that could not have been otherwise obtained.

Using distributive, procedural and interactional justice dimensions of organisational justice theory, this study has demonstrated the multiple layers of injustice perceived by health workers in the hospital setting. It brings to light the influence of worker perception of injustice on worker motivation in the provision of health care. Where workers perceived injustice, workers were more likely to be demotivated and it affected their response to client health care needs. However, issues of injustice could not explain why some workers were motivated to respond to clients' needs. Factors that were identified to motivate workers were intrinsic. Thus, this study contributes to knowledge on the complexity of factors that influence frontline worker motivation within the hospital setting. 
To promote worker motivation a 'people-centred care' approach that considers frontline workers within the health system as 'people' to whom the system should be responsive is essential. Health care should draw upon CQI philosophy and should be organised around health workers as internal customers and clients as external customers. Frontline workers' interest should be factored into any intervention that aims at improving quality health care.

Within our study setting a 'people-centred' approach that includes frontline health workers in the concept should include the following:

At facility level, supportive leadership and supervision should be instituted to foster good working relationships between frontline workers and managers. There is a need to train managers in transparency, communication, respect in interaction and the need to see team work as a priority as proposed in the CQI philosophy.

At facility level a radical change in management culture is needed. Management should put in structures that will ensure effective communication, transparency and accountability. Also, managers and supervisors should learn to see workers as members of a team, who should be treated with dignity and respect even in matters of discipline. Facilities should improve motivation through provision of basic incentives to frontline workers.

At national and regional levels efforts should be made to synchronise the needs of the various facilities in order to be able to distribute frontline workers based on need of facilities. Transparent processes for allocating workers that engage frontline workers and are seen as fair in the context of overall national resource constraints should be adopted.

We believe that without the creation of a conducive atmosphere where frontline workers will feel their concerns are that of their department and organisation managers, policy makers and other agents responsible for health care in a way that is fair, it will be difficult to have frontline workers motivated to see the health of their clients as their concern. 



\section{Chapter 4}

\section{4 'I used to fight with them but now I have stopped!' Conflict and doctor- nurse-anaesthetists' motivation in maternal and neonatal care provision in a specialist referral hospital}

The chapter discusses how personal, interpersonal and organisational determiners contribute to frequent conflicts between collaborating professionals in the health care environment. Frequent conflicts led to workers becoming demotivated, and so they lost interest in collaborating in the provision of maternal and neonatal care. Demotivation led to poor collaboration between health workers, which resulted in a compromise in clinical decision making, resulting in poor worker response to clients' health needs, which affected interpersonal quality health care provision. The chapter recommends collaborative approach to addressing conflicts in health care organisations, since it is noted as the most effective way of finding permanent solutions to conflicts. Concepts including power, trust and organisational conflict are employed to discuss the findings.

This chapter has been published as: Aberese-Ako, M., Agyepong, I. A., Gerrits, T., \& van Dijk, H. (2015). 'I Used to Fight with Them but Now I Have Stopped!': Conflict and DoctorNurse - Anaesthetists' Motivation in Maternal and Neonatal Care Provision in a Specialist Referral Hospital. PLOS One, 10(18), 1-20. doi: 10.1371/journal.pone.0135129 


\subsection{Introduction and analytical concepts}

Health worker motivation can be defined as '...an individual's degree of willingness to exert and maintain an effort towards organizational goals' (Franco et al. 2002). Motivation is affected by internal psychological as well as transactional processes and interactions between individuals and their work environment, as well as the broader societal context (Franco et al. 2002). As such, individual workers' motivation can be affected by conflicts between collaborating workers. Individual, interpersonal and organisational factors contribute to conflicts and unequal power relations and relations of distrust among workers can affect how workers respond to conflicts (Almost 2006; Coombs 2003; Gilson 2003; Rowe et al. 2005). Poor responses to conflicts can lead to persistent conflicts, which can frustrate efforts towards achieving organisational goals. Conflicts can be particularly devastating where health care provision is dependent on cooperation, understanding and interdependence between different professional groups.

Health worker motivation has been widely studied using a variety of qualitative (Dieleman et al. 2003; Dieleman et al. 2006; Purohit and Bandyopadhyay 2014) and quantitative methods (Franco et al. 2004; Purohit and Bandyopadhyay 2014). In Ghana, low motivation of health workers in maternal and neonatal health care provision has been cited as one of the factors impeding the achievement of the set targets of Millennium Development Goals 4 [reduce child mortality] and 5 [improve maternal health] by 2015 (Agyepong et al. 2004; Ansong-Tornui et al. 2007; Bonenberger et al. 2014; National Development Planning Commission et al. 2010).

There is however very little published literature examining inter- professional conflicts and their role on workers' motivation, care provision and outcomes for maternal and newborn health care in low and middle income countries (Coombs 2003; Gilson 2003; Rowe et al. 2005). This paper therefore aims to contribute to knowledge in this area by presenting the findings of an in-depth exploration of why and how unequal power relations and relations of distrust can lead to conflicts, which in turn affect the motivation of doctors and nurse-anaesthetists in the provision of maternal and neonatal health care in a specialist public hospital in Ghana, a lower middle income sub-Saharan African country. Understanding the links between conflicts, power, trust/distrust and motivation in health care organisations can contribute towards finding solutions to improve health workers' 
motivation and performance, which can help accelerate progress towards achieving the unfinished Millennium Development Goals 4 and 5 agenda (Agyepong et al. 2001; Agyepong et al. 2004; Ansong-Tornui et al. 2007; Bosu et al. 2007; Dieleman et al. 2006; Mathauer and Imhoff 2006; National Development Planning Commission et al. 2010).

We theorized that health workers' motivation can be influenced by conflicts resulting from personal, interpersonal and organisational factors. How individuals and organisations respond to conflicts is influenced by trust and power relations. Where there is distrust, disagreements can be interpreted with suspicion, which can influence responses that can intensify conflicts. Also where there is contestation of power, workers' desire to assert themselves can intensify conflicts. When appropriate responses are not employed to resolve conflicts, workers may lose trust in co-workers and the organisation, become less motivated and exhibit poor attitudes in collaborating with co-workers and a cycle of conflicts in worker relations develops. Persistent conflicts may hinder the achievement of organisational goals. We therefore draw upon the concepts of conflict, trust and power relations to guide our analysis.

\subsubsection{Conflict}

Conflict can be defined as a difference in opinion (Brinkert 2010). Most authors agree that conflicts in health care organizations result from individual differences, interpersonal differences and organisational arrangements and gaps (Almost 2006; Almost et al. 2010; Bercovitch 1983; Cinar and Kaban 2012). Classical organisational theory and the human relations school suggest that conflicts have negative consequences on organisations, because conflicts prevent organisations from achieving their goals (Slack and Parent 2006). From this perspective, conflicts should be avoided. However other studies suggest that organisational conflicts should not be necessarily perceived as negative (Almost 2006; Brinkert 2010; Whetten et al. 1996). Rather the way the parties to a conflict perceive and respond to it determines its potential negative or positive consequences on an organisation. Conflicts can have positive consequences if they encourage self-examination, lead to healthier relations, enhance workers' motivation and contribute to organisational transformation (Pondy 1967; Slack and Parent 2006; Vivar 2006). Zydziunaite and Katiliute (2007) found that when conflicts between co-workers are resolved constructively, their 
motivation increases, which impacts positively on their performance. However even this school of thought also agrees that persistent conflicts if not constructively resolved can be dysfunctional, negatively affecting psychological and physical wellbeing, motivation, job satisfaction and performance of workers (De Dreu and Weingart 2003; Jehn et al. 2006; Rowe et al. 2005; Vivar 2006).

Three major causes of conflicts in health care organisations have been proposed (Almost 2006; Cinar and Kaban 2012; Whetten et al. 1996) as follows: 1) Individual characteristics such as differences in values and demographic dissimilarity; 2) Interpersonal factors among co-workers such as lack of trust, injustice or disrespect and inadequate or poor communication; and 3) Organizational factors including interdependence between different professionals, organisational changes due to restructuring, and asymmetric power relations in health care institutions.

Whetten et al. (1996), categorise how individuals and organisations manage conflicts into five possible responses including forcing, accommodating, avoiding, compromising and collaborating. 'Forcing' refers to situations where a party attempts to satisfy his/her need at the expense of the other. Strategies employed include the use of formal authority, physical threats, manipulation ploys or ignoring the claims of the other. 'Accommodating' refers to situations in which a party tries to satisfy the concerns of the other at the expense of his/her own. 'Avoiding' occurs when the interests of both parties are neglected by side-stepping the conflict or postponing the solution. A 'compromising' response occurs where each party gives up something to resolve the conflict. It can cause a rapid resolution of a conflict but may not resolve underlying problems. 'Collaborating' or 'cooperating', which is also referred to as the 'problem-solving' response, tries to find solutions to the cause of the conflict that are satisfactory to both parties. It takes time and expertise to resolve conflicts by collaborating, and not all conflicts are amenable to being solved that way. Whetten et al. (1996) suggest that when the time and expertise is available to use it, collaborating can be the most effective approach, since in the end, both parties perceive that their interests have been met. So resolutions tend to be long lasting. 


\subsubsection{Trust}

Trust especially in hospitals with multi-disciplinary, specialized and interdependent professionals is considered to be crucial to employee commitment and performance (Gilson et al. 2005; Gilson 2006; Laschinger et al. 2000; Thom et al. 2004). Co-worker trust is '...confidence that one's colleagues are competent and will act in a fair, reliable and ethical manner' (Ferres et al. 2004). This implies a two-way relationship between the 'trustor', defined as 'the person who trusts' (Johns 1996) and the 'trustee' defined as 'the person (s) trusted by the trustor' (Johns 1996). Relations of distrust among co-workers in a hospital can contribute to conflicts, which can impact negatively on interpersonal interactions, motivation and performance (Ferres et al. 2004; Fox 1974; Gilson et al. 2005; Mansour et al. 2005; Zand 1972). The contrary is true. Gilson et al. (2005) found that trust among health workers is a motivator to workers' performance and fosters a conductive work climate.

\subsubsection{Power}

Mintzberg (1983) describes power in organisations as '...the capacity to effect (or affect) organisational outcomes.' Various groups or actors within the organisation have different levels of power. In a medical situation, the frontline health workers - such as nurses, anaesthetists and doctors, who Mintzberg refers to as 'operators' are highly skilled and knowledgeable and are among the most powerful actors. Their expertise gives them discretionary power (Fox 1974; Mintzberg 1983), and they carry out the actions, which are the basic outputs of the organisation. Lipsky (1980), labels this group of actors as 'streetlevel bureaucrats' and suggests that their decisions and actions in implementation effectively become public policies. Health workers can influence decisions by exercising power through the use of threats, sabotage, etcetera. This can result in and intensify conflicts (Dahl 1957; Mintzberg 1983). 


\subsection{Methods}

\subsubsection{Study setting}

The hospital (alias Adom hospital) in which the study was conducted, has several specialist departments, which provide general as well as specialist outpatient and inpatient care and walk-in services. In addition, it serves as a referral hospital for smaller surrounding public and private health care facilities. It has a surgical theatre and a maternity theatre equipped to provide the full range of emergency obstetrics care. At the time of data collection, the central management comprised the medical director, accountant, administrator, and the directors of nursing and clinical services respectively. Each specialised department was semi-autonomous and had a departmental head who was accountable to the medical director.

The study was conducted in the obstetrics and gynaecology (O\&G) department, which had two administrative sub-units: a nursing unit and a medical officers' unit. Anaesthesia, was also an independent department and was headed by a senior nurseanaesthetist. The department served the anaesthesia needs of the surgical, O\&G and eye departments.

The first author, MA, also referred to as 'the researcher' conducted hospital ethnography. She spent a total of eleven months as a participant observer in the hospital as part of her PhD thesis research. The extensive engagement was to enable her to observe, experience, understand and represent the lives of subjects in their natural setting (Emerson et al. 2005; Van der Geest and Sarkodie 1998). In the first nine months, MA was an active observer and participant in the process of health care provision in the O\&G department; conducting tasks such as assisting nurses to deliver babies, watching over clients in the wards, while nurses followed up on laboratory tests results etcetera. Additionally, she collected data through conversations and in-depth interviews. After preliminary analysis of the data, she returned to the hospital for two more months to clarify gaps in the data by conducting further interviews and conversations. Table 4.1 provides a summary of the number of interviews and conversations by staff category. 
Table 4.1 Categories of workers included in conversations and interviews

\begin{tabular}{lcc}
\hline Category of workers & Data collection methods \\
& Conversation Interviews & \\
\hline Nurses and midwives & 62 & 12 \\
House officers & 5 & 2 \\
Senior doctors & 11 & 4 \\
Nurse-Anaesthetists & 5 & 3 \\
Ward Aids & 2 & 2 \\
Orderlies & 6 & 6 \\
Doctors who left Adom hospital & - & 2 \\
Laboratory officials & - & 2 \\
Departmental supervisors & 9 & 1 \\
Hospital managers & 3 & 4 \\
\hline
\end{tabular}

Ethical clearance was obtained from the Ghana Health Service Ethics Review board [approval number GHS-ERC:06/01/12] and from the University of Wageningen. Entry to the hospital was gained through an introduction from the regional director of health services. Within the hospital, one of the senior hospital managers introduced the researcher to the O\&G department staff as a student researcher. They were informed of the objectives of the study, and they gave her permission to participate in and observe activities in the wards, at meetings and training programmes. Written informed consent was obtained from all interview participants. Verbal consent was obtained for conversations. To protect the identity of the hospital and research participants pseudonyms are used throughout this article and the part of Ghana in which this study was conducted is not mentioned.

\subsubsection{Analysis}

Notes from observations and conversations were refined and expanded at the end of each day in line with standards in ethnographic studies (Emerson et al. 2005). Interviews were recorded and later transcribed verbatim by a research assistant. The data were typed, grouped and saved in two data sets: 1) interviews 2) observations and conversations. They were then analysed in Nvivo [version 8], by systematically coding to identify common patterns, differences and contradictions. Common patterns from both sets were then 
grouped into five major themes: incidences of conflict, causes of conflicts, category of professionals engaged in conflicts, how conflicts were managed, effects on health workers and quality client care.

In the analysis, any situation of disagreement between two health workers scheduled to collaborate in the provision of health care was labelled as conflict. Causes of conflicts were grouped into personal, interpersonal and organisational. How conflicts were addressed were categorised into five sub themes in line with Whetten et al.'s (1996) five conflict management responses.

When workers expressed sentiments including feeling emotionally low, lack of job satisfaction etcetera, as emanating from conflict experiences, this was labelled as negative effects of conflicts on health workers' motivation. Situations where conflicts contributed to delay and/or failure to provide care were labelled as negative effects of conflicts on quality client care.

Positive consequences of conflicts on health workers' motivation included: 1) situations where workers expressed personal satisfaction with the way conflicts were resolved 2) when an incident of conflict resulted in standard procedures being followed in the provision of health care.

The majority of conflicts were between doctors and nurse-anaesthetists. This appeared to be the main area where conflicts were affecting motivation and performance. The rest of this paper therefore focuses on these conflicts.

\subsection{Findings}

While accompanying a midwife on her ward rounds, MA begun to converse with her about challenges to maternal and neonatal health care provision in Adom hospital. The midwife said:

They [nurse-anaesthetists] are the cause of most of the problems in the theatre.

They decide when they want to come, when they want to do a case and which case 
they will want to do. They sometimes decide that they will not do elective cases, but will only do emergency cases..$^{63}$

This was one of the many occasions that the researcher heard or observed in meetings, conversations and workshops, complaints about nurse-anaesthetists. So she decided to devote some time in the operating theatre, to observe the interaction between doctors and nurse-anaesthetists. An incident observed on a morning when the theatre was bustling with activities is illustrative of the several incidences of conflicts that MA observed between doctors and nurse-anaesthetists in the hospital. The causes of the various conflicts appeared to be similar and included individual, interpersonal and organizational factors, with deeper roots of power struggle and distrust relations between doctors and nurseanesthetists (see summary in Error! Reference source not found.2). We first present this conflict and then disentangle the causes of this and other conflicts the researcher observed, and the way they were addressed (using the five responses as proposed by Whetten et al. (1996)). In addition, we illustrate how these conflicts and the way they were addressed affected health workers' motivation.

Dr. Hilary, a senior doctor, Dr. Kofi, a junior doctor and Dr. Kumoji, a house officer, were on duty in the O\&G department. Dr. Hilary stayed in the consulting room, while the other two worked in the operating theatre. Mr. John, a senior nurse-anaesthetist and Ms. Joan, a junior nurse-anaesthetist were scheduled to work with the O\&G and the surgery departments respectively. The first emergency obstetric case for the morning was a pregnant woman with a diagnosis of placenta previa type 2,64 who was bleeding profusely. Fortunately there was still a foetal heartbeat, and an emergency caesarean section $(\mathrm{C} / \mathrm{S})$ to save mother and neonate was arranged. The mother was wheeled into the operating theatre where Dr. Kofi and Dr. Kumoji were waiting for Mr. John, to anaesthetise her. Mr. John turned to Dr. Kofi and asked: 'Have they done blood count?'65 [In this hospital it is the responsibility of the doctor to request the test and instruct the nurses

\footnotetext{
${ }^{63}$ Conversation with a midwife, 29/06/12.

64 Placenta praevia (placenta previa AE) is an obstetric complication in which the placenta is inserted partially or wholly in the lower uterine segment.[1] It is a leading cause of antepartum haemorrhage (vaginal bleeding). (Encyclopedia Wikipedia 2014a)

65 Blood count tests offers information that the doctor can use to determine the client's health status (Discombe 1954)
} 


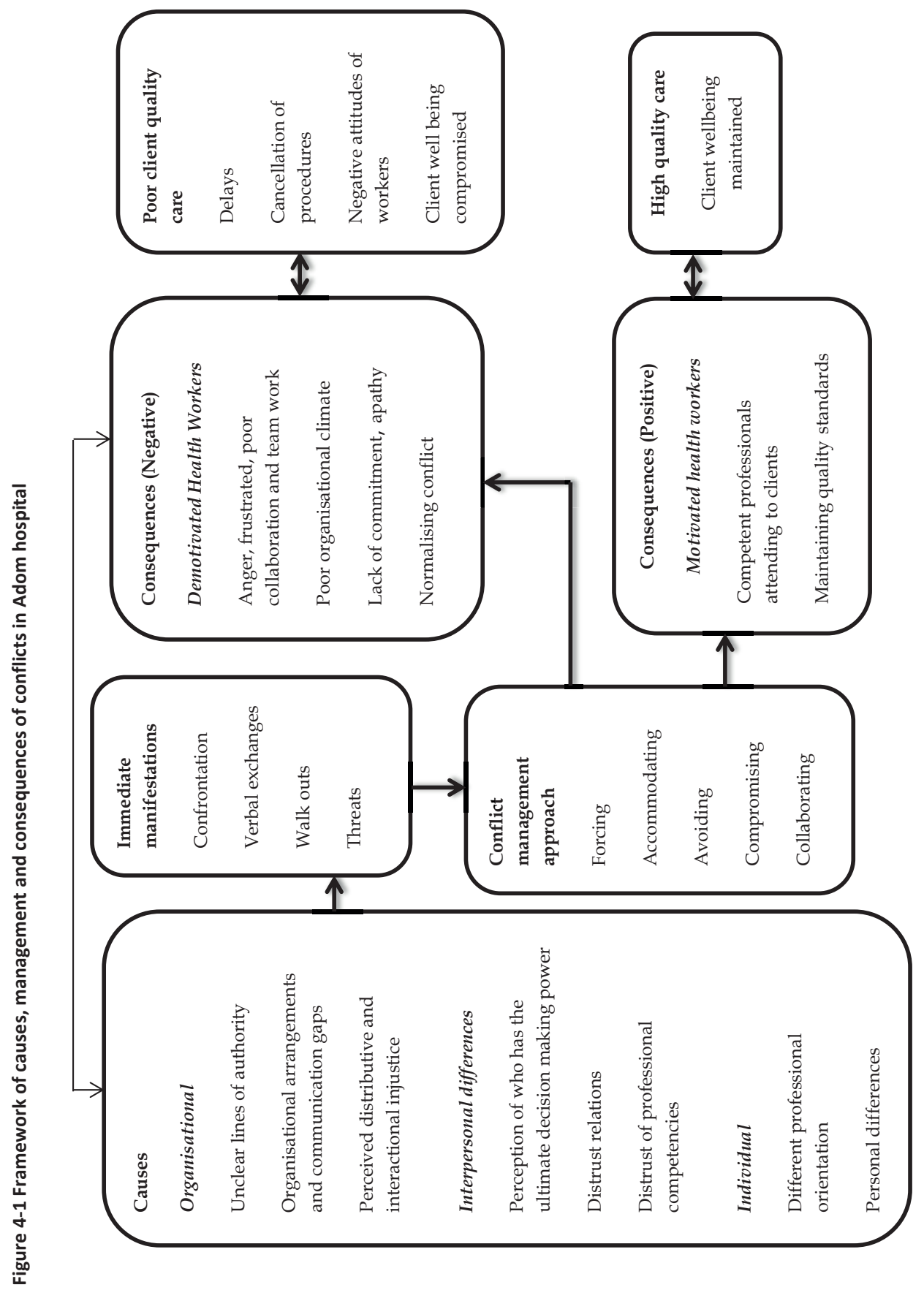


Mr. John calmly repeated his question: 'I am asking whether they have done the blood count?' Dr. Kofi retorted: 'You have had this coming since morning. You should have asked this question before the patient came in. I am not the one to liaise with the laboratory to conduct it before surgery]. Dr. Kofi retorted: 'Don't ask me!'to answer that question!' To which Mr. John now seemingly irritated replied: 'Then I will leave the patient!'. 'Yes, you can leave, after all what is it! I will also leave!' Dr. Kofi retorted angrily. Mr. John also visibly angry ordered his assistants: 'Wheel the patient out, we won't do it!'

Dr. Kofi and Mr. John continued the angry exchanges as both men stormed out of the theatre. Some of the nurses, orderlies and anaesthetist assistants present appealed to them to stop arguing, because the patient was suffering, but both men ignored the pleas. Then the theatre in-charge said to the pregnant woman who was sitting on the theatre table and moaning: 'You too, they are fighting because of you and you are here crying!' About ten minutes after their disappearance, Dr. Hilary arbitrated in the incident using a 'compromising' approach (Whetten et al. 1996). She asked Dr. Kofi to return to the theatre and Ms. Joan, the nurse-anaesthetist originally assigned to the surgical theatre, was called in to give spinal anaesthesia. Dr. Kofi safely delivered the mother of a live baby within thirty minutes. ${ }^{66}$

Subsequently we explore the causes, responses and consequences of this conflict as well as other conflicts between doctors and nurse-anaesthetists in the rest of the results section.

\subsubsection{Unclear lines of authority at organisational level and perceived lack of recognition of nurse-anaesthetists}

An organisational factor of unclear lines of authority between doctors and nurseanaesthetists, coupled with an interpersonal factor of perceived lack of recognition of nurse-anaesthetists, contributed to the occurrence of conflicts.

Several informants suggested that there was no clear definition between the doctors and nurse-anaesthetists as to which of the two professional groups had the ultimate authority to decide whether a client should undergo surgery. Both doctors and nurse-anaesthetists felt that the discretionary nature of their work, gave them this authority. The nurse-anaesthetists felt that the doctors were wrongly assuming that they should take instructions from them because they are originally nurses. A nurse-

${ }^{66}$ Observation notes, $18 / 07 / 2012$. 
anaesthetist explained: '...because here we are all nurse-anaesthetists, they [doctors] think we have no right to suggest to them to cancel a case, so they get upset about it. ${ }^{67}$

A house officer in an interview suggested that while it was easy to get nurses to take instructions from doctors, it was nearly impossible to get nurse-anaesthetists to take instructions from doctors. A senior doctor also stated in an interview: 'They [nurseanaesthetists] ... have some airs around them that without them a case cannot be done.... So initially I used to fight with them, but now I have stopped.' 68

The majority of the nurse-anaesthetists said that their motivation for pursuing the anaesthesia profession was to gain independence from doctors and to become more empowered. They added that unlike nurses who take instructions from doctors, nurseanaesthetists take their own independent decisions on which cases to attend to. They suggested that being nurse-anaesthetists boosted their morale and made them feel important. So they resisted collaborating with doctors on occasions that they perceived the latter were trying to impose their authority on them.

Follow up conversations with the different parties connected to the described incident, revealed that Mr. John had decided on his own discretion to work on an elective hernia case that morning with a surgeon from the surgery department, even though he was scheduled to work with the O\&G department. Dr. Kofi said he had earlier sent a nurse to inform Mr. John of the impending emergency C/S. However Mr. John had asked him to wait for the hernia case to be done first or refer the C/S case to the polyclinic. Dr. Kofi said he disagreed with Mr. John's request, because Adom hospital was the main referral hospital within that geographical area that was most competent to perform the emergency C/S. Also in his opinion, it was too risky to refer a bleeding woman to another facility, as it would delay emergency care provision, which could result in the death of mother and child. ${ }^{69}$ The surgeon who worked on the hernia case with Mr. John, said the information about the emergency case was not communicated to him, else he would have postponed his case, which was not an emergency.

Similar incidences of conflicts in decision-making on client care between doctors and nurse-anaesthetists were observed on several other occasions. Senior doctors asserted authority over nurse-anaesthetists by resorting to 'forcing'. For example, a senior doctor stated:

${ }^{67}$ Conversation with a nurse-anaesthetist, 20/09/2012.

68 Interview with a senior doctor, 23/11/2012.

${ }^{69}$ Conversation with Dr. Kofi, 17/09/2012. 
Once, I had a case of ovarian cyst and when I took her to the theatre, there was a female nurse-anaesthetist who asked me 'Have you done HIV/AIDS test? If you haven't done the test on the patient, I won't administer anaesthesia. ${ }^{\prime 70} \mathrm{I}$ told her 'It is not your business to ask whether a patient has been tested for HIV/AIDS or not. ${ }^{71}$

On the other hand, some junior doctors used 'accommodating' response by agreeing to the nurse-anaesthetists' decisions. For instance a junior doctor, had completed a $\mathrm{C} / \mathrm{S}$ case and was preparing to perform the next $C / S$, when the nurse-anaesthetist on duty asked him to suspend all elective C/Ss and perform only emergency C/Ss, because he wanted to go somewhere. The junior doctor insisted to know where the nurseanaesthetist wanted to go, however, the nurse-anaesthetist refused to disclose it. When the nurse-anaesthetist left the scene, the doctor cited the attitude of the nurseanaesthetist as one of the issues that demotivated him from working in the hospital. ${ }^{72}$

Thus nurse-anaesthetists exercised power by using 'avoiding' response such as coming to work late and closing early. Sometimes they suggested that they were tired and other times they chose to work with particular doctors that they felt comfortable with. While senior doctors sometimes resorted to 'forcing', junior doctors either used accommodating response or reported the poor conduct of nurse-anaesthetists to the senior doctor responsible for the O\&G department. The senior doctor in turn either reported such cases to the head of anaesthesia or the hospital director. The director in turn referred some of the cases back to the head of anaesthesia for action to be taken. However observations and discussions with the head of anaesthesia suggested that he only issued verbal reprimand to the culprits.

Persistent conflicts frustrated both doctors and nurse-anaesthetists and demotivated them from collaborating, which occasionally delayed health care provision.

\footnotetext{
70 The Ghana Health Service code of ethics enjoins all workers not to discriminate against any client on account of nature of illness. (Ghana Health Service 2003)

71 Conversation with a senior doctor, 17/08/ 2012.

72 Observation notes, $12 / 02 / 2012$.
} 


\subsubsection{Different professional orientation resulting in different decision making pathways}

Different professional orientation of doctors and nurse-anaesthetists, contributed to different views and decision pathways on client care, which sometimes contributed to conflicts.

Nurse-anaesthetists suggested that compared to doctors they had a greater responsibility to determine if clients were fit for surgery and its aftermath. Additionally, from the nurse-anaesthetists' point of view, not all clients proposed for surgery needed it. Also they perceived that if a client died, they would be held responsible and that most of the doctors were not interested in the welfare of clients, but were interested in just conducting surgeries. So the nurse-anaesthetists became upset when clients were brought into the theatre for surgery without undergoing the necessary laboratory examination and made statements like:

The doctors are supposed to request and ensure that the various lab tests are done, the necessary preparations are made, but they won't follow up. So cases are brought (to the operating theatre) with a lot of things undone. ${ }^{73}$

The doctors will recommend the patient for surgery, but will not bother to ensure that the necessary preparations [routine laboratory tests] are done. ... you will see the client being brought to the theatre and ... in the client folder, it is clearly stapled neatly 'lab test required' and there is nothing done. It can be so annoying and frustrating. ... definitely you will compromise with quality and punish the client. ${ }^{74}$

A hospital management team member supported the nurse-anaesthetists' point of view. He suggested that doctors sought to satisfy their interest at the expense of the nurse-anaesthetists' efforts:

If a doctor finishes an operation and the patient is not well, it becomes the nurse-anaesthetist's headache. He has to keep the patient alive, resuscitate the patient.... So that is why they don't agree with the doctors. ${ }^{75}$

On the other hand, the doctors felt that they were the ones who knew what was best for clients and had the greatest responsibility in client care. They needed to make quick

\footnotetext{
${ }^{73}$ Conversation with a nurse-anaesthetist, 20/09/2012.

74 Conversation with a nurse-anaesthetist, 18/07/2012.

${ }^{75}$ Interview with a hospital manager, 31/07/2012.
} 
decisions on client care in order to avoid delays, which could result in a client's death, since they would be blamed for any mishaps.

... these delays, and by the time you are ready to do the surgery the patient has bled so much. Now when you go in to do the surgery DIC (Disseminated intravascular coagulation $)^{76}$ could occur, then it will now be the doctor's responsibility to ...save the patient's life. At that critical point it is now left with you the doctor to try to arrest any situation that could cause the death of the client, because when the client dies, you will be blamed. ${ }^{77}$

The doctors perceived that nurse-anaesthetists and other collaborating workers did not share their view on client care, which they suggested contributed to delays and conflicts in decisions on client care. The doctors also felt that a team must have a leader and they were the natural leaders, as a junior doctor stated in an interview:

Sometimes they [nurse-anaesthetists] think about the complications for you [doctor] and want to decide that this is not a case that should be done this way. But I mean invariably there is supposed to be a leader of the team. ${ }^{78}$

During a maternal audit meeting, a senior nurse appealed for clear guidelines on client diagnoses for $C / S$, to help reduce such doctor-nurse-anaesthetist conflicts. In response, a doctor said that the nurse-anaesthetists were the cause of the conflicts in the theatre, because they refused to comply with doctors' decisions.

Consequently doctors and nurse-anaesthetists' different professional work orientation contributed to conflicts in perception of urgency of client care, which influenced each group's response to client care. The two groups responded to conflicts by using 'forcing', 'avoiding' and sometimes 'accommodating' response. Most of the conflicts were not resolved, so they persisted.

Repeated incidence of conflicts contributed to feelings of anger and frustration. Consequently a poor organisational climate emerged and it demotivated both professional groups from collaborating in the provision of health care.

\footnotetext{
76 Disseminated intravascular coagulation (DIC) occurs when the finely controlled process of haemostasis becomes disrupted. As a result, coagulant responses can change from being naturally protective to the host into a maladaptive response with pathological consequences. Clinically, this is reflected in the increased morbidity and mortality that is associated with DIC. (Thachil and Toh 2009)

77 Conversation with a junior doctor, 23/07/2012.

78 Interview with a junior doctor, 14/09/2012.
} 


\subsubsection{Distrust of co-workers' professional competencies}

An interpersonal factor that created conflicts that impacted on the motivation of doctors and nurse-anaesthetists were attempts to prevent workers whose competencies were distrusted from performing procedures.

Due to the scarcity of doctors in the O\&G department, sometimes junior doctors and house officers performed tasks that some senior theatre nurses and nurseanaesthetists deemed beyond their level of competence. Nurse-anaesthetists indicated that they did not feel comfortable when junior doctors and house officers who were supposed to work under the supervision of senior doctors, were allowed to perform complicated surgery cases unsupervised. Nurse-anaesthetists explained that in order to protect clients from poor quality care, they resisted such attempts by recommending that more senior persons performed the surgeries, or gave excuses that the client was not ready for surgery or openly refused to collaborate. However the junior doctors got upset as a nurse-anaesthetist narrated:

We prefer that the senior doctor does it [emergency C/S]. So that you do not risk the life of the client. And the complaints we hear is that we are trying to frustrate the young doctors. Their [the doctors] head will come telling us that 'eh my young doctors want to learn, but you are trying to frustrate them.' How can you use human beings as guinea pigs! So we tell them: 'Well if you want to do so, then we do not want to be part of it. ${ }^{\prime} 79$

Similarly, doctors who did not trust the competencies of nurse-anaesthetists that they were scheduled to work with preferred to invite a senior anaesthetist to perform the anaesthetic procedure. A senior doctor shared an experience:

... there was a certain patient that I operated on and that patient was not producing urine and I thought that this nurse-anaesthetist who was on duty should have called the doctor-anaesthetist [a senior anaesthetists, who was on study leave at the time of the study]. When I mentioned it, she nearly had some verbal exchange with me and so I kept quiet...We did the case and after the case, the patient was not passing urine... So I had to call the doctor-anaesthetist to come and review the case. ${ }^{80}$

79 Conversation with a senior nurse-anaesthetist, 20/09/2012.

${ }^{80}$ Interview with a senior doctor, 23/11/2012. 
So doctors and nurse-anaesthetists used 'collaborating', 'avoiding' and 'forcing' responses to prevent colleagues whose competencies they distrusted from performing procedures.

Both nurse-anaesthetists and doctors who succeeded in ensuring that distrusted colleagues did not perform procedures, said they derived inner satisfaction from occasions that they were able to ensure that experienced persons performed procedures. For instance the senior doctor expressed his satisfaction that the doctoranaesthetist, who is more experienced, came in to save the client. Also, the nurseanaesthetists said they were always happy whenever they succeeded in preventing a doctor who was deemed incompetent from performing a procedure on a client. On such occasions clients received quality care, so such workers felt motivated.

\subsubsection{Locum practice and illegal charges and the inability of the hospital to resolve such matters}

Most of the private health facilities within Adom hospital's catchment area engaged the services of some of the skilled and experienced doctors and nurse-anaesthetists in Adom Hospital as locum (private practice) staff. This sometimes resulted in scheduled doctors and nurse-anaesthetists reporting late or absenting themselves from work. Such practices contributed to delays, cancellation of procedures and sometimes emergency cases had to be referred to other facilities. Aggrieved workers repeatedly reported such practices to hospital managers, but managers did not seem to be able to get the culprits to desist from such practices. So some workers became frustrated, lost faith in management and resigned themselves to sharing such workers with private facilities - even when such workers were scheduled to be on duty in the hospital. A senior doctor shared an experience:

Whenever he [nurse-anaesthetists] was on duty you had to virtually share him with several other facilities, for he was working in several other facilities. So you will be working with him and he will say he is coming, then he will disappear for up till two hours. ${ }^{81}$

A nurse-anaesthetist admitted that most doctors and nurse-anaesthetists were doing locum, but he distrusted doctors who sacrificed their schedule in Adom hospital to do locum. He cited an instance when a client was sent from the study hospital to a private

${ }^{81}$ Conversation with a senior doctor, $17 / 08 / 2012$. 
facility, because the scheduled doctor was absent. It turned out that the absentee doctor who was scheduled for duty in the study hospital was the very doctor attending to clients in the private facility.

So when a scheduled doctor or a nurse-anaesthetist delayed or was absent from work it was suspected that the worker was engaged in locum. A nurse-anaesthetist described the state of suspicion and its consequent influence on workers' motivation:

People just go about doing whatever they feel like doing and earning their salary, but there is no joy and there is too much suspicion. Now when a doctor or a nurse- anaesthetist is not there, the perception is that the person is gone to do locum. ${ }^{82}$

Additionally nurse-anaesthetists and nurses suspected that some doctors brought in clients from their locum practice and secretly charged them illegal fees. So they felt it was unfair to collaborate with such doctors on such cases, because such clients were not their responsibility. A nurse-anaesthetist shared her suspicion:

... there were three emergencies ... the senior person [doctor] convinced us that he could do all three cases within a stretch of two hours, so if we could sacrifice to stay, we could work on the cases. ...Then he brought up a myomectomy case [refers to the surgical removal of uterine leiomyomas (Encyclopedia Wikipedia 2014b)] and convinced us that he will work on it first and then he will quickly work on the emergencies. Being a specialist we all rationalized that ...with his skill and level of expertise he will be able to finish the myomectomy, which wasn't any of the emergencies and quickly work on the other three cases and we will be done in no time, so we agreed. Now he finished the myomectomy case and he called a very junior doctor to come and do the emergencies and left. ${ }^{83}$

The nurse-anaesthetist further stated:

I have lost trust in him [senior doctor]. For all you know he had an arrangement with the myomectomy client. By now he told her 'You come and I will do this for you for this amount.' So he had taken his money from the client and we had to work for it.

82 Interview with a nurse-anaesthetist, 15/08/2012.

${ }^{83}$ Conversation with a junior nurse-anaesthetist, 20/09/2012. 
Distrust relations and perception of unfairness in rewards from illegal charges were also noted in connection with the incident in the theatre, described earlier. In a follow up conversation with Mr. John he confirmed his suspicion that Dr. Kofi brought in the pregnant woman from his locum practice. He asserted that if the woman had come through one of the wards in the hospital routine laboratory tests including a blood count would have been done. He suspected that Dr. Kofi was benefiting alone from an illegal deal with the client. He said the doctor's illegal activities had been reported to the hospital management, but hospital management was reluctant to discipline him, because the O\&G department had few doctors, so they could not risk losing him.

Conversations and interviews were conducted with department and hospital managers to understand how illegal charges were addressed at organisational level. A nurse manager explained that it was illegal for doctors to charge clients fees, as the hospital's accounts department was responsible for such matters. Most obstetrics and gynaecological services were free, as per the fee exemption policy of the government. She added that as a nurse manager she had no power to discipline doctors, so she reported doctors who charged illegal fees to the head of the doctors, who had the power to discipline them. She cited an instance that she reported a house officer who repeatedly charged clients illegal fees to the senior doctor acting as the head of the department and the hospital administrator. The senior doctor reprimanded him, but she had no idea how the administrator addressed the case.

Interviews with two hospital management members revealed that workers were free to practice locum, once it did not affect their work schedule. Nevertheless one said that it was nearly impossible to get evidence of workers who shuttled between their jobs and locum practice, because their colleagues shielded them. The other manager, who was the head of the hospital, however admitted that she had had repeated confrontations with one of the senior doctors in the O\&G department over his frequent locum practice, at the expense of his work in the hospital. Both managers also admitted that illegal charges existed. The other who was the hospital administrator, said she only heard about them, but she had no evidence suggesting that workers engaged in it. In the case of the house officer who charged illegal fees, she said she had been informed, but she had no power to discipline doctors, only the head of the hospital had such power. ${ }^{84}$ The head explained that illegal charges were not reported when collaborating parties shared the money, but conflicts arose when the benefits

${ }^{84}$ Interview with hospital administrator, 29/11/2013 
were not distributed among collaborating parties. She cited the case of a nurseanaesthetist who reported the illegal deals of a doctor to the hospital management. When it was investigated, it was realised that the doctor shared the benefits with her colleagues, which she was not privy to. She added that workers were free to report illegal practices to their immediate superiors or to hospital management for the necessary disciplinary actions to be taken..$^{85}$

The lack of a clearly defined organisational reporting system and strategy to deal with illegal charges and locum practice contributed to distrust relations between doctors and nurse-anaesthetists. Both doctors and nurse-anaesthetists who reported suspicious cases of locum and illegal charges, felt that the department and hospital managers did not adequately address their concerns. Consequently they took matters into their own hands by using 'avoiding' and 'forcing' responses to deal with such cases, which rather intensified conflicts and sometimes delayed health care provision.

\subsubsection{Organisational arrangements inhibited frequent communication and the building of team spirit}

The organisational work arrangements and practices limited interaction and created gaps in communication between collaborating workers, which contributed to conflicts. Firstly, a doctor on duty conducted daily ward rounds and on Monday mornings a senior doctor led a team of doctors to conduct general ward rounds. Such rounds were used to review, discuss and decide on surgery cases. However nurse-anaesthetists were not privy to such decisions, because they did not participate in such rounds. Secondly, being a specialist referral hospital, it receives emergency obstetrics and gynaecological cases referred from other facilities. Doctors sometimes sent such emergency cases directly to the theatre, without involving the nurse-anaesthetists. So doctors and nurse-anaesthetists mostly met and interacted in the midst of surgical procedures. A management member described the situation:

Normally they [nurse-anaesthetists] don't see patients. Surgeons and gynaecologists see all the patients. They only see the patients when they are going to sleep [being anaesthetised] and after that they only see them briefly and that is all. ${ }^{86}$

85 Interview with hospital head, 04/12/2013

${ }^{86}$ Interview with a hospital manager, 31/07/2012. 
The limited interaction between doctors and nurse-anaesthetists, as well as the latter's non-participation in initial decisions on surgery cases heightened their suspicion that some of the clients were not emergency referrals, but were individual doctors' private clients. So nurse-anaesthetists collaborated well with particular doctors they trusted, while they sometimes avoided collaborating with doctors they distrusted. For instance on one occasion a team of doctors had to delay an emergency C/S referral case that was brought the previous day. When the doctors were ready to perform the procedure, the scheduled nurse-anaesthetists and other theatre workers closed at $1.30 \mathrm{pm}$, instead of the official $2.00 \mathrm{pm}$. So the doctors had to wait for the staff scheduled for the afternoon shift to arrive and settle in, before the emergency C/S could be performed ${ }^{87}$. A senior doctor lamented over other professionals' poor attitude towards collaborating: 'Sometimes when you want to do a $C / S$, you have to convince the nurseanaesthetists, convince several people.' ${ }^{88} \mathrm{He}$ added that he started to work in the hospital with enthusiasm, followed by persistent conflicts to get co-workers to collaborate. Subsequently he became frustrated, apathetic and demotivated. He said one day after quarrelling with co-workers to get work done, his blood pressure shot up, so he stopped quarrelling with them and 'had become like them' [exhibiting lackadaisical attitude to work], because he needed to stay alive. Also a junior doctor expressed his frustration with the culture of collaborating: ' ...sometimes there is a lot of resistance [from nurses and nurse-anaesthetists]. You have to be very very friendly, so that you are best friends with them before things are done.'s9

Nurse-anaesthetists used 'avoiding' responses such as leaving work early or complained that they were tired, so they could not work on a case, to deal with situations that they perceived the client to be the doctor's client. Sometimes doctors had no option but to resign themselves to 'accommodating' response towards nurseanaesthetists who were reluctant to collaborate with them.

Consequently organisational arrangements and communication gaps hindered effective interaction between doctors and nurse-anaesthetists, which contributed to a lack of team spirit. It further bred suspicion and distrust relations that affected decisions on client care, which sometimes led to conflicts.

87 Observation notes, 23/07/2012.

88 Interview with a senior doctor, 23/11/2012.

${ }^{89}$ Interview with a junior doctor, 14/09/2012. 


\subsubsection{Distrust resulting from perceived distributive and interactional injustice}

Interpersonal factors including perceived distributive and interactional injustice contributed to distrust relations between doctors and nurse-anaesthetists, resulting in conflicts and worker demotivation.

In particular, the nurse-anaesthetists perceived distributive injustice in their treatment by the hospital management. Nurse-anaesthetists suggested that the hospital gave doctors incentives including fuel coupons and phone-call credits among others, but other workers were not given such incentives.

Also nurse-anaesthetists perceived interactional injustice in their claim that other professionals perceived them as disrespectful and uncompromising, but they felt that was untrue. Additionally they perceived interactional injustice by claiming that other workers raised concerns when nurse-anaesthetists failed to report to work, while nobody raised concerns when doctors failed to report to work. The head of anaesthesia illustrated this perception in the following narration. On one Sunday evening no surgeries could be performed in the $O \& G$ theatre, because it was reported that the nurse-anaesthetist scheduled for work was absent. The O\&G department management team convened a meeting with the head of the anaesthesia department to address this problem and other complaints that scheduled nurse-anaesthetists came late or did not come to work. The conflict was resolved using 'forcing' strategy. The O\&G department management blamed nurse-anaesthetists for perceived negative attitudes and also blamed their head for not disciplining nurse-anaesthetists who misbehaved. It was reported that the head admitted the shortfall and promised to convene a meeting with the other nurse-anaesthetists to address the issues. Relations between nurses, nurseanaesthetists and doctors improved for about three months before the complaints about nurse-anaesthetists resumed. So the researcher conversed with the head of anaesthesia to understand how he addressed the issues from the meeting. He explained that the allegation levelled against the scheduled nurse-anaesthetist was untrue, as the nurse-anaesthetist later explained to him that he had briefly stepped out of the theatre, but the O\&G department concluded that he had vacated post. The head therefore suggested that the other professionals sometimes made false allegations against them.

A management member agreed that nurse-anaesthetists were not receiving incentives unlike nurses and doctors. Consequently, the hospital supported the nurse- 
anaesthetists to set up an anaesthetic clinic, where they attended to clients in order to get some extra income. He also agreed that nurse-anaesthetists were a marginalised group and sometimes they were not involved in major decisions that affected them:

When we were renovating the theatre, the nurses went to take the nice rooms for their own restrooms and their storerooms. The doctors already have one room for resting, where will the anaesthetists stay? ... Anaesthetists were an afterthought and then they went and positioned them outside the theatre. ${ }^{90}$

Nurse-anaesthetists responded to perceived injustice by using 'avoiding' strategy including not pasting their schedule on the notice board, so that no nurse-anaesthetist could be held accountable. They also sometimes left work before scheduled times, and other times they skipped work. Resultantly, sometimes elective C/Ss were delayed, because when other parties were ready, the scheduled nurse-anaesthetist was absent or late. Delays contributed to some elective C/S cases progressing into emergency cases. This resulted in heavy workload and pressure on workers in the theatre and wards, which contributed to tensions and petty quarrels that poisoned the organisational climate.

Over time frequent conflicts became the norm, so workers who experienced conflicts did not report such incidences to department and hospital management for redress.

\subsection{Discussion}

This article contributes to knowledge on the influence of conflicts on health workers' motivation in the provision of maternal and neonatal health care. Organisational gaps including unclear lines of authority between doctors and nurse-anaesthetists, perceived distributive and interactional injustice, organisational arrangements and communication gaps and a lack of team spirit contributed to frequent conflicts. Individual factors such as doctors and nurse-anaesthetists' different professional orientation and personal differences contributed to conflicts in decisions on client care. Interpersonal factors including distrust between doctors and nurse-anaesthetists based on locum practice, distrust of professional competencies and perception of who has the ultimate decision making power also contributed to conflicts. Lack of effective conflict management mechanisms intensified conflict situations, which frustrated workers and

${ }^{90}$ Interview with a hospital manager, 31/07/2012. 
affected their motivation to collaborate in the provision of health care. However conflicts that resulted from workers' determination to ensure that quality health care was provided to clients motivated such workers.

The study found that conflicts in the operating theatre were more frequent between doctors and nurse-anaesthetists. This finding contrasts with studies that suggest that conflicts in the operating theatre are more common between doctors and theatre nurses (Booij 2007; Coe and Gould 2007). Nevertheless disagreements over roles, schedules and goals, which were noted as the causes of the conflicts between doctors and theatre nurses (Coe and Gould 2007), were also some of the causes of the conflicts between doctors and nurse-anaesthetists in this study.

Doctors and nurse-anaesthetists disagreed on who had the ultimate authority to decide on client care, which contributed to frequent conflicts. Similarly Fox (1994) notes that the doctor has the power to admit the client into the ward and plan the surgery. However in the operating theatre the anaesthetist becomes equally powerful, because the doctor is dependent on his input for a successful surgery. So when the two are not able to come to a consensus conflicts occur.

Doctors favoured intervening promptly in client care to remove or reduce the disease, while nurse-anaesthetists favoured a holistic understanding of a client's condition before deciding whether surgery should be performed. These different decision pathways contributed to conflicts. Similarly, Fox's (1994) study in selected British hospitals notes that the surgical discourse perceives the client as carrier of disease or illness, which should be removed or reduced, while the anaesthetic discourse sees the client as possessor of a complement of fitness, which the anaesthetist should maintain. He suggests that this different orientation influence each professional groups' decision making pathways, which contributes to frequent disagreements and conflicts between doctors and anaesthetists.

Organisational arrangements and poor communication contributed to poor team spirit and distrust relations that contributed to conflicts between doctors and nurse-anaesthetists in the hospital. Similarly, Brinkert (2010) and Pavlakis et al. (2011) suggest that poor communication is a major cause of co-worker conflicts, which can lead to delays in carrying out procedures. Conflicts resulting from communication gaps and weak team spirit between doctors and anaesthetists in the operating theatre have also been documented in the UK (Mohammed et al. 2012) and the Canadian (Katz 2007) health care systems. 
Nurse-anaesthetists' perception of distributive and interactional injustice at organisational and interpersonal levels contributed to conflicts with doctors. Booij's (2007) study corroborates this finding that anaesthetists' perception of unfair treatment from the organisation and doctors is common. He attributes this to hospital politics, which perceives anaesthetists as an expense and not an asset to the hospital and also anaesthetists' belief that surgeons do not appreciate them.

Distrust relations resulting from locum practice and illegal charges contributed to the occurrence of conflicts, which was a source of demotivation to both doctors and nurse-anaesthetists. Similarly, Bousari et al.'s (2009) study found that health workers having other jobs affected work schedule, which frustrated collaborative efforts of their colleagues and contributed to conflicts.

Doctors and nurse-anaesthetists who prevented co-workers who they deemed not competent to perform particular tasks were motivated in situations that their actions created conflicts, but it resulted in clients receiving care from competent professionals. This suggests that conflicts are not always negative, they can help to prevent medical complacency and negligence, which is essential for quality health care provision. Our finding supports studies that suggest that conflicts are not necessarily negative, but can enhance workers' motivation and performance and contribute to organisational growth and development (Almost 2006; Guerra et al. 2011; Pondy 1967; Slack and Parent 2006; Vivar 2006). For instance Smyth's study found that conflicts increased creativity and the development of innovation and also increased workers' motivation (Vivar 2006).

Health sector employment in Ghana is centralised and beyond the control of hospital managers. Resultantly department and hospital mangers have no power to hire and fire permanent workers. So they could only give verbal and written queries to doctors and nurse-anaesthetists, who used part of their official work hours to practice locum and those who charged illegal fees. This national arrangement as well as the specialised nature of their skill, gave doctors and nurse-anaesthetists a lot of power, which they used to influence organisational processes and practices in Adom hospital. As noted by Lipsky (1980) and Mintzberg (1983), their decisions and actions in implementation effectively became the policies of the hospital.

Most conflicts were not reported to the department and hospital management, because there was no clear organisational structure for reporting and managing conflicts. Consequently conflicts persisted and became part of the organisational 
culture. Similarly Katz's (2007) study notes that poor conflict management destroys professional relationships and team work, which is essential for client care. Other studies suggest that conflicts are common in health care organisations in most parts of the world including the UK (Coe and Gould 2007) and the USA (Rosenstein 2011). Rosenstein (2011) suggests that they continue to exist, because they are tolerated and most doctors do not see them as conflicts, but as part of the game of protecting the client's interest.

Frequent conflicts had multiple effects on frontline workers, the hospital, as well as indirect and direct effects on client quality care. Conflicts contributed to workers feeling frustrated, experiencing lack of job satisfaction and lack of personal joy in working. At the hospital level there was poor organisational climate and workers lacked the desire to collaborate. This resulted in indirect effects on quality health care including workers feeling demotivated and exhibiting negative attitudes towards clients, which hampered the hospital's goal of providing quality care. The direct effects included delays in health care provision and sometimes failure to provide essential care to clients. The negative effects of conflicts on health workers' wellbeing have been reported (Bazin et al. 2014; Capitulo 2009; Rosenstein 2011). At hospital level various studies confirm that conflicts can lead to poor organisational climate, low productivity and worker turn over (Bazin et al. 2014; Booij 2007; Capitulo 2009). A study of mental health workers in Ghana found that the reverse is true. Good work relationship with colleagues is a motivator to workers (Jack et al. 2013). Other studies suggest that the direct effects of conflicts on client quality care include compromising client safety, possible medical errors and sometimes mortality among clients (Bazin et al. 2014; Booij 2007; Capitulo 2009). Indirect effects include a poor responsive health care system to client health care needs, thus decreasing their satisfaction (Bazin et al. 2014; Booij 2007; Capitulo 2009).

\subsection{Conclusion and policy implication}

In a poor resource setting like Ghana, where judicious use of resources is of the essence, frequent co-worker conflicts deny hospitals the ability to make maximum use of scarce human resources. Frequent conflicts result in clients receiving poor quality care not only because of the absence of skilled human resources, but also from poor management. Consequently, understanding the causes of conflicts and how to manage them is crucial for the wellbeing of workers, the organisation and clients. 
The hospital needs to see frequent conflicts as a threat to quality health care provision. As a preventive measure, the causes of conflicts need to be investigated in order to address them holistically. This will require that hospital managers, departmental managers and frontline workers engage in regular and constant dialogue to discuss potential causes of conflicts and make broad consultations on how to address them and also commit themselves to addressing them.

Resources should be committed to frequent training workshops for managers and frontline workers to improve their skills in identifying and managing conflicts. This will enable workers to reduce their frequency and severity. A reduction in the frequency of conflicts can foster positive relations between doctors and nurseanaesthetists, which can help improve collaboration in health care provision.

Organisational guidelines for reporting conflicts and unethical professional conduct and professional incompetence should be put in place to enable workers to report such practices to the appropriate authority. Also measures should be established to correct such practices in the hospital.

Structures should be put in place at ward, department and hospital levels to manage conflicts between individual health workers, as well as between professional groups, by resorting to collaborative response, through addressing the concerns of all conflicting parties. The formation of an anaesthetist clinic is a step towards addressing incentive gaps. However, hospital management can go a step further to address the perception of injustice by involving representatives of the various professional groups in decision making at organizational level, especially when such matters have a direct bearing on them.

Hospital managers should aim at promoting strong team spirit between the different professionals, since maternal and neonatal health care requires team work. This will require that managers imbibe in all professionals the need to respect and appreciate each other and to communicate more effectively on client care. Regular meetings and interactions between doctors, nurse-anaesthetists, nurses and hospital managers to identify, discuss and address challenges of the different professional groups and the hospital should be promoted. This can help workers to understand one another and develop a common sense of purpose, which is essential for building team spirit. In sum a good team spirit will foster collective response to client care, which will facilitate the provision of quality care to clients. Hopefully, this will contribute to the effective use of human resources towards the achievement of MDGs 4 and 5. 



\section{Chapter 5}

\section{Even me, sometimes I get sick': Reflections on hospital managers' decision making power in two Ghanaian public hospitals}

The chapter analyses hospital and floor level managers' decision making power in organizing health care in two Ghanaian hospitals, to see whether they are sufficiently empowered to meet the needs of frontline health workers and their organizations in order to facilitate the provision of quality maternal and neonatal health care. The findings suggest that hospital managers operate in a complex and dynamic environment, yet they have limited decision making power, so they face high levels of resource and environmental uncertainty. Consequently they are not able to meet the needs of frontline workers and their organization, resulting in demotivation among managers as well as frontline workers, which also contributes to poor worker response to client care. Resultantly for managers to be able to meet the needs of frontline workers they must be empowered to take decisions that respond to frontline workers and organizational needs. Concepts including power and motivation are used to discuss the findings.

This chapter has been accepted for publication in the International Journal of Health Planning and Management. 


\subsection{Introduction}

Hospital managers are expected to facilitate the achievement of organisational goals through the maintenance of a favourable work climate, which will motivate frontline workers to provide health care that is responsive to clients' needs (Gilson 2007; Hartog and Verburg 2004; Hawkins 2008; Mansour et al. 2005; Ostroff 1992). To achieve this feat hospital managers must have the decision making power and resources to meet the personal and work needs of workers. This will in turn influence workers' trust in managers and motivate them in the provision of care that is responsive to clients' needs (de Silva 2000; Larbi 1998, 2005).

Hospitals in Ghana, as elsewhere, operate in the context of a wider health system. The legislation that currently governs public sector service delivery in Ghana, where this study was conducted is 'The Ghana Health Service and Teaching Hospitals Act 525 of 1996 (Republic of Ghana Act 525 1996). Under Act 525, the health system in Ghana has been re-organized into an agency model with provider, purchaser, regulatory and training agencies under the oversight and coordination of the Ministry of Health. The Ghana Health Service (GHS) is the public sector health service delivery agency. Over time several other public sector health service delivery agencies and authorities have been created such as the mental health authority, the national blood service, and the national ambulance service.

The GHS, has a governing council - the GHS Council and a Chief Executive, the Director General. Under the director general are ten regional health directors presiding over service delivery in the ten regional health directorates of the GHS. Under the regional health directors are the district directors who preside over the districts in the various regions. The public hospitals operate under the oversight of the regional and district health directorates (Agyepong 1999; Larbi 1998).

The act seeks to increase the autonomy of the peripheral units including hospitals, through the transfer of decision making power from the centre to the periphery (Agyepong 1999; Larbi 1998, 2005; Unger et al. 2000). Arguments have been made that even in a decentralised system, the degree of operational autonomy that hospital managers can have to effectively make decisions is dependent on a task network of key organisations and governance structures, which are layered with power (Larbi 1998, 2005). Drawing upon the philosophy of continuous quality improvement; frontline health workers can be conceptualized as internal customers of the health care system (Aberese-Ako et al. 2014; Agyepong et al. 2001; Agyepong et al. 
2004). They have personal and work needs such as a good salary, incentives, professional promotion, transportation to work, housing, in-service training, appropriate infrastructure, drugs, essential equipment, tools and supplies, which managers must have the decision making power and the necessary resources to respond to (Agyepong 1999; Larbi 1998, 2005; Unger et al. 2000). When managers are able to respond to workers' needs, they become better positioned to provide health care that is responsive to clients' needs. The contrary is true, when managers are not able to respond to their needs, frontline health workers become frustrated, demotivated and lose trust in their managers. This reflects in frontline workers sometimes exhibiting negative attitudes in the provision of health care (Aberese-Ako et al. 2014; Agyepong et al. 2001; Agyepong et al. 2004). But questions have been raised on whether hospital managers are sufficiently empowered to respond to the personal and work needs of frontline workers (Larbi 1998, 2005).

This ethnographic study sought to fill this gap by exploring how public hospital managers are sufficiently empowered (or not) to respond to the needs of frontline health workers and their hospitals, to facilitate the provision of quality maternal and new born health care. We drew on concepts of power and trust to explore organisational processes and outcomes of daily management practices in two public hospitals in Ghana.

\subsubsection{Power and trust relations in public hospitals}

An analysis of how different actors exercise power in organisations is central to understanding whether managers are able to exercise adequate decision making power (or not) to meet the needs of frontline health workers. How managers are able to meet these needs can influence workers' trust in managers and their motivation in the provision of health care.

The study adopts Mintzberg (1983:4) definition of power in organisations as '...the capacity to effect (or affect) organisational outcomes'. Public hospitals operate in a complex and dynamic environment with external and internal actors who can exercise power to influence organisational outcomes (Mintzberg 1983). Public hospitals' managers are potentially the most powerful internal actors who can exercise decision making power to influence organisational outcomes. Another group of internal actors are frontline workers who Lipsky (1980) refers to as street level bureaucrats. They are skilled professionals who have access to clients through the services they provide, in 
addition to discretion in decision making for clients; which makes them very powerful (Agyepong 1999; Mintzberg 1983; Pfeffer 1981). Their decisions contribute to the achievement of the hospital's goals and their actions and inactions effectively become the policy of the hospital (Lipsky 1980; Mintzberg 1979, 1983; Pfeffer 1981). External actors who can exercise power to influence organisational processes include owners, board members [in public institutions they also include policy makers, governmental bodies, professional organisations, communities, donors] (Duncan 1972; Mintzberg 1983).

Pfeffer (1981) argues that increasingly there is excessive centralisation in both private and public organisations, which leaves organisational managers with very little decision making power. Yet public hospital managers are held accountable for organisational outcomes and are expected to be responsive to the varied demands of the different stakeholders such as frontline workers, external actors including governmental bodies, donors and the external customers of the health care system (Mintzberg 1983:125; Pfeffer 1981). Lacking adequate decision making power to satisfy conflicting demands from the different stakeholders puts the public hospital manager in a dilemma to either simultaneously 'meet the expectations of one party, and violate the expectations of another' (Dirks and Skarlicki 2004).

Of interest in this study is how managers are able to respond to the needs of their internal customers or frontline workers, since they are at the forefront of service provision and their decisions, which become the policies of the hospital determine the extent to which managers can achieve organisational goals. When hospital managers are able to respond to the needs of frontline health workers and the hospital, workers develop trust in managers. Where managers are not able to meet their needs workers lose trust in managers and become demotivated, which can affect their performance and for that matter compromise their response to client care.

Organisational trust has been defined as: a psychological state held by the follower involving confident positive expectation about the behaviour and intentions of the leader, as they relate to the follower (Dirks and Skarlicki 2004). Other studies suggest that trust is critical for successful health care delivery as it helps to build legitimacy, confidence and it influences the therapy of healing (Calnan and Rowe 2006; Gilson 2003). Empirical studies on the impact of trust on workplace relationships in South Africa reveals that workers' trust in managers contributes to their commitment to the organisation, it facilitates collaboration between health workers and they feel 
motivated, which enhances positive attitudes in client care (Gilson 2003). The contrary is true - a breakdown of trust relations between managers and frontline workers leads to workers withholding information from superiors, workers feeling frustrated and demotivated, which can result in workers exhibiting negative attitudes towards clients (Gilson 2006). Conditions that promote trust include workers' believing that they are being treated fairly by the organisation, open communication and when workers perceive that managers are responsive to their personal and work needs (Aberese-Ako et al. 2014; Konovsky and Cropanzano 1991).

\subsection{Methods}

\subsubsection{Study design and setting}

This article is based on an ethnographic study, which employed conversations, indepth interviews and participant observation in two public hospitals referred to as Grace* and Adom* hospitals in a municipality and a metropolis respectively, in the South of Ghana along the coast. Adom hospital, which is a specialist referral hospital was selected to help gain insight into the study question in the context of a big specialist hospital. Grace hospital provides basic maternity services and was thus chosen to help understand the same issues in a smaller non-specialist hospital. The first author, M.A. collected data in the maternity and new-born units of Adom hospital from January to September 2012, and in Grace Hospital from October to December 2012. In a second phase of the same study, she collected data in Grace Hospital in July and August 2013 and in Adom hospital from October to December 2013. Follow up interviews were carried out in Grace hospital in March 2014 and in Adom hospital in October 2014. Table 1 presents the methods used to obtain data and the categories of study participants who were contacted.

Ethical clearance was obtained from the University of Wageningen and the Ghana Health Service Ethical Review Boards [approval number GHS-ERC:06/01/12]. Written and verbal informed consent were obtained from interview and conversation participants respectively. In line with ethical principles pseudonyms are used for hospital names and the exact location in Southern Ghana is not disclosed.

Data was collected on management decision making, communication and interaction between hospital and department managers, ward managers and frontline workers. Additionally the study reviewed documents such as health policies, 
Table 5.1 Data collection methods used and category of study participants who were contacted

\begin{tabular}{lcc}
\hline Category of workers & Data collection methods \\
& Conversation Interviews & \\
\hline Adom hospital & 62 & 12 \\
Nurses and midwives & 5 & 2 \\
House officers & 11 & 4 \\
Senior doctors & 5 & 3 \\
Anaesthetists & 2 & 2 \\
Ward Aids & 6 & 6 \\
Orderlies & - & 2 \\
Doctors who left Adom hospital & - & 2 \\
Laboratory officials & 9 & 1 \\
Departmental supervisors & 3 & 4 \\
Hospital managers & & \\
Grace hospital & & \\
Nurses and midwives & 23 & 7 \\
Nurse who left the facility & 1 & 1 \\
Doctor & 1 & 1 \\
Ward Aids & 4 & - \\
Departmental supervisors & 3 & 4 \\
Hospital managers & 2 & \\
\hline
\end{tabular}

guidelines and circulars to enhance our understanding of hospital managers' decision making power.

Notes from observations of events, participation in meetings, workshops among others and conversations were jotted down in field notebooks. The notes were refined and expanded at the end of each field visit in line with standards in ethnographic studies (Emerson et al. 2005). Interviews were recorded and transcribed verbatim by a research assistant. Observation notes, conversations and transcribed interviews were typed and transferred to Nvivo [version 8] software for qualitative analysis. A coding list on common themes that arose from the data was generated using the software. Subsequently, the data were systematically analysed to identify patterns, differences and contradictions. 


\subsection{Findings}

Hospital managers faced pressure from multiple stakeholder groups and individuals in the health sector such as frontline workers, their superiors in the Ghana Health Service, donors and sometimes communities to meet the personal and work needs of frontline workers, so that the frontline workers could in their turn be enabled to meet the needs of clients. However our investigation suggested that the problem is not a simple matter of non-responsive hospital managers who could respond if they chose to do so. Managers had limited decision making power to meet the multiple personal and work needs of frontline workers, despite recognizing and acknowledging the validity of many of them. Factors that limited hospital managers' decision making power included national policies and guidelines, lack of control over human resource, lack of purchasing power emanating from erratic sources of funding, lack of control over unreliable suppliers and high dependency on other service agencies. A manager admitted that the perception of frontline workers that managers were not responsive to their personal and work needs was true. He explained that such a perception resulted from obstacles that managers face in managing their hospitals. He cited how the national procurement policy contributed to bureaucratic processes that disenabled managers from taking prompt decisions on routine repairs of air conditioners as an example:

...we have planned to repair air conditioners. First we have to ask for public bidding. They will submit their company proposals. We will do competitive bidding. We will select the one who qualifies and then we will give the contract. We will sign the contract, then they will come and do the servicing and now the last bit between when the thing is needed and when the thing is provided is a long duration of time. Although all the administrative processes are being taken care of - so administratively the institution is running perfectly, but managerially on the day to day basis the staff on the ground do not see it running perfectly. So I seem to feel that that perception they [workers] have is true [that managers are not responsive to their needs]. Even me, sometimes I get sick. ${ }^{91}$

The manager's concluding comment 'Even me, sometimes I get sick' was an expression of his own feelings of frustration and disempowerment over cumbersome and bureaucratic procurement process that he nevertheless had to comply with. His feeling

91 Adom, hospital, interview with a hospital manager, 3/07/2012. 
of frustration was equally shared by other hospital managers who expressed feelings of disempowerment in decision making over core resources including workforce, infrastructure, medical supplies, equipment and drugs. Nevertheless managers were not totally powerless. National policies gave managers power to make decisions on donations and internally generated funds (IGF), which are funds that accrue to the hospitals through the provision of services to insured clients, which are then paid for by the National Health Insurance scheme or uninsured clients or services, which are paid for out of pocket by these clients. These resources alone however were inadequate for the needs of both hospitals. Managers adopted various coping strategies to meet workers' personal and work needs, which brought in little success.

Thus a vicious cycle was created and perpetuated reinforcing frontline workers' distrust of managers and feelings of demotivation, because of a non-conducive work environment for which they blamed managers and the wider health system. For instance while accompanying doctors in the O\&G department of Adom hospital on a ward round a senior doctor linked poor culture of maintenance of infrastructure, lack of essential supplies, low worker morale, motivation and attitudes to managers' poor performance with the following proverb '...When fish is stinking, it starts from the head.' 92 In the rest of this section we further elaborate on these findings in Adom and Grace hospitals.

\subsubsection{Managers' decision making power on human resource}

Both Adom and Grace Hospitals' managers and frontline workers complained of shortage of core staff including medical doctors, midwives, nurses and anaesthetists, especially in the O\&G department. At the time of the study the O\&G department of Adom hospital had seven doctors, three of whom left by the end of this study, despite the fact that the regional health directorate had estimated that the department needed twenty-five doctors to run optimally. Grace hospital had one O\&G specialist who survived a transfer attempt during the study period.

Yet hospital and department managers could do little about this troubling situation, because they lacked the power to employ doctors due to the centralised system of employment. Adom hospital managers resorted to making frequent formal requests to the district and regional health directorates for doctors and lobbying the human resource directorate of the GHS, to post doctors to the hospital. They also used

92 Adom hospital, observation notes, 30/04/2012. 
the media to draw attention to their plight. These measures yielded some small returns of one or two doctors per year. However the high turnover of the few who came in erased the gains. The regional health directorate and the national human resource directorates could not supply the required number of doctors, even with intense lobbying, because of the absolute shortage of doctors in the health system. A department manager cited an instance when he lobbied the national human resource directorate to post a junior doctor who he had observed to be hardworking and skilful during his internship in the $\mathrm{O} \& \mathrm{G}$ department back to Adom hospital. However the doctor was sent to a lower level facility, where he was underutilised, as the said junior doctor later wrote to the department manager to complain.

Since the few doctors in the O\&G department of Adom hospital could not manage the workload, managers adopted a coping strategy by using some of the hospital's IGF, to hire doctors from other public facilities as locum. Overtime this strategy had become a permanent organisational norm. It was however an unreliable arrangement since locum doctors chose to work at times that were convenient to them. Adom hospital managers and $O \& G$ department managers expended energy chasing locum doctors to fill in the gaps, which was not only a strain on managers' time and efforts, but also frustrating. Sometimes, there were no doctors to run the night and weekend shifts, and clients were referred to other facilities.

\subsubsection{Managers' decision making power on health workforce financial and financial related incentives}

The availability of direct and indirect financial incentives were a major felt-need among frontline workers in a context of low salaries. By direct incentives we refer to actual financial hand outs and salary top ups. By indirect incentives we refer to fuel coupons, free lunches and other such measures. Hospital managers' decision making power related to staff motivation in the form of direct or indirect financial incentives was constrained by national policies and directives, availability of the IGF funds they controlled and the extent to which the different professional groups were able to lobby. An instance of how national directives on incentives for workers influenced managers decision was noted in Adom hospital management's decision making process on incentives for workers:

We got a letter from director general [of the Ghana Health Service], that ministry of finance says that IGF is government money and so we cannot use 
IGF [as financial incentives for workers]. That we cannot give out cash and that all facilities that were doing that should stop and if you want to do that you should write to them. ${ }^{93}$

Thus an effort by hospital management to address this felt need with a decision to pay financial incentives at the hospital level was centrally curtailed by the Ghana Health Service directorate and the national ministry of finance. An Adom hospital manager reported that following this circular they stopped giving money as incentives to all workers. However, they were successful in writing to justify financial top-ups as incentives for doctors, but had not been able to do so for other frontline workers.

Despite these constraints managers made efforts to respond to this felt need of frontline workers. Moreover they were sometimes encouraged by their superiors to be responsive. A manager quoted her superiors as follows: 'The GHS will tell you to find ways of motivating staff within the ability of the resources to support it.' ${ }^{\prime 4}$ Hospital managers in both hospitals reported a tradition of giving an incentive package to each worker at the end of each year. However hospital managers in both hospitals admitted that they had failed to provide Christmas package in at least one of the recent years, because the NHIS delayed in reimbursing them, which made it impossible to raise money to provide such an incentive package to workers.

Powerful groups were also sometimes able to lobby hospital managers for direct and indirect incentives despite the constraints. For instance doctors were able to lobby for weekly fuel coupons, for snack and lunch for those on duty. They were also able to lobby the hospital management for accommodation allowance, though this was not nationally approved. Because of high attrition and an acute shortage of doctors in the O\&G department of Adom hospital, they formed a strong lobby group. Additionally, some of the O\&G wards were able to lobby management to provide lunch for at least four workers per day.

In the case of Grace hospital, managers explained that auxiliary workers such as the laboratory and accounts staff were given transportation allowance, because they had to come to work early. ${ }^{95}$ Frontline workers lobbied for incentives, which hospital managers explained that whenever the hospital had extra funds, they were able to

\footnotetext{
${ }^{93}$ Interview with a hospital manager, 04/12/2013.

94 Interview with a hospital manager, 04/12/2013.

95 Grace hospital, interview with two hospital managers, 06/08/2013.
} 
provide each worker with a Christmas package. For instance in 2013 each worker was given some rice, oil and some canned fish for Christmas. ${ }^{96}$

Despite the numerous efforts that hospital managers made they could not satisfy the financial related incentives needs of the different professionals, which contributed to some professional groups such as nurse-anaesthetists and nurses perceiving that hospital managers were not fair in the distribution of incentives to the different category of workers. Conversations and interviews with some doctors in Adom hospital suggested that most of them felt that the snack package they received was not appropriate, as they would have preferred that it was converted to money instead. Also the O\&G wards that were not offered lunch perceived injustice from hospital management and appealed to management to review the hospital's incentive policy. At the end of data collection management was reviewing their request. By the time the decision on the accommodation allowance for the $O \& G$ doctors was implemented, a third doctor had left the department for private practice. Frontline workers in both hospitals continued to complain that the incentive package offered at the end of the year was too little and infrequent.

\subsubsection{Managers' decision making power on infrastructure development, supplies and equipment}

Managers' decision making and implementation power on infrastructure development and maintenance ${ }^{97}$ and essential drugs, medical supplies and equipment ${ }^{98}$ was determined by national and health policies, GHS directives and the availability of funds.

Pressures from superiors at the GHS, frontline workers, donors and clients influenced managers' decision on prioritising infrastructure development in the face of resource constraints. For example, Adom hospital managers were compelled to quickly repair the O\&G theatre doors after the department staff sent a memo to the hospital management threatening not to work if the $O \& G$ theatre door was not repaired within two weeks. The threat was precipitated when the already weak theatre door fell on a nurse, which made it unsafe to perform surgeries in the theatre. In another instance in

\footnotetext{
96 Interview with a hospital manager, 05/03/2014.

${ }_{97}$ Hospital managers had to make decisions on infrastructure development for their hospitals, because the Ministry of Health (MOH), which is the government body responsible for providing infrastructure could not meet the infrastructure needs of the individual public hospitals.

98 Hospitals managers made decisions on the acquisition of essential drugs, medical supplies and equipment.
} 
Grace hospital, management was compelled by the regional health directorate and a donor to urgently develop a comprehensive O\&G facility. Interviews with hospital managers, the O\&G specialist and a review of correspondences to the hospital from the regional health directorate, suggested that the directorate felt that the specialist was being underutilised, because of the lack of a comprehensive O\&G facility for the specialist to optimise the use of his skills. So the regional health directorate had given the hospital an ultimatum to construct an $O \& G$ facility within a period of one year, to enable the specialist to practice his skills or risk losing him to a transfer. Additionally the hospital risked losing a donation of theatre equipment from an international donor, for the setting up of a comprehensive O\&G facility. The donor threatened to donate the equipment to a different facility by a given deadline if the theatre was not set up. A hospital manager explained how such pressures influenced their decision to stop spending money on other personal and work needs of frontline workers and channel all their IGF to the construction of a theatre: '...we said no, we cannot let the equipment go, because if they take them out of the compound, I do not know when we will ever get money to buy theatre equipment. So we suspended everything. ${ }^{\prime 9}$

Additionally hospital and department managers as well as frontline workers faced pressure from the teeming number of clients who visited the hospitals. The hospitals tried to cope with the overwhelming number of clients by referring clients to other facilities. Also Adom hospital introduced a consent form to discourage clients. While these measures discouraged some clients, others were not deterred and insisted on being attended to in the facilities.

In the face of resource constraints, in satisfying one need hospital managers denied other personal and work needs of frontline workers. For example, during the period of study both hospitals complained that they could not offer ultra-scan services, yet scanning during pregnancy is a prerequisite for clinical decision making. Both hospitals explained that they had one ultra-scan machine, which had broken down, but they did not have money to buy new ones. Yet Adom hospital spent a huge chunk of their IGF on snacks for staff. Pregnant clients in both hospitals were referred to private facilities and that required them to travel out of the hospital, which put them at risk. Frontline workers found this inappropriate and embarrassing and felt their managers were not responding to their work needs.

${ }_{99}$ Grace hospital, interview with a hospital manager, 05/03/2014. 
A national health directive for hospitals to first buy drugs and medical supplies from the national medical stores and only buy from the open market when there is none in the medical stores, affected the timing and quality of drugs acquired for service delivery. Hospital managers in Grace hospital confirmed that sometimes some of the essential supplies and drugs acquired from the national medical stores were of inferior quality and other times expired drugs that were acquired from the medical stores had to be returned. 100 Such occurrences disrupted service provision, which frustrated both managers and frontline workers.

As part of coping strategies, managers used available opportunities to influence decisions on infrastructure projects and to acquire essential supplies that would otherwise require bureaucratic procedures to accomplish. In two separate interviews hospital managers from the two hospitals reported that they took advantage of an impending regional peer review exercise to sidestep bureaucratic procedures to acquire basic supplies that their hospitals lacked and to carry out maintenance and repair works on existing infrastructure.

Managers depended on external suppliers for some of their essential supplies and equipment. Sometimes suppliers supplied hospitals with inferior products after having presented superior samples and received approval. In an interview with two hospital managers in Grace hospital one of them shared hospital managers and workers' experiences with suppliers who presented inferior products: 'Sometimes after winning the bid the suppliers will supply inferior items sealed. So it is only when they [frontline workers] open to use it that they realise that it is an inferior product.' 101 Managers coped with unreliable suppliers by involving frontline health workers who are the end users of requested products in the procurement process, by showing samples to them for approval before purchasing. While some frontline workers appreciated managers' initiative to involve them in decision making on drugs, medical supplies and equipment, others complained that sometimes the medical supplies and equipment that were supplied to them were inferior to the samples that they were initially provided. Such frontline workers perceived that managers conspired to cheat the hospital by acquiring inferior products, so they did not trust their managers. ${ }^{102}$ The mixed responses from frontline workers gave managers mixed feelings. Sometimes managers felt that workers appreciated the initiative to involve them, but sometimes

100 Grace hospital, interview with two hospital managers, 06/08/2013.

101 Grace hospital, interview with two hospital managers, 06/08/2013.

102 Adom hospital, conversation with two nurse-anaesthetists, 18/07/2012. 
managers felt frustrated, when some workers expressed doubts, which suggested that managers were not honest.

\subsubsection{High dependency on external agencies}

ACT 525 gives hospital managers power to use funds accrued to the hospital to make key decisions to meet their hospitals' needs. Hospital managers' potential sources of funding included government subvention, donor support and internally generated funds (IGF). Both hospitals indicated that a large amount of their IGF came from provision of services to clients of the National Health Insurance Scheme (NHIS). However, reimbursement by the National Health Insurance Authority (NHIA) for NHIS subscribers, who formed over $50 \%$ of clients of both hospitals, was erratic and as at the time of this study, had delayed for over six months. At the same time, the government had not given the hospitals any subvention in the last several years, so both hospitals were cash strapped, as described by an Adom hospital manager:
Now the hospital does not have money. As I sit with you NHIA has paid us up to June. July, August, September no payments, meanwhile we offered the service. There is no money in the kitty [hospital's coffers] now. Even suppliers we have not paid them, some of them as far back as February. 103

The hospitals were overwhelmed. To ensure that they continued to function, managers had to prioritise the use of the limited funds available even when issues were urgent.

For example, Adom hospital suffered from frequent water shortage, yet water is one of the crucial resources that the hospital depend on to provide emergency obstetric and gynaecological services, as well as to maintain hygiene. While frontline workers perceived that managers were not responsive to their water needs, managers suggested that the hospital had a faulty pipeline and needed to fix it, which was beyond their capacity. A hospital manager reported on their efforts to address the water problem over the years:

... Ghana Water Company [service agency responsible for providing pipe borne water in Ghana] came here about two years ago...and surveyed the water problem and brought a bill. As at that time it was five billion old cedis [500,000 Ghana cedis, equivalent of $\$ 126,418]$... Because they claimed the hospital was put up more than fifty years ago. The pipes have all worn out and they need to be changed. And that money was outside the range of the hospital and so we

103 Adom hospital, interview with a hospital manager, 04/12/2013. 
referred their quotation to ministry of health. And up till now we have not heard much. ${ }^{104}$

Probably the $\mathrm{MOH}$ was also not able to do much, because they could not raise the needed money. However the $\mathrm{MOH}$ was in a better position to lobby the Water company or partner it to fix the water problem. Subsequently, the hospital was able to lobby the national security to sink three boreholes. However the quantity of water supplied from the boreholes was not enough to meet the water requirement of the hospital, so they had to find alternate sources of water. The hospital resorted to using tanker services, which cost them about 10,000 Ghana cedis $(\$ 2,598)$ a month. Sometimes the hospital run out of water and O\&G services had to be suspended. At times clients were asked to bring in water for services to be provided for them.

\subsubsection{Managers' successes and frustrations}

Managers spent a lot of time struggling to meet the multiple needs of their hospitals at the expense of spending time interacting with frontline workers, communicating management and administrative decisions to frontline workers and getting feedback from them. Resultantly there was a communication gap and frontline workers perceived hospital managers as distant and uninterested in their personal and work needs.

Hospital managers in both hospitals suggested in interviews that they worked very hard to mobilise resources to enable their facilities to function. Managers experienced mixed emotions - sometimes they were proud to achieve little successes, a manager stated: 'Things have improved. When I came the whole place we had about two computers or one computer, nothing!' 105 Another hospital manager suggested that hospital management decision to provide doctors incentives was effective in getting doctors to run night shifts:

...it just shows that the hospital is meeting them [doctors request for incentives] half way. I think it has worked significantly [decision to offer incentives to doctors]. Because there were times we used to hear a whole week you won't get a doctor to do night duties or you won't get a doctor to take up certain shifts. But now we are getting doctors who are willing to take up certain shifts. ${ }^{106}$

\footnotetext{
${ }^{104}$ Adom hospital, interview with a hospital manager, 04/12/2013.

105 Grace hospital, interview with a hospital manager, 05/03/2014.

106 Adom hospital, interview with a hospital manager, 31/07/2012.
} 
Other times hospital managers felt disempowered and frustrated, because they felt that their efforts were not being appreciated by their subordinates and that they received little support from their superiors. A hospital manager in Grace hospital suggested that sometimes she felt that the hospital had been forgotten by her superiors at the regional and national directorate. Also a manager stated her frustration over high expectations of managers from frontline workers and superiors, to meet the hospital's multiple needs with limited funds: '...I am not government and so where am I supposed to get money to do that?..., I can do my bit. But I cannot bite more than I can chew.'107

Some managers vented their frustration on frontline workers by resorting to shouting and insulting workers who made mistakes.

\subsubsection{Recommendations from managers}

Hospital managers in interviews and conversations offered recommendations, to address some of the challenges that arose from the different factors that disenabled them from effectively making decisions that responded to frontline workers' personal and work needs.

Hospital managers appealed for policy makers to effect changes to the procurement process in order to reduce the bureaucracy surrounding it. A manager suggested that such a measure would facilitate prompt decision making, which is essential for effective service provision as follows:

The policy makers should be able to give managers some kind of concession that 'when this is urgent and you need it urgently, go for it, get it and be accountable for it. You go for it, side-track the procurement process provided everything is clear and transparent.' There should be probably a rigorous accounting process where every decision you take, you should go and account for it. So that people will not take it loosely and abuse the system. ${ }^{108}$

Also hospital managers suggested that the national and regional health directorates should focus on distributing health professionals based on the specific needs of the various public health facilities and not only to satisfy geographical equity. A hospital manager buttressed this recommendation to the human resource division of Ghana:

107 Grace hospital, interview with a hospital manager, 05/03/2014.

108 Adom hospital, interview with a hospital manager, 3/07/2012. 
'...when you are doing the distribution, don't just say one person here. Look at the workload. That is what we call equity and then you will do the posting, based on the workload.'109

A manager suggested in an interview that the district and regional health directorates do not generate money and so they cannot support the facilities financially. However regional and district health managers can boost the hospital managers' morale by commending them for the few successes that they are able to achieve and also giving them supervisory support, which will motivate them to work hard.

\subsection{Discussion}

Good management exists if people can make the right decisions and have the right type of resources to influence organisational outcomes - whether at the hospital or ward level. Using Mintzberg's (1983) definition of organisational power as the capacity to influence organisational outcomes, this study explored how limited decision making power hindered hospital managers' capacity to create a conducive work environment to motivate frontline workers to respond to clients' health needs.

Having to refer to procurement process hindered managers' capacity to take prompt decisions in response to workers' work needs to enable them respond to clients' health needs. Managers felt frustrated, disempowered and sick that they could not readily meet the work needs of frontline workers in order to facilitate service delivery. Similarly a study of South African health facility managers suggests that extreme bureaucratic procurement process frustrated and stressed them. Managers complained that the procurement process usually resulted in inappropriate or poor quality materials being purchased and led to lengthy delays (Holdt and Murphy 2007). Our finding also bears testimony to Larbi (1998) and Unger et al.'s (2000) suggestion that having to refer to a number of external agencies such as the procurement process for reviews and approvals of what should be normal and routine business decisions, is a major source of operational inefficiency in public institutions in most lower and middle income countries including Ghana.

Hospital managers' lack of decision making power on staff recruitment contributed to staffing gaps. Consequently the shortage of doctors and nurseanaesthetists sometimes led to delays in the provision of emergency obstetric care and other times clients were referred to other facilities to access health care. This was a

109 Adom hospital, interview with a hospital manager, 2013. 
source of demotivation to both managers and frontline workers. Stuff shortages and attrition are not limited to the study facilities. The Ghanaian $\mathrm{MOH}$ equally reports of a shortage of core staff including doctors and nurses as well as a high attrition rate of doctors in public health facilities nationally (Ministry of Health 2011:11). Consequently, efforts have been made to address the human resource gap through training programmes. However the efforts have not led to marked increase in doctor numbers in public facilities (Ministry of Health 2011:13). Similarly, Holdt and Murphy's (2007) study of the South African health care system report that facility managers felt frustrated and disempowered, because employment is centralised, which does not give them decision making power over staff numbers and skill mix. Another study suggests that there exist severe human resource gaps in lower and middle income countries, which hamper the attainment of the MDGs (Dieleman and Harnmeijer 2006). Also, severe staff shortage has been noted as a global phenomenon, as even industrialised countries including the USA, Canada and Australia equally experience staff shortages (Duffield and O'Brien-Pallas 2003; Friedman 2005). Studies in Australia have shown that the consequence of staff shortage is lower nurse-client ratio, which contributes to poor health outcomes. Additionally staff shortages negatively affect workers' motivation, causes more stress and contributes to high attrition and absenteeism of frontline workers (Friedman 2005).

Hospital managers' power to decide on how IGF should be used enabled them to address some of the personal and work needs of frontline workers, which was a source of satisfaction, pride and motivation to managers. The finding contrasts with findings of a study of public health facilities in South Africa, which suggests that the centralised nature of financing in South Africa was a problem, as facility managers had little influence over budgets that were prepared at the head office. Additionally facility managers had little say on finances in their facilities (Holdt and Murphy 2007). However Leon et al. (2001) report that the ability to initiate or oversee physical infrastructure development is a source of motivation to facility managers in South Africa, to work hard.

High resource uncertainty resulting from erratic supply of funds coupled with hospital managers having to take up additional responsibility such as infrastructure development, affected their capacity to meet the multiple needs of their facilities. This no doubt affected frontline workers' ability to respond appropriately to client health needs, and also forced frontline workers and managers to turn some of the clients 
away, so that they could concentrate on a few. This practice contradicts the goal of the policies on exemptions for pregnant women and children, as well as the National Insurance Scheme, both of which aim at extending health care access to all Ghanaians. Other studies in a teaching hospital in Ghana corroborate the finding that hospital managers are unable to meet the personal and work needs of frontline workers (Bohmig 2010; Böhmig 2010). Similarly, Agyepong and Nagai's (2011) study of health financing implementation in Ghana suggests that facilities suffer from resource uncertainty due to unpaid claims from the government and unreliability of reimbursement especially from the NHIS. Consequently public facilities devise coping strategies by charging fees from clients who are supposed to benefit from exemptions in order to save their facilities from collapsing. Studies in other African countries suggest that the problem of limited resources and central government failure to provide funds to lower level facilities is common. For instance Nyikuri et al. (2015) report that some facility managers coped with Kenyan government's delay in providing them with funds to meet their facilities' needs by charging fees, despite the removal of user fees and maternity fees.

The permanent state of resource uncertainty contributed to managers feeling disempowered, frustrated and sick over their inability to meet the multiple needs of frontline workers and their hospitals, to which they were held accountable. Managers lost trust in their superiors and the health care system. They perceived that their superiors were not interested in supporting them to develop their hospitals. Sometimes managers vented their frustration on frontline health workers, which only led to tensions, contributed to distrust relations between managers and frontline workers and led to poor organisational climate that further demotivated health workers. This has been reported in previous articles (Aberese-Ako et al. 2014; Aberese-Ako et al. FC). Resultantly, some workers visited their frustration on their clients by exhibiting negative attitudes, which compromised with their responsiveness to client care. Similarly, Gilson (2003) reports that when there is no trust between managers and frontline workers, workers become demotivated and they exhibit negative attitudes towards the clients who visit the hospital and this can have negative therapeutic effect on clients 


\subsection{Conclusion}

This study has revealed that managers are expected to provide the conductive environment that will motivate frontline workers to provide health care that is responsive to the needs of clients. To ensure that managers are able to create such a conductive work atmosphere multi-level structural changes are needed at national and hospital levels.

National and health policies should aim at giving hospital managers more power and autonomy to make decisions on critical resources including the right workforce mix, infrastructure development, drugs, medical supplies and equipment. This could facilitate timely planning and coordination of activities required for effective maternal and new born health care.

Adequate resources and financial support should be provided to managers to enable them meet frontline workers' personal and work needs. Also the Ghanaian government needs to commit more resources into training skilled providers to fill the staffing gaps in health care facilities. Friedman (2005) adds that countries will only be able to graduate and retain adequate numbers of motivated health workers if governments invest in health workforce and health systems.

Communication between frontline health workers and managers is essential to building organisational trust and harmony. Managers need to improve the system of communication on management and administrative issues as well as on organisational development with frontline workers. This could help frontline workers appreciate and understand the challenges that managers deal with in their efforts to facilitate health care delivery, which could facilitate the building of trust relations between workers and their managers.

Hospital managers are human beings who equally face difficult conditions and so they need to be encouraged, appreciated, listened to and supported by higher level managers to perform their functions. Also frontline workers, district and regional health managers need to boost the morale of hospital managers, by congratulating them when they put in efforts to meet their facilities' needs. 


\section{Chapter 6}

\section{Concluding chapter}

The concluding chapter of the thesis presents a summary and a synthesis of all the findings of this work to draw conclusions on the extent to which the research questions of this thesis have been answered with the material presented in chapters one to five. The section also presents theoretical and methodological considerations, limitations of the study, implications of the research findings and recommendations for health care delivery in Ghana and conclusions. The section draws on literature on motivation, power, and trust. 


\subsection{Introduction}

This study set out to explore, describe and analyse the motivation of hospital-based frontline health workers, who are providers of maternal and newborn health care, using ethnographic methods including participant observation, conversations, and interviews. Four questions were addressed: (1) interpersonal processes influencing health worker motivation; (2) organisational and managerial processes influencing health worker motivation; (3) the Ghana health sector setup and its associated policies influencing health worker motivation; and (4) health worker motivation and responsiveness to clients' health needs. The different determinants of worker motivation are not mutually exclusive, they interact and together produce motivated or demotivated workers. Where appropriate I will discuss some more data from the field research that could not be discussed in the papers, to highlight some issues in more detail.

\subsection{Interpersonal processes influencing health worker motivation}

Interpersonal factors including poor communication and interaction processes, differences in professional orientation, unclear lines of authority between the different professionals, perceived disrespect from collaborating professionals and distrust relations based on suspicion that some professionals were sacrificing official time for locum practice, contributed to professionals easily misunderstanding each other. Unclear lines of authority between the different professionals led to power struggles and conflicts. An example, in the conflict in the theatre between the nurse-anaesthetist and the doctor presented in chapter four, where the lack of clarity as to who had the power to make clinical decisions on client care, was a major source of the conflict.

These factors helped to create a tense environment that frequently escalated into conflicts. Frequent conflicts contributed to poor co-worker relations that poisoned the organisational climate and created a chasm between workers who could not tolerate and communicate with each other. Most of the conflicts were not resolved, so they degenerated into further conflicts. Each professional group took sides and with time conflicts became part of the organisational culture. Frequent conflicts led to suspicions and distrust relations between collaborating professionals. Conflicts also sapped the energy and time of collaborating professionals, who became increasingly 
frustrated, felt disempowered and demotivated over their inability to explore their medical skills to the maximum.

However, several frontline health workers were found to be intrinsically motivated, and although they admitted that they also faced these challenges that were acting as demotivators for other staff, their intrinsic motivation toned down or moderated the effect on them. Their sources of motivation were varied and included some believing that their work as health care providers was a 'calling', a strong sense of duty, and personal satisfaction and joy in providing health care. Others believed in a Supreme Being or God, who blesses or punishes people who treat others badly. They believed that health workers would be judged and rewarded in an afterlife based on how they treated clients. Still others believed that clients had a right to be treated with respect, while others had a desire to maintain work ethics and standards. Examples of the kinds of explanations intrinsically motivated staff gave are illustrated with a quote from a doctor and from a nurse:

I don't want to mismanage anyone. I don't want to give half-half treatment to anyone. I don't want to see someone and it is like you are experimenting, no. If I see you, I want to give you the very best I can and the standard treatment that you deserve. Not because you are in Ghana, so you don't have this, no... I don't want to cut corners. ${ }^{110}$

You see, I believe that when you are doing a job you have to do it well. When I came here [Grace hospital] the first time, I realized that there was no oxygen and I said I won't work without oxygen. The then matron had to get it before I became comfortable to work here. You know, when you are working, the inner satisfaction is very important. How can you deliver a mother and the baby needs resuscitation and you cannot do so, and you watch the baby die. ${ }^{111}$

\subsection{Organisational and managerial processes influencing health worker motivation}

Organizational and managerial factors and processes influenced the kind of environment that health workers interacted in, which had a consequent influence on their motivation. These included perceptions of distributional, interactional and procedural justice, availability of resources including equipment, tools, drugs and

110 Adom hospital, interview with a junior doctor, 14/09/2012.

111 Grace hospital, conversation with a nurse, 05/09/2012. 
medical supplies for workers to work with, availability of adequate infrastructure, adequate workforce and effective monitoring and supervision, influenced worker motivation in the provision of health care. The way in which communication was organized and resulted in institutionalized interactional processes at the level of the organization, including effective communication, clear lines of authority, work arrangements and workers' participation in decision making, impacted on workers' trust in their managers and organisation, which determined worker motivation. A management member in Adom hospital admitted that the gap in communication and the disconnect between management and frontline workers suggested that the level of interaction is not bearing fruit:

Since I joined management, I think to be very candid with you. I think it is real. But I think it is on the blind side of management. Management seems to believe that they are close to the ground and they are satisfying the needs of those on the ground. That they are seeing to the requests of the staff on the ground, but the staff does not seem to see it that way. ${ }^{112}$

Frontline health workers perceived distributional injustice in managers' response to their personal and work needs including incentives, equipment, medical supplies and essential drugs. Workers argued that since their work brought in revenue to the hospital it was only fair that part of that revenue should be used to provide them with some incentives and essential supplies to enable them provide care to clients. They felt frustrated whenever they could not exercise power in combining their skills with the available resources to respond appropriately to clients' health needs. A doctor who had recently joined the $\mathrm{O} \& \mathrm{G}$ department of Adom hospital during the period of the study, became disappointed and subsequently left the hospital. He summed up how negative attitudes of other health care professionals and the lack of work needs made him to lose trust in his colleagues, managers and the health care system, which demotivated him:

The anaesthetist this morning says he has to go to the bank, so he will come in late, so he is currently not at post. There is no water, no sonic aid. I am disappointed, because I cannot work. If all these facilities and equipment are there, then I can work well. I am not doing this for myself but for the patient. Then when I am driving I feel okay. If I am not able to do this, then I feel bad and I will leave. I don't want to grow apathetic with these issues and can't work

${ }^{112}$ Adom hospital, interview with a hospital manager, 31/07/2012. 
well. I have just come and I have realized that they do not have these equipment. ${ }^{113}$

Unfortunately managers communicated minimally on management and administrative decisions to staff in both hospitals and also received very little feedback from them. Consequently there was a chasm between managers and frontline staff, which fostered distrust relations between the two groups. Distrust relations contributed in poisoning the organizational climate, which was a source of demotivation to mangers as well as to frontline workers.

\subsection{Ghana wider health sector design and policies influencing health worker motivation}

The wider Ghana health sector design and policies influenced health worker motivation in a direct and indirect way. Direct policy determiners of worker motivation included terms and conditions of service, workplace protection and supply of adequate health workforce. Indirect policy determiners included the influence of the implementation of policies on the management of hospitals such as the fee exemption policy, the implementation process of the NHIS, the procurement policy and GHS directives, which impacted on worker motivation and attitudes in the provision of maternal and neonatal health care.

Frontline health workers perceived a sense of injustice from policy makers with regards to terms and conditions of service and workplace protection. Workers perceived distributional injustice in low salaries and unequal distribution of incentives to workers.

Frontline health workers also suggested that it is unfair that health policies are made at the national level without considering the opinion of the frontline health workers, who are the implementers of these policies and have to deal with the challenges of implementation. For instance, the policy on fee exemption for pregnant women and under five year olds, promotes the use of public health facilities for health care. However, the policy was not backed by expansion of infrastructure nor an increase in budgetary allocation to health care facilities. Consequently the facilities got overwhelmed with high numbers of clients. Workers perceived this as unfair, because this disempowered them from being able to provide quality health care to clients.

113 Adom hospital, observation notes, 25/01/2012. 
The issue of human resource management is pivotal in improving the way in which hospitals function. Its absence disempowers hospital managers to improve the quality of care. Managers in both institutions did not control employment of skilled heath workers, and they were given limited power to discipline malfunctioning workers. Even if they requested transfer and replacement of a poorly functioning worker, they had no control over what kind of replacement they would receive and whether they would get a better or worse performing staff. As a result, managers were afraid to request the release of malfunctioning workers from their facilities. Instead, they chose to tolerate malfunctioning workers. Such a decision made other workers to perceive managers as favouring malfunctioning workers, so they lost trust in their managers' commitment to managing the workforce, which demotivated them. Managers on the other hand felt helpless and frustrated about their lack of power in managing their workforce. For instance a hospital manager stated out of frustration over a doctor who combined locum practice with his official work: 'You cannot serve two masters and be faithful to both.'114

There were high expectations from superiors in the Ghana Health Service for hospital managers to address frontline health workers' personal and work needs, including infrastructure development, yet hospitals received very little support from the $\mathrm{MOH}$, which is technically responsible for the provision of infrastructure in public facilities. Also managers reported that they had not received subvention from central government for close to a decade.115 So managers lacked purchasing power and resorted to borrowing from suppliers to meet their hospitals' needs. Other coping mechanisms that managers adopted were taking advantage of opportunities to sidestep cumbersome bureaucratic procurement procedures and using part of the IGF to address the multiple needs of their hospitals.

The different strategies managers used helped the hospitals to function, but they only addressed a few of the multiple needs and did not lead to permanent organisational transformation. As a result managers felt sick, frustrated and disempowered over their inability to address frontline workers' personal and work needs. Hospital managers believed that they received little support from their superiors and policy makers to deal with the challenges that they faced in managing their facilities, so they lost trust in their superiors and policy makers. A hospital

\footnotetext{
114 Interview with a hospital manager, 04/03/2014.

${ }^{115}$ Government is responsible for providing an annual budgetary allocation through the $\mathrm{MOH}$ to public health facilities to cover administrative cost and services, including stationery and other items for their smooth running (Akortsu and Abor 2011).
} 
manager stated '...I am not government and so where am I supposed to get money to do that?..., I can do my bit. But I cannot bite more than I can chew.'116

\subsection{Health worker motivation and response to clients' health needs}

The complex set of determiners including interpersonal, organizational and managerial as well as policy processes, influenced health workers' trust in their colleagues, managers and the health care system. This ultimately affected worker motivation, with both direct and indirect consequences on workers' attitudes and responsiveness to clients' health care needs, as reported in chapters two, three and four of this thesis.

Demotivation affected workers' wellbeing including workers feeling frustrated, experiencing job dissatisfaction and no personal joy in working. An important consequence of organizational processes that demotivated frontline health workers was that it affected the health of some workers. For instance a doctor narrated how frequent fights with collaborating nurses and nurse-anaesthetists affected his health: 'That is what I was doing [quarrelling with co-workers to get them to collaborate in performing medical procedures on clients] when I started here [working in Adom Hospital]. One day I came to work and my blood pressure had shot up [after a quarrel with co-workers to get them to collaborate]. So I realized that I have to cool down. I have small children at home. So I have also now become like them.'117 Thus he had equally adopted a lackadaisical attitude to client care in order to remain healthy.

Some workers had reached a point where they were so distrustful of their colleagues, managers and the health care system that it demotivated them to the point that they had become apathetic. A hospital manager stated in an interview that some of such workers had stayed in the hospital for so long that they complained about everything, but they were not interested in helping to fix the very wrongs that they complained about. ${ }^{118}$

Demotivated workers exhibited negative attitudes in health care provision including reporting to work late, leaving work early, charging illegal fees and sacrificing official work hours to do locum. Some were uncooperative, which resulted in poor collaboration with other health care professionals that resulted in conflicts, which led to delays and sometimes cancellation of clinical procedures. Some

116 Grace hospital, interview with a hospital manager, 05/03/2014.

117 Adom hospital, interview with a senior doctor, 22/11/2012.

118 Adom hospital, interview with a hospital manager, 31/07/2012. 
demotivated workers exercised power negatively on clients such as shouting at clients, insulting clients and turning clients away. This resulted in client dissatisfaction and contributed to a poor responsive health care system.

Workers who were observed to be intrinsically motivated as reported in chapters three and four of this thesis, exhibited positive attitudes including providing respectful care, being attentive to clients and going the extra mile to stay on to complete procedures. Others resisted some of their colleagues who wanted to give substandard treatment to clients. Also other frontline workers resisted colleagues who were not qualified from performing procedures and ensured that the appropriate workers collaborated with them to provide quality care to clients as reported in chapter four. This resulted in clients receiving quality care, which contributed to client satisfaction and a responsive health care system.

However even workers who were observed to be motivated, as well as those who were reported to have initially been motivated, indicated that repeated incidences of shortage of resources including skilled workers to work with, frequent conflicts with co-workers, poor conditions of service and perceived poor response from superiors to their personal and work needs, ultimately affected them. A doctor who was reported to have been highly motivated, but left Adom hospital summed up some of the contributory factors that demotivated him resulting in his departure as:

Every once in a while, there were these situations where you don't have enough doctors and we threaten to close down the labour ward and the regional health directorate will come in and we sit down to talk. We go back to work and we expect that the matter is solved and at the end the matter is not resolved. And then you find out that you are getting more and more irritated with everybody who work with you. You snap at nurses, you snap at patients. You get up in the morning, particularly on the days that you are going on calls, you are not happy to be going to work. ${ }^{119}$

\subsection{Summary of core findings of the thesis}

This thesis set out to describe and explore the ways in which interpersonal interactions and organisational processes influence health worker motivation and the consequent effect on workers' attitudes in the provision of maternal and new born or neonatal health care in a Ghanaian hospital setting. Employing ethnographic methods including

119 Interview with a doctor who left Adom hospital. 
participant and non-participant observations, conversations and in-depth interviews in two public hospitals over two months, the study found that extrinsic and intrinsic factors influenced frontline health worker motivation in the provision of health care. Power and trust relations at the various organisational and interpersonal interactional processes were identified to play crucial roles in health worker motivation. Worker motivation influenced worker attitudes in the provision of health care, which affected the responsiveness of workers to the health needs of the clients who visited the hospital (Figure $6.1 \& 6.2$ ).

\section{Extrinsic motivation}

A complex set of extrinsic motivation factors including wider health system policies and procedures, managerial and organizational processes and interpersonal relations influenced frontline worker motivation. The complex set of factors were determined by power relations at organizational and interpersonal levels, which influenced health workers' trust in the health care system, their managers and their colleagues. Thus power and trust both affected worker motivation, which in turn influenced worker attitudes and responsiveness to client care (Figure 6.1).

\section{Wider health system (National level) determined policies and procedures}

Direct policy determiners of extrinsic motivation included terms and conditions of service - which includes pay scales and remuneration, workplace protection and policies that influenced staff postings and transfers, and as a result also the adequacy or otherwise of the health workforce (numbers as well as skills mix). Indirect policy determiners included the influence of the implementation of policies on the management of hospitals such as the fee exemption policy for pregnant women and children, infrequent reimbursement from the national health insurance scheme and government's failure to provide adequate subvention to enable hospitals meet their multiple needs. Others were, challenges from implementing the procurement policy at hospital level and conflicting GHS directives.

\section{Facility organizational and managerial processes and their responsiveness to FLHW}

Frontline workers' perceptions of distributional, interactional and procedural justice in managerial processes influenced motivation. Resource availability is influenced by facility, as well as wider health sector managerial priorities, decisions and processes as well as financing. Availability of resources including equipment, tools, drugs and 
medical supplies to work with, affected worker motivation. Additionally, the availability of adequate and appropriate infrastructure, and effective monitoring and supervision, influenced frontline workers' trust in managers, which affected their motivation in the provision of health care.

Organisational interactions including power relations between managers and frontline workers and among the different health care professionals, clear lines of authority, effective communication and work arrangements and workers' participation in decision making, impacted on workers' trust in their managers and the health care system. These affected frontline worker motivation in the provision of health care.

\section{Interpersonal relationships, conflicts and conflict management at the floor level}

Interpersonal relationships between frontline health workers at the floor level such as poor communication and interactional processes, differences in professional orientation, unclear lines of authority between the different professionals and perceived disrespect from collaborating professionals affected frontline health worker motivation. Also unclear lines of authority between the different professionals led to power struggles, which resulted in suspicions and distrust relations resulting in conflicts, which hampered effective collaboration between nurses, doctors and nurseanaesthetists. Also suspicions of illegal charges and locum practice contributed to distrust relations between the different professionals and created further conflicts, which resulted in poor organisational climate that demotivated workers (Figure 6.1). The extrinsic motivators worked together interactively as summarized in figure 6.1, to influence the motivation state of individual health workers. Unfortunately the predominant status of these extrinsic motivators was negative. Thus predominantly, the complex set of extrinsic motivating factors contributed to workers becoming demotivated. Demotivated workers exhibited negative attitudes such as reporting to work late, closing early, frequent absenteeism and refusing to collaborate with other health professionals in the provision of health care. Also some workers used demotivation as an excuse to charge illegal fees, while others sacrificed official working hours to do locum in private facilities, which led to frequent conflicts with collaborating professionals. Frequent conflicts among the different professionals resulted in other professionals taking sides that further fuelled distrust relations and poisoned the organisational climate. Such frequent conflicts resulted in workplace tensions, which made some workers ill, while others dreaded coming to work. Some 
frontline workers complained of lack of joy in working and job dissatisfaction. In extreme cases demotivation resulted in some workers leaving the facility.

\section{Figure 6-1 Complex set of extrinsic factors influencing worker motivation}

Facility Organizational

and Managerial processes

and their responsiveness

to FLHW needs

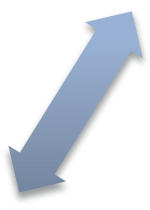

Trusł

\&

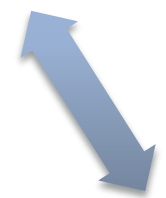

Power

Wider health system

policies and procedures

and responsiveness to

FLHW needs
Interpersonal

relationships including

conflict and its

management

Negative frontline worker attitudes contributed to delays in clinical decision making and cancellation of procedures. Other effects included some frontline workers exercising power negatively on clients, by shouting at clients, some turned clients away and others reprimanded clients on the least provocation. Additionally some workers interacted poorly with clients. On such occasions clients were dissatisfied with the care that they received and others wellbeing was compromised. This contributed to poor response to client care resulting in a poor responsive health care system (Figure 6.2).

\section{Intrinsic factors}

Intrinsic factors that influenced frontline health worker motivation included strongly held personal values such as perceiving clients as human beings with a right to quality health care. They also included faith with some frontline workers suggesting that their belief in God was a source of motivation to them in the provision of health care. Another source of intrinsic motivation was being in their desired career, such as to be nurses, doctors and nurse-anaesthetists. For such health workers the provision of health care to clients was in itself a fulfilment of their desired goal to be health 
Figure 6-2 Extrinsic and intrinsic determiners of health worker motivation and consequences on health worker responsiveness to clients' health needs

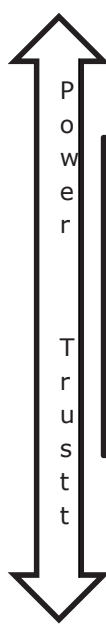

Extrinsic factors

- Wider health system policies and procedures and their responsiveness to FLHW

- Facility organizational and managerial processes and their responsiveness to FLHW

- Inter-personal relationships, conflicts and conflict management

Poor responsiveness to client care

- Delays, cancellation of procedures

- Poor interaction with clients

- Dissatisfied clients

- Client wellbeing compromised

狳

Demotivated FLHW exhibit negative attitudes

- Absenteeism to work

- Frequently late to work, leaving work early

- $\quad$ Angry and bitter

- Easily irritated

- Feel frustrated

Intrinsic factors

- Values

- Faith in God

- Work ethic

- Past experience

- Career path

Individual level factors

- FLHW knowledge, acquired skills, capacity,

- $\quad$ Perceived competency of worker

Client and external environment factors

- Client attitude

- Community socio-cultural and socio-economic

- Other national issues
- No joy in working

- Experiencing high blood pressure after conflicts

- Feel disrespected and excluded

- Lack of commitment

- Apathy

- Poor collaboration

- Poor organisational climate

- Normalising conflict

- No sense of belonging

- Distrust colleagues, managers and health care system

- Dread work environment<smiles>C1CC1</smiles>

Motivated FLHW exhibit positive attitudes

- $\quad$ Rise above organizational and other challenges

- Derive satisfaction from service provision

- Insist on providing standard care

- Attentive and respectful

- Empathetic to clients

Responsiveness to clients health needs

- $\quad$ Prompt clinical decision making

- Positive interaction with clients

- Satisfied clients

- Clients wellbeing restored

- Clients desire to return to same provider in next visit 
workers. Another source of intrinsic motivation was work ethic. Workers with high work ethic saw the need to maintain minimum and higher standards in care provision to clients as their ultimate goal, valued in itself. Also health workers who had personal experiences of near misses in the past and were able to successfully save lives, saw such experiences as motivation to give quality care to clients. Success in attaining a desired goal in itself became a motivator to further pursue the goal.

An or a combination of these intrinsic factors motivated some frontline workers in the provision of health care in a unique individual way, over and above whatever extrinsic motivation was or was not in place. Though intrinsically motivated workers admitted that they experienced organisational and managerial, interpersonal and policy challenges, they rose above these challenges to respond positively to client care, because of the power of their intrinsic motivators (Figure 6.2).

Intrinsically motivated workers exhibited positive attitudes such as being attentive, respectful, showing empathy and were quick to respond to clients' health needs. Others stayed on beyond their closing hours to attend to clients. Such positive attitudes resulted in client satisfaction in health care provision and a possible return to the facility for future health care. Pregnant women who experienced positive provider responses during their first ANC visit were more likely to request to be attended to by the same health care provider in their subsequent visits (Figure 6.2). In sum, staff who were intrinsically motivated managed to negate the predominant negative tendency of the state of the extrinsic motivators to some extent, with more positive results.

\subsection{Motivation, power and trust}

Motivation is central to health care provision in all environments whether developing or developed country context, as the findings and discussions in previous chapters of this thesis have shown. Power determined how health managers organised health care provision in health facilities, how they interacted with frontline workers, how frontline workers interacted and collaborated with colleagues and even in the researcher's relations and interactions with research participants. Ultimately the way in which health workers exercised power on clients whether positively or negatively was influenced by this complex set of power relations at policy, managerial, organisational and interpersonal levels. In this whole process of interaction experiences were shared and meanings made. How power was exercised positively in meeting workers' personal and organisational needs led to trusting relations, which was a source of 
motivation for workers in the performance of their job. On the other hand, where managers lacked the capacity to exercise power to meet the personal and work needs of frontline workers, distrust set in, which was a source of demotivation to workers. Demotivation contributed to negative worker attitudes in the provision of health care to clients, resulting in poor worker response to client health needs. This makes it more credible to perceive motivation as not only an outcome of organisational and interpersonal processes but as a process in itself.

Therefore, we need to develop a fresh look at the relations between motivation, power and trust. Motivation arises from organisational processes and interactions between different actors within and outside the hospital environment, particularly by those who are able to exercise power in different forms to influence organisational processes and outcomes. Positive power play results in trusting relations that serve as a source of motivation to workers in the provision of health care and the contrary is true. However, the centralized structure of Ghana Health Service with centralized allocation of human resources, cumbersome procurement procedures, and a high degree of uncertainty about the allocation of resources and infrastructure, lead to a situation where managers are unable to exercise their capacities to help health workers provide quality care. They are not able to have control over the human and material resources to have their institutions function better. Health workers on the one hand are disempowered in the sense that they have no control over their conditions of work and cannot use their expertise in the right way. On the other hand they are empowered because their expertise is in short supply and they can afford to do locum and provide substandard care without being sanctioned. The sum total of these mechanisms are that health workers are put in situations of such high uncertainty about the organization itself and their colleagues that they lose trust.

Most studies of health worker motivation take little account of these power dynamics embedded in organizational interactions. However, they are crucial, because they provide the bedrock on which clinical decisions are made to provide patient care. This is where this study departs from Okello and Gilson (2015) and many others, because it not only highlights the role of trust in worker motivation, but also gives some insight in the organizational processes that produce trust and motivation. They provide strong evidence that interpersonal trust between workers, trust in superiors, trust in the organisation and trust in clients affect worker motivation. 
By employing ethnographic methods the researcher was able to witness organisational processes in interactions between people, between people and the organisation, and between people and managers that produce motivation and demotivation in the hospital setting. Secondly by being part of the process of motivation and trust relations and by paying systematic attention to her emotions in fieldwork, the researcher was able to get beyond her frustration and demotivation to understand what was going on.

Thus this study contributes to theory by propounding that motivation is not an individual possession of the worker, but it is an outcome of interactions between the worker and the work environment. Also power and trust relations within and outside the hospital influence worker motivation and for that matter theories on organisational power and trust relations are central to understanding and analysing worker motivation.

However the study has two limitations. The researcher's personal experiences became part of the data collection and analysis process, which introduced a degree of subjectivity in the study and a personal element. However, this limitation was checked by triangulating the different data sets in order to enable a validation, which was necessary to minimise the bias. Also the researcher's experiences were critically interrogated and discussed in chapter two of this thesis.

The study was limited to two public hospitals, which makes one hesitant to generalise. But drawing on literature from other studies, the findings suggest that the study is comparable to previous studies in Ghana and worldwide (Agyepong et al. 2001; Agyepong et al. 2004; Alhassan et al. 2013; Adzei and Atinga 2012; Bohmig 2010; Böhmig 2010; Bonenberger et al. 2014; Dieleman et al. 2003; Dieleman et al. 2006; Dieleman et al. 2009; Franco et al. 2004; Mbindyo et al. 2009a; Mbindyo et al. 2009b; Okello and Gilson 2015).

Despite the fact that these studies did not explicitly adopt a power approach to analyse organizational processes, they are full of hints that management and organizational factors matter in relation to health workers' motivation, though they do not go into the details as to how motivation or demotivation is 'produced'.

\subsection{Implications of findings for MDG 4 and 5 in Ghana}

This study agrees with Agyepong et al.'s (2004) assertion that putting the blame of poor quality care on health workers will not provide solutions to address the quality needs 
of the health care system. Blaming workers will only drive them into defence, as is evidenced in chapter two, three and four of this thesis. Managers' stance in blaming workers for organisational gaps contributed to frontline workers developing distrust in managers and the health care system, which affected worker motivation in the provision of health care. So improving worker motivation demands a more comprehensive approach than providing money, infrastructure, etcetera. There is the need to build confidence in the health care system, and also all the people responsible for health policies should consider the way they are engaged in discussions on motivation in a more positive and comprehensive manner. From this discussion I include a shopping list, with the hope that most of them can be addressed. However, none of the more detailed measures will have much of an effect if they do not touch the core of policies, organization and management.

Motivation and demotivation are produced in an organisational context, thus for any practical change that is aimed at ensuring motivation of workers in the provision of health care, there must be concomitant changes at policy, organisational and managerial levels, thus the following recommendations are proposed.

Hospitals are distinct from other state organisations and should be treated as such - timely decision making is of the essence. National and health policies should aim at giving hospital managers more freedom to make decisions on critical resources including appropriate workforce mix, infrastructure maintenance, drugs, supplies and equipment. Such a measure would facilitate timely planning and coordination of activities required for effective health delivery. It would also ensure that pressing health workers' personal and work needs are met, which would enhance frontline workers' trust and contribute to improving health workers' motivation in the provision of health care.

Additionally the Ghanaian government needs to invest more resources into training more health professionals especially doctors, nurses and nurse-anaesthetists, to fill up the large health worker-patient gap that exists in most public health facilities.

Clear accountability structure is crucial for effective health care delivery. Frontline workers need to be accountable to managers. With the current health system arrangement workers are accountable to their employer, the Ghana Health Service, which is distant and so power is too far away. So workers are free to exhibit dysfunctional attitudes without being accountable to managers. Consequently health policies should seek to give hospital managers the power to make contributions to staff 
recruitment, so that workers would be accountable to managers. This would ensure that managers are able to check the abuse of staff time in pursuing locum and other negative attitudes that compromise the provision of quality care to clients. Also managers should be given clear policy guidelines on incentive provision to workers. This would ensure that perceived discriminatory practices against particular groups of professionals are corrected. Having more powers would enable managers to find more collaborative approaches to resolving conflicts instead of the current approaches, which are mostly compromising and forcing, as managers lack the power to effectively discipline dysfunctional workers.

The provision of health care is labour intensive and very much dependent on the availability of other critical resources. Thus financial backing is key and for that matter the NHIS should endeavour to reimburse health care facilities promptly. Also government should renew the old policy of supporting health facilities with funds to enable them meet their basic needs, including the acquisition of equipment and payment for basic services like water. This would help reduce the level of uncertainty and enable health care institutions to be able to strategically plan to create the needed conducive environment for health care provision. The reformed per capita provider payment system (capitation), would have been appropriate for more financial security to health care institutions. Therefore it is unfortunate that primary care maternity services are excluded, which is due to heavy public social and political contestation of the policy (Koduah et al. 2016). It is a matter of urgency that this stance should be reconsidered, so that maternal health care can be included in the capitation system.

While the procurement policy aims at ensuring that corruption and wastage of scarce resources in public organisations are checked, it is still essential that health care institutions are empowered to take prompt decisions on resource acquisition in health facilities. Thus, the procurement policy should be relaxed and other forms of accountability that would facilitate prompt decision making at facility level should be introduced.

Infrastructure development is very essential for quality health care provision. Thus the Ghanaian government through the ministry of health should put in more efforts to provide the basic infrastructure needs of public hospitals. Such provision would reduce managers' burden of having to commit scarce resources to developing major infrastructure projects, so that managers can devote the limited IGF to meeting other critical needs. An additional benefit to infrastructure development is that the 
hospital would be able to accommodate and provide appropriate care to the increasing number of clients that utilise their services.

There is the need that implementers of policies including managers and frontline workers are consulted during policy formulation in order to ensure that workable policies are implemented. There is also the need that policies are evaluated during implementation, to ensure that conflicting policies and challenges that arise from policy implementation are well addressed.

Effective communication between managers and frontline workers is crucial for organisational harmony and the building of trust relations. Managers therefore need to make conscious efforts to improve organisational structures of communication and feedback processes. Effective and frequent communication between managers and frontline workers will contribute to workers appreciating the efforts that managers put in to mobilise resources to facilitate health care delivery. Also it would help frontline workers to appreciate the bureaucratic process that managers have to go through to meet their needs. This could enhance frontline health workers' trust in managers, which would boost workers' motivation. Improved worker motivation could contribute to workers exhibiting positive attitudes towards clients, which could enhance a responsive health care system.

At facility level accountability and transparency from top to the bottom is very essential for health workers to be able to build trust in managers. Managers should endeavour to account to frontline workers how revenue generated is used in order to help frontline workers to appreciate how the hospital's finances are appropriated. This could contribute to health workers perceiving a sense of justice and trust in managers and their hospitals.

Even intrinsically motivated workers' level of motivation diminishes when they continuously experience the different processes that demotivate them. So there is the need that managers identify workers who go the extra mile to render health care services and commend them in order to help sustain their motivation.

The provision of health care requires collaboration between different professionals, so effective communication and respect among co-workers is of the essence. Thus managers should endeavour to create a conducive work environment including prioritising the prevention of conflicts as well as making efforts to use collaborative approach to manage conflicts, as this could help bring lasting solutions to conflicts. 
Human resource management should not be limited to only hire and fire workers, but people should feel that they are being taken care of. In other words, power should be exercised on people in a positive way - workers should be listened to and guided to do their work. Disciplining health workers is an essential component of human resource management. However frontline workers who make mistakes should be disciplined with dignity and respect, so that such workers would not feel that they are being treated unfairly. Also disciplinary procedures should be transparent in order to ensure that workers understand and appreciate managers' actions on such matters.

The various measures at the different levels could contribute to a responsive health care system that meets the needs of managers, health workers, as well as the clients who utilise health services.

\subsection{Conclusion}

This study used ethnographic methods in two Ghanaian hospitals to understand and analyse frontline health worker motivation as a complex and dynamic process. Motivation does not only affect the quality of health care that external clients receive, but also the quality of health of frontline workers and managers. This makes the consequences of demotivation and motivation more complex than previously assumed.

Worker motivation influences workers' attitudes and responsiveness in the provision of health care, which impacts on the quality of clients' health care. Hence motivated frontline health workers would ultimately contribute to a responsive health care delivery system that would ensure equity and improve willingness of clients to utilise skilled delivery care. This would ultimately facilitate the acceleration of the achievement of the targets set for MDGs 4 and 5 post 2015 and the sustainable development goals. For that matter attention needs to be paid to the complex processes that affect health worker motivation. Resultantly multi-dimensional approaches need to be employed to address them.

The study found that facility managers are an important link to worker motivation, because they determine the quality of care that health workers receive in their work environment. When managers have the capacity to make decisions, that create a conducive work environment for health care provision, managers become motivated. Thus how the health care system treats managers affects how they make decisions that meet the needs of frontline health workers and their hospitals. 
Consequently managers should be empowered with the needed resources that would enable them to meet the personal and work needs of frontline workers. 


\section{References}

Aberese-Ako, M., I. A. Agyapong, and H. V. Dijk. FC. 'I won't take part!': Exploring the multiple identities of the ethnographer in two Ghanaian hospitals. Journal of Ethnography.

Aberese-Ako, M., I. A. Agyepong, T. Gerrits, and H. VanDijk. 2015. 'I Used to fight with them but now I have stopped!': Conflict and doctor-nurse- anaesthetists' motivation in maternal and neonatal care provision in a specialist referral hospital. PLOS One 10 (18):1-20.

Aberese-Ako, M., H. VanDijk, T. Gerrits, D. K. Arhinful, and I. A. Agyepong. 2014. 'Your health our concern, our health whose concern?': Perceptions of injustice in organizational relationships and processes and frontline health worker motivation in Ghana. Health Policy and Planning 29 (Supplement 2):15-28.

Adzei, F. A., and R. A. Atinga. 2012. Motivation and retention of health workers in Ghana's district hospitals: Addressing the critical issues. Journal of Health Organization and Management 26 (4):467-485.

Agyepong, I. 1999. Reforming health service delivery at district level in Ghana: the perspective of a district medial officer. Health Policy Planning 14 (1):59-69.

Agyepong, I. 2012. Development, equity, gender, health, poverty and militarization: Is there a link in the countries of West Africa? In 10th Anniversay Lustrum conference of the Prince Claus Chair in Equity and Development. The Hague, Netherlands, 47-57.

Agyepong, I., P. Anafi, E. Ansah, D. Ashon, and C. Na-Dometey. 2004. Health Worker (internal customer) satisfaction and motivation in the public sector in Ghana. International Journal of Health Planning and Management 19 (4):319-336.

Agyepong, I., W. Sollecito, S. Adjei, and J. Veney. 2001. Continues quality improvement in public health in Ghana: CQI as a model for primary health care management and delivery. Quality Management in Health Care 9 (4):1-10.

Agyepong, I. A., A. Kodua, S. Adjei, and T. Adam. 2012. When 'solutions of yesterday become problems of today': crisis-ridden decision making in a complex adaptive system (CAS) - the Additional Duty Hours Allowance in Ghana. Health Policy and Planning 27:20-31.

Agyepong, I. A., and R. A. Nagai. 2011. "We charge them; otherwise we cannot run the hospital" front line workers, clients and health financing policy implementation gaps in Ghana. Health Policy 99:226-233.

Akortsu, M. A., and P. A. Abor. 2011. Financing public healthcare institutions in Ghana. Journal of Health Organization and Management 25 (2):128-141.

Alhassan, R. K., N. Spieker, P. van Ostenberg, A. Ogink, E. Nketiah-Amponsah, and T. F. R. de Wit. 2013. Association between health worker motivation and healthcare quality efforts in Ghana. Human Resources for Health 11 (37):1-11.

Almost, J. 2006. Conflict within nursing work environments: concept analysis. Journal of Advanced Nursing 53 (4):444-453.

Almost, J., D. M. Doran, L. M. Hall, and H. K. S. Laschinger. 2010. Antecedents and consequences of intra-group conflict among nurses. Journal of Nursing Management 18:981-992.

Ameyaw, C., S. Mensah, and E. Osei-Tutu. 2012. Public Procurement in Ghana: The implementation challenges to the public procurement Law 2003 (ACT 663). International Journal of Construction Supply Chain Management 2 (2):55-65.

Anas, A. A. 2015. People and Power - Spirit Child. Tigercraft Multimedia Studios 2015 [cited 2015]. Available from http://anasaremeyawanas.org/people-and-powerspirit-child/. 
Andersen, H. M. 2004. "Villagers": Differential treatment in a Ghanaian hospital. Social Science \& Medicine 59 (2004):2003-2012.

Ansong-Tornui, J., M. Armar-Klemesu, D. Arhinful, S. Penfold, and J. Hussein. 2007. Hospital based maternity care in ghana - findings of a confidential enquiry into maternal deaths. Ghana Med J 41 (3):125-132.

Appiah-Denkyira, E., C. H. Herbst, and C. Lemiere. 2011. Interventions to increase stock and improve distribution and performance of HRH. In Towards Interventions in Human Resources for Health in Ghana, edited by E. AppiahDenkyira, C. H. Herbst, A. Soucat, C. Lemiere and K. Saleh. Washington DC: he World Bank, Ministry of Health 111-.

Atinga, R., G. Abekah-Nkrumah, and K. Domfeh. 2011. Managing Healthcare Quality in Ghana: a necessity of patient satisfaction. International Journal of Health Care Quality Assurance 24 (7): 548 - 563.

Bazin, J.-E., A. Attias, H. Baghdadi, A. Baumann, P. Bizouarn, F. Claudot, B. Eon, F. Fieux, C. Frot, C. Guibet Lafaye, O. Muzard, A. Nicolas-Robin, V. Orjubinm, M. Otero-Lopez, C. Pelluchon, J. Pereira, F. Roussin, B. Vigue and I. Beydon. 2014. Perioperative conflicts between anaesthesiologists and surgeons: Ethics and professionalism. Annales Franc, aises d'Anesthe' sie et de Re'animation 33:335-343.

Bell, B. S., D. Wiechmann, and A. M. Ryan. 2006. Consequences of organizational justice expectations in a selection system. Journal of Applied Psychology 91 (2):455466.

Bercovitch, J. 1983. Conflict and conflict management in organisations: A framework for analysis. The Asian Journal of Public Administration 5 (2):104-123.

Bohmig, C. 2010. Ghanaian Nurses at a Crossroads: Managing Expectations on a Medical Ward. Doctoral thesis, Faculty of Social and Behavioural Sciences, University of Amsterdam.

Böhmig, C. 2010. "There is somebody in heaven who takes care of you!" Nursing care and religiosity on a hospital ward in Ghana. Medische Antropologie 22 (1):47-61.

Bonenberger, M., M. Aikins, P. Akweongo, and K. Wyss. 2014. The effects of health worker motivation and job satisfaction on turnover intention in Ghana: a crosssectional study. Human Resources for Health 12 (43):1-12.

Booij, L. H. D. J. 2007. Conflicts in the operating theatre. Current Opinion in Anaesthesiology 20:152-156.

Bosu, W., J. Bell, M. Armar-Klemesu, and J. Ansong-Tornui. 2007. Effect of delivery care user fee exemption policy on institutional maternal deaths in the Central and Volta Regions of Ghana. Ghana Med J 41 (3):118-124.

Bousari, P. M., H. Ebrahimi, F. Ahmadi, H. A. Abedi, and N. Kennedy. 2009. The process of nurses interpersonal conflict: Qualitative study. Research Journal of Biological Sciences 4 (2):236-243.

Bowles, D., and C. Cooper. 2009. Employee Morale: Driving performances in challenging times. New York, USA: Palgrave Macmillan.

Brinkert, R. 2010. A literature review of conflict communication causes, costs, benefits and interventions in nursing. Journal of Nursing Management 18 (2):145-156.

Bruce, J. 1990. Fundamental elements of the Quality of Care: A simple framework. Studies in Family Planning 21 (2):61-91.

Calnan, M., and R. Rowe. 2006. Researching trust relations in health care: Conceptual and methodological challenges -an introduction. Journal of Health Organization and Management 20 (5):349-358.

Capitulo, K. L. 2009. Addressing disruptive behavior by implementing a code of professionalism to transform hospital culture. Nurse Leader 7 (2):38-43. 
Chandler, C. I. R., S. Chonya, F. Mtei, H. Reyburn, and C. J. M. Whitty. 2009. Motivation, money and respect: A mixed-method study of Tanzanian nonphysician clinicians. Social Science \& Medicine 68 (11):2078-2088.

Chege, N. 2015. 'What's in it for me?': Negotiations of asymmetries, concerns and interests between the researcher and research subjects. Ethnography 16 (4):463481.

Chen, L., T. Evans, S. Anand, J. I. Boufford, H. Brown, M. Chowdhury, M. Cueto, L. Dare, G. Dussault, G. Elzinga, E. Fee, D. Habte, P. Hanvoravongchai, M. Jacobs, C. Kurowski, S. Michael, A. Pablos-Mendez, N. Sewankambo, G. Solimano, B. Stilwell, A. de Waal, and S. Wibulpolprasert. 2004. Human resources for health: overcoming the crisis. Lancet 364:1984-1990.

Cinar, F., and A. Kaban. 2012. Conflict management and visionary leadership: An application in hospital organizations. Social and Behavioral Sciences 58:197-206.

Coe, R., and D. Gould. 2007. Disagreement and aggression in the operating theatre. Journal of Advanced Nursing 61 (6):609-618.

Colquitt, J. A., D. E. Conlon, M. J. Wesson, C. O. L. H. Porter, and K. Y. Ng. 2001. Justice at the millennium: A meta-analytic review of 25 years of organizational justice research. Journal of Applied Psychology 86 (3):425-445.

Colquitt, J. A., B. A. Scott, T. A. Judge, and J. C. Shaw. 2006. Justice and personality: Using integrative theories to derive moderators of justice effects. Organizational Behavior and Human Decision Processes 100 (2006):110-127.

Coombs, M. 2003. Power and conflict in intensive care clinical decision making. Intensive and Critical Care Nursing 19 (3):125-135.

Coumans, C. 2011. Occupying spaces created by conflict: Anthropologists, development NGOs, responsible investment, and mining: with CA comment by Stuart Kirsch. Current Anthropology, Corporate Lives: New Perspectives on the Social Life of the Corporate Form: Edited by Damani J. Partridge, Marina Welker, and Rebecca Hardin (Supplement to April 2011) 52 (S3):S29-S43.

Cropanzano, R., C. A. Prehar, and P. Y. Chen. 2002. Using social exchange theory to distinguish procedural from interactional justice. Group $\mathcal{E}$ Organization Management 27 (3):324-351.

Dahl, R. A. 1957. The concept of power. Journal of Behavioral Science 2 (3):201-215.

Dartey-Baah, K., and G. K. Amoako. 2011. Application of Frederick Herzberg's TwoFactor theory in assessing and understanding employee motivation at work: a Ghanaian perspective. European Journal of Business and Management 3 (9):1-9.

Davies, A. C. 2008. Reflexive Ethnography: A guide to researching selves and others. New York Routledge.

De Dreu, C. K. W., and L. R. Weingart. 2003. Task versus relationship conflict, team performance and team member satisfaction: A meta-analysis. Journal of Applied Psychology 88 (4):741-749.

de Silva, A. 2000. A framework for measuring responsiveness. Geneva: EIP/GPE/EBD: World Health Organization.

Dickin KL, Dollahite JS, and H. J. 2011. Enhancing the intrinsic work motivation of community nutrition educators: how supportive supervision and job design foster autonomy. J Ambul Care Manage 34 (3):260-273.

Dieleman, M., P. V. Cuong, L. V. Anh, and T. Martineau. 2003. Identifying factors for job motivation of rural health workers in North Viet Nam. Human Resources for Health 1 (10):1-10.

Dieleman, M., B. Gerretsen, and G. J. van der Wilt. 2009. Human resource management interventions to improve health workers' performance in low and middle income countries: a realist review. Health Research Policy and Systems 7 (7):1-13. 
Dieleman, M., and J. W. Harnmeijer. 2006. Improving health worker performance: in search of promising practices. Geneva: World Health Organisation.

Dieleman, M., J. Toonen, H. Touré, and T. Martineau. 2006. The match between motivation and performance management of health sector workers in Mali. Human Resources for Health 4 (2):1-7.

Dirks, K. T., and D. Skarlicki. 2004. Trust in leaders: Existing Research and Emerging Issues. Edited by R. Kramer and K. Cook. New York: Russell Sage Foundation.

Discombe, G. 1954. The normal blood count. British Medical Journal 1 (4857):326-328.

Donabedian, A. 1980. Explorations in Quality Assessment and Monitoring. Vol. 1. University of Michigan: Health Administration Press.

Dovlo, D. 1998. Health sector reform and deployment, training and motivation of human resources towards equity in health care : Issues and concerns in Ghana. In Human Resources for Health Development Journal. Geneva: WHO.

Duffield, C., and L. O'Brien-Pallas. 2003. The causes and consequences of nursing shortages: a helicopter view of the research. Australian Health Review 26 (1):186193.

Duncan, R. B. 1972. Characteristics of organisational environments and perceived organisational uncertainty. Administrative Science Quarterly 17 (3):313-327.

Emerson, R. M., R. I. Fretz, and L. L. Shaw. 2005. Writing ethnographic fieldnotes. Chicago: The University of Chicago Press.

Encyclopedia Wikipedia. 2014a. Placenta praevia. In Wikipedia the Free Encyclopedia: Wikimedia Foundation, Inc.,.

- - - 2014b. Uterine myomectomy. In Wikipedia the Free Encyclopedia: Wikimedia Foundation, Inc., .

Eriksen, T. H. 2004. What is Anthropology? London: Pluto press.

Evans-Pritchard, E. 1976. Witchcraft, Oracles, and Magic among the Azande. New York: Oxford university press.

Faye, A., P. Fournier, I. Diop, A. Philibert, F. Morestin, and A. Dumont. 2013. Developing a tool to measure satisfaction among health professionals in subSaharan Africa. Human Resources for Health 11 (30):1-23.

Ferres, N., J. Connell, and A. Travaglione. 2004. Co-worker trust as a social catalyst for constructive employee attitudes. Journal of Managerial Psychology 19 (6):608-622.

Folger, R. 1993. Justice, motivation, and performance beyond role requirements. Employee Responsibilities and Rights Journal 6 (3):239-248.

Fonn, S., and M. Xaba. 2001. Health workers for change: developing the initiative. Health policy and planning 16 (Supplement 1):13-18.

Fox, A. 1974. Beyond Contract: Work, Power and Trust relations. London: Faber \& Faber

Fox, N. J. 1994. Anaesthetists, the discuorse on patient fitness and the organisation of surgery. In Basil Blackwell limited, edited by E. Board. Oxford, UK: Blackwell Publishers.

Franco L M, Bennett S, Kanfer R, and S. P. 2004. Determinants and consequences of health worker motivation in hospitals in Jordan and Georgia. Social Science and Medicine 58:343-355.

Franco, L. M., S. Bennett, and R. Kanfer. 2002. Health sector reform and public sector health worker motivation: a conceptual framework. Social Science and Medicine 54 (8):1255-1266.

Franco, L. M., S. Bennett, R. Kanfer, and P. Stubblebine. 2004. Determinants and consequences of health worker motivation in hospitals in Jordan and Georgia. Social Science \& Medicine 58 (2):343-355.

Freeman, R. K., and M. Nageotte. 2007. A protocol for use of oxytocin. American Journal of Obstetrics \& Gynecology 197 (5):445-446. 
Friedman, E. A. 2005. Africa's health worker shortage undermines global health goals. J Ambulatory Care Manage 29 (1):98-100.

Galer, J. B., S. Vriesendorp, and A. Ellis. 2005. Managers who lead: A handbook for improving Health Services. Edited by J. Miller, C. Bahamon and B. K. Timmons. Cambridge, Massachusetts.

Geertz, C. 1973. The Interpretation of Cultures. 2000 ed. New York, USA: Perseus.

Gergen, K., M. Greenberg, R. Willis, and G. Leventhal. 1980. What should be sone with Equity Theory? In Social Exchange: Springer US, 27-55.

Ghana Health Service. 2003. Code of Ethics and Disciplinary Procedures. Accra: The City Printers.

- - - 2011. Ghana Health Service 2011 Annual Report. Accra: Ghana Health Service.

- - - 2014. Greater Accra - Regional Health Directorate, Ghana Health Service. [cited 19th March, $2015 \quad$ 2014]. Available from http:/ / www.ghanahealthservice.org/rhdcategory.php?ghsrid=1\&cid=31.

Ghana Statistical Service. 2012. 2010 Population and housing census: Summary report of final results, edited by G. S. S. (GSS). Accra: Sakoa Press Limited.

Ghana Statistical Service (GSS), Ghana Health Service (GHS), and ICF Macro. 2009. Ghana Demographic and Health Survey 2008. Accra, Ghana: GSS, GHS, and ICF Macro.

Gilson, L. 2003. Trust and the development of health care as a social institution. Social Science and Medicine 56:1453-1468.

Gilson, L. 2006. Trust in health care: theoretical perspectives and research needs. Journal of Health Organization and Management 20 (5):359-375.

Gilson, L. 2007. What sort of stewardship and health system management is needed to tackle health inequity, and how can it be developed and sustained? A literature review. Technical Report.WHO Social Determinants Knowledge Network.

Gilson, L., N. Palmer, and H. Schneider. 2005. Trust and health worker performance: exploring a conceptual framework using South African evidence. Social Science $\mathcal{E}$ Medicine 61 (7):1418-1429.

Government of Ghana. 1996. Ghana Health Service and Teaching Hospitals Act 525. Accra, Ghana: Government Printer Assembly Press.

- - - . 2014. Public Procurement Act. Governement of Ghana 2003 [cited 30th Octorber 2014 2014]. Available from http://www.lexadin.nl/wlg/legis/nofr/oeur/arch/gha/PUBLICPROCUREM ENTACT2003.pdf.

- - - 2006. Whistleblower Act, 2006 Act 720. Accra, Ghana: Assembly Press.

Greenberg, J. 1993. Justice and organizational citizenship: A commentary on the state of the science. Employee Responsibilities and Rights Journal 6 (3):249-256.

Guerra, S. T., A. G. Prochnow, M. A. Trevizan, and L. d. A. Guido. 2011. Conflict in nursing management in the hospital context. Rev. Latino-Am. Enfermagem 19 (2):362-369.

Hartog, D., and R. Verburg. 2004. High performance work systems, organisational culture and firm effectiveness. Human Resource Management Journal 14 (1):55-78.

Hawkins, B. 2008. Double agents: Gendered organizational culture, control and resistance. Sociology 42 (3):418-435.

Heponiemi, T., H. Kuusio, T. Sinervo, and M. Elovainio. 2010. Job attitudes and wellbeing among public vs. private physicians: organizational justice and job control as mediators. European Journal of Public Health 21 (4):520-525.

Heritage, C. G. a. J. 1990. Conversation analysis. Annual Review of Anthropology 19:283307. 
Holdt, K. V., and M. Murphy. 2007. Public hospital in South Africa: Stressed institutions, disempowered managers. In State of the Nation: South Africa 2007 edited by S. Buhlungu, J. Daniel, R. Southall and J. Lutchman. Cape Town: HSRC press, 312.

Ibrahim, A. 2014. Poor health worker attitude: Are the health workers solely to blame or do health policy decisions contribute as well to this poor attitude? In Knowledge translation Network Africa, edited by E. Kajumba.

Ibrahim, A., and A. M. O'Keefe. 2014. Do infant birth outcomes vary among mothers with and without health insurance coverage in Sub-Saharan Africa? findings from the National Health Insurance and cash and carry eras in Ghana, West Africa. International Journal of MCH and AIDS 2 (2):200-208.

Jack, H., M. Canavan, A. Ofori-Atta, L. Taylor, and E. Bradley. 2013. Recruitment and retention of mental health workers in Ghana. PLOS One 8 (2e57940.):1-8.

Jehn, K. A., J. Rupert, and A. Nauta. 2006. "The effects of conflict asymmetry on mediation outcomes". International Journal of Conflict Management 17 (2):96-109.

Johns, J. L. 1996. A concept analysis of trust. Joumal of Advanced Nursing 24:76-63.

Kanfer, R. 1999. Measuring health worker motivation in developing countries. In Major Applied Research 5, 1-20.

Katz, J. D. 2007. Conflict and its resolution in the operating room. Journal of Clinical Anesthesia 19:152-158.

Koduah, A., H. van Dijk, and I. A. Agyepong. 2015. The role of policy actors and contextual factors in policy agenda setting and formulation: maternal fee exemption policies in Ghana over four and a half decades. Health Research Policy and System Journal. 13 (27):1-20.

Koduah, A., H. van Dijk, and I. A. Agyepong. 2016. Technical analysis, contestation and politics in policy agenda setting and implementation: the rise and fall of primary care maternal services from Ghana's capitation policy. BMC Health Service Research 16 (323):1-14.

Koenig, M., M. Hossain, and M. Whittaker. 1997. The influence of quality of care upon contraceptive use in rural Bangladesh. Studies in Family Planning 28 (4):278-289.

Konovsky, M. A. 2000. Understanding procedural justice and its impact on business organizations. Journal of Management 26 (3):489-511.

Konovsky, M. A., and R. Cropanzano. 1991. Perceived fairness of employee drug testing as a predictor of employee attitudes and job performance. Journal of Applied Psychology 76 (5):698-707.

Larbi, G. A. 1998. Institutional constraints and capacity issues in decentralizing management in public services: The case of health in Ghana. Journal of International Development 10:377-386.

- - - 2005. 'Freedom to manage', task networks and institutional environment of decentralized service organizations in developing countries. International Review of Administrative Sciences 71 (3):447-462.

Laschinger, H. K. S. 2003. R-E-S-P-E-C-T Just a little bit: Antecedents and consequences of nurses' perceptions of respect in hospital settings. Paper read at National Nursing Administration Research Conference, at Chapel Hill, North Carolina.

- - - 2004. Hospital nurses' perceptions of respect and organizational justice. JONA 34 (7/8):354-364.

Laschinger, H. K. S., J. Finegan, J. Shamian, and S. Casier. 2000. Organizational trust and empowerment in restructured healthcare settings: Effects on staff nurse commitment. The Journal of Nursing Administration 30 (9):413-425.

Latham, G. P., and C. C. Pinder. 2005. Work motivation theory and research at the dawn of the twenty-first century. Annual review of psychology 56:485-516. 
Leon, N., F. Bhunu, and C. Kenyon. 2001. Voices of facility managers. In South African Health Review, edited by F. S. Antoinette Ntuli, Peter Barron, David McCoy. Durban: Health System Trust, 207-220.

Leventhal, G. S. 1976. What should be done with Equity Theory? New approaches to the study of fairness in social relationships In Social Exchange: advances in theory and research edited by K. Gergen, M. Greenberg and R. Willis. New York: Plenum 27-55.

Lin, H.-F. 2007. Effects of extrinsic and intrinsic motivation on employee knowledge sharing intentions. Journal of Information Science 33 (135):135-149.

Lipsky, M. 1980. Street-level Bureaucracy:Dilemmas of the Individual in Public Services. New York: Russell Sage Foundation.

Long , D., C. Hunter, and S. van der Geest. 2008. When the field is a ward or a clinic: Hospital ethnography. Anthropology \& Medicine 15 (2):71-78.

Luoma, M. 2006. Increasing the motivation of health care workers. In Technical brief: USAID, 1-4.

M.O.H. 2001. The Health of the Nation: Reflections on the first five year health sector programme of work 1997- 2001. Accra, Ghana: Ministry of Health.

- - - 2007. Health sector 5 year programme of work 2002 - 2006: Independent Review of POW-2006. Accra, Ghana: Ministry of Health.

Manongi, R. N., T. C. Marchant, and I. C. Bygbjerg. 2006. Improving motivation among primary health care workers in Tanzania: a health worker perspective. Human Resources for Health 4:(6.) 1-7.

Mansour, J. B., S. Vriesendorp, and A. Ellis. 2005. Managers Who Lead: A handbook for improving Health Services. Edited by J. Miller, C. Bahamon and B. K. Timmons. USA: Quebecor World.

Mathauer, I., and I. Imhoff. 2006. Health worker motivation in Africa: the role of nonfinancial incentives and human resource management tools. Human Resources for Health 4 (24):1-17.

Mbindyo, P., L. Gilson, D. Blaauw, and M. English. 2009a. Contextual influences on health worker motivation in district hospitals in Kenya. Implementation Science 4 (43):1-10.

Mbindyo, P. M., D. Blaauw, L. Gilson, and M. English. 2009b. Developing a tool to measure health worker motivation in district hospitals in Kenya. Human Resources for Health 7:(40)1-11

McLaughlin, C., and A. Kaluzny. 1994. Continuous Quality Improvement in Health Care: Theory, Implementation and Application. 2nd ed. Gaithersburg, Maryland: Aspen publishers, Inc.

Mensah-Tsotorme, E. 20 Judges, Magistrates dismissed. New Times Corporation, 2015 [cited 24th December, 2015]. Available from http://www.ghanaiantimes.com.gh/20-judges-magistrates-dismissed/

Merriam, S. B., J. Johnson-Bailey , M.-Y. Lee , Y. Kee , G. Ntseane, and M. Muhamad. 2001. Power and positionality: negotiating insider/outsider status within and across cultures. International Journal of Lifelong Education 20 (5):405-416.

Ministry of Health. 2011. Ghana Human Resources for Health Country Profile: Republic of Ghana, World Health Organisation, European Union, Global Workforce alliance.

Ministry of Health, Government of Ghana, and United Nations. 2011. Ghana MDG Acceleration framework and country action plan: Maternal Health. Accra, Ghana: Ministry of Health (MoH), Government of Ghana and United Nations.

Mintzberg, H. 1979. The Structuring of Organisations. United States of America: PrinticeHall. 
- - - . 1983. Power in and around organisations. USA: Prentice-Hall.

Mohammed, A., J. Wu, T. Biggs, and S. Duffy. 2012. Differences in the perception of urgency of cesarean delivery between obstetricians and anesthetists. International Federation of Gynecology and Obstetrics: 117 (3) 292.

Mulemi, B. A. 2010. Coping with cancer and adversity: Hospital Ethnography in Kenya. Doctoral thesis, Faculty of Social and Behavioural Sciences, University of Amsterdam.

Mullings, B. 1999. Insider or outsider, both or neither: some dilemmas of interviewing in a cross-cultural setting. Geoforum 30:337-350.

Mutale, W., H. Ayles, V. Bond, M. T. Mwanamwenge, and D. Balabanova. 2013. Measuring health workers' motivation in rural health facilities: Baseline results from three study districts in Zambia. Human Resources for Health 11 (8):1-16.

Narayan, K. 1993. How native is a "Native" Anthropologist? American Anthropologist 95 (3):671-686.

National Development Planning Commission, Government of Ghana, and United Nations Development Programme (UNDP) Ghana. 2010. 2008 Ghana Millennium Development Goals report. Accra: National Development Planning Commission (NDPC), Government of Ghana and the United Nations Development Programme (UNDP) Ghana.

National Health Insurance Authority. 2013. "Towards universal health coverage: Increasing enrolment whilst ensuring sustainability". Accra: National Health Insurance Authority.

Ntim, S. 2013. Economic governance and social accountability. In: Andoh IF (ed). The Catholic Standard. Accra: Standard Newspapers and Magazines Ltd.

Nyikuri, M., B. Tsofa, E. Barasa, P. Okoth, and M. Sassy. 2015. Crises and resilience at the frontline-Public health facility managers under devolution in a sub-county on the Kenyan Coast. PLOS One:1-18.

Okello, D. R. O., and L. Gilson. 2015. Exploring the influence of trust relationships on motivation in the health sector: A systematic review. Resources for Health 13 (16):1-18.

Ortner, S. B. 2006. Anthropology and Social Theory. Durham and London: Duke University Press.

Ostroff, C. 1992. The relationship between satisfaction, attitudes and performance: an organizational level analysis. 1992. Journal of Applied Psychology 77 (6):963-974.

Parliament of the Republic of Ghana. 2003. Labour Act, 2003 (Act 651). Accra: Ministry of Labour and employment and social welfare National Legislative Bodies.

Patton, M. Q. 2002. Qualitative and Research Evaluation Methods. Third Edition ed. London, New Delhi: Sage Publication.

Pavlakis, A., D. Kaitelidou, M. Theodorou, P. Galanis, P. Sourtzi, and O. Siskou. 2011. Conflict management in public hospitals: the Cyprus case. International Nursing Review 58:242-248.

Pfeffer, J. 1981. Power in Organisations. Massachusetts: Ballinger Publishing Company.

Pondy, L. R. 1967. Organizational conflict: concepts and models. Administrative Science Quarterly 12 (2):296-320.

Prytherch, H., M. T. Leshabari, C. Wiskow, G. A. Aninanya, D. C. V. Kakoko, M. Kagone, J. Burghardt, G. Kynast-Wolf, M. Marx, and R. Sauerborn. 2012. The challenges of developing an instrument to assess health provider motivation at primary care level in rural Burkina Faso, Ghana and Tanzania. Glob Health Action 5 (19120):1-18. 
Purohit, B., and T. Bandyopadhyay. 2014. Beyond job security and money: Driving factors of motivation for government doctors in India. Human Resources for Health 12 (12):1-13.

Razee H, Whittaker M, Jayasuriya R, and Yap L. 2012. Brentnall L. Listening to the rural health workers in Papua New Guinea - the social factors that influence their motivation to work. Soc Sci Med. 75 (5):828-835.

Republic of Ghana. 2012. National assessment report on achievement of sustainable development goals and targets for Rio+20 Conference. Accra: Ministry of Environment, Science and Technology.

Republic of Ghana Act 525. 1996. Ghana Health Service and Teaching Hospitals Act edited by P. o. t. R. o. Ghana. Accra, Ghana: Government Printer Assembly Press, 1-24.

Rosaldo, R. 1989. Culture and Truth: The Remaking of Social Analysis. Boston: Beacon Press.

Rosenstein, A. H. 2011. Managing disruptive behaviors in the health care setting: focus on obstetrics services. American Journal of Obstetrics \& Gynecology 204 (3):187192.

Rowe, A. K., D. de Savigny, C. F. Lanata, and C. G. Victora. 2005. How can we achieve and maintain high-quality performance of health workers in low-resource settings? Lancet 366 (9490):1026-1035.

Senah, K. 2003. Maternal mortality in Ghana: The other side. Research Review NS 19 (1):47-55.

Slack, T., and M. M. Parent. 2006. Understanding Sport Organisations: The Application of Organisation Theory. Vol. 2. United States of America: Sheridan Books.

Smits, F. 2011. "I don't mind, they'll blame you anyway!” An Ethnographic Research on a Labour Ward of a Ghanaian Hospital. Master's Thesis, Medical Anthropology \& Sociology, University of Amsterdam.

Snow, R., C. H. Herbst, D. Haddad, J. Kwansah, J. Antwi, and F. V. Ekey. 2012. The distribution of health workers. In Towards interventions in human resources for Health in Ghana, edited by E. Appiah-Denkyira, C. H. Herbst, A. Soucat, C. Lemiere and K. Saleh. Washington DC: The World Bank, Ministry of Health 4963.

Songstad, N. G., O. B. Rekdal, D. A. Massay, and A. Blystad. 2011. Perceived unfairness in working conditions: The case of public health services in Tanzania. BMC Health Services Research 11 (34):1-15.

Spradley, J. 1980. Participant Observation. Orlando, FL: Harcourt Brace Jovanovich.

Stinglhamber, F., D. De Cremer, and L. Mercken. 2006. Perceived support as a mediator of the relationship between justice and trust : A multiple foci approach. Group $\mathcal{E}$ Organization Management 31 (4):442-468.

Thachil, J., and C.-H. Toh. 2009. Disseminated intravascular coagulation in obstetric disorders and its acute haematological management. Blood Reviews 23:167-176.

The, A.-M. 1999. Emotie en inzicht: Eigen onderzoekservaringen als data. Medische Anthropologie 11 (2):323-234.

Thom, D., M. Hall, and G. Pawlson. 2004. Measuring patients' trust in physicians when assessing quality of care. Health Affairs 23 (4):124-132.

Thu, N. T. H., A. Wilson, and F. McDonald. 2015. Motivation or demotivation of health workers providing maternal health services in rural areas in Vietnam: Findings from a mixed-methods study. Human Resources for Health 13 (91):1-11.

Tsuda, T. 1998. Ethnicity and the Anthropologist: Negotiating identities in the field. Anthropological Quarterly 71 (3):107-124. 
Turkson, P. 2009. Perceived quality of healthcare delivery in a rural district of Ghana. Ghana Medical Journal 43 (2):65-70.

Unger, J.-P., J. Macq, F. O. Bredo, and M. Boelaert. 2000. Through Mintzberg's glasses: a fresh look at the organization of ministries of health. Bulletin of the World Health Organization 78 (9):105-1014.

Van der Geest, S., and K. Finkler. 2004. Hospital ethnography: Introduction. Social Science \& Medicine 59 (10):1995-2001.

van der Geest, S., T. Gerrits, and F. S. Aaslid. 2012. Introducing 'Ethnography and SelfExploration'. Medische Anthropologie 24 (1):1-25.

Van der Geest, S., and S. Sarkodie. 1998. The fake patient: A research experiment in a Ghanaian Hospital. Soc. Sci. Med. 47 (9):1373-1381.

Vivar, C. G. 2006. Putting conflict management into practice: a nursing case study. Journal of Nursing Management 14:201-2006.

Westaway, M., P. Rheeder, D. Vanzyl, and J. Seager. 2003. Interpersonal and organizational dimensions of patient satisfaction: the moderating effects of health status. Int J Qual Health 15 (4):337-344.

Whetten, D. A., K. Cameron, and M. Woods. 1996. Effective Conflict Management. Edited by D. A. Whetten and K. S. Cameron. Hammersmith, London: HarperCollins Publishers.

WHO. 2013. World Health Organization Health Systems Strengthening Glossary. WHO 2011 [cited 17 October 2013]. Available from http://www.who.int/healthsystems/Glossary_January2011.pdf.

Wikipedia. 2015. Anas Aremeyaw Anas 2015 [cited 30th September, 2015]. Available from https://en.wikipedia.org/wiki/Anas_Aremeyaw_Anas.

Willis-Shattuck, M., P. Bidwell, S. Thomas, L. Wyness, D. Blaauw, and P. Ditlopo. 2008. Motivation and retention of health workers in developing countries: A systematic review. BMC Health Services Research 8:247.

Wind, G. 2008. Negotiated interactive observation: Doing fieldwork in hospital settings. Anthropology \& Medicine 15 (2):79-89.

Witter, S., A. Kusi, and M. Aikins. 2007. Working practices and incomes of health workers: Evidence from an evaluation of a delivery fee exemption scheme in Ghana. Human Resources for Health 5 (1):1-10.

Yin, R. K. 2009. Case Study Research: Design and Methods. Edited by L. Bickman and D. J. Rog. Vol. 5. United States of America: SAGE.

Zaman, S. 2004. Poverty and violence, frustration and inventiveness: Hospital ward life in Bangladesh. Social Science \& Medicine 59 (2004) 2025-2036 59 (2004):2025-2036.

- - . 2008. Native among the Natives: Physician Anthropologist doing hospital ethnography at home. Journal of Contemporary Ethnography 37 (2):135-154.

Zand, D. E. 1972. Trust and managerial problem solving. Administrative Science Quarterly 17 (2):229-239.

Zapata-Phelan, C. P., J. A. Colquitt, B. A. Scott, and B. Livingston. 2009. Procedural justice, interactional justice, and task performance: The mediating role of intrinsic motivation. Organizational Behavior and Human Decision Processes 108:93-105.

Zydziunaite, V., and E. Katiliute. 2007. Improving motivation among health care workers in private health care organizations: A perspective of nursing personnel. Baltic Journal of Management 2:213-224. 


\section{Appendix 1: Managers' consent form}

\section{FRONTLINE HEALTH WORKER MOTIVATION IN THE PROVISION OF MATERNAL AND NEONATAL HEALTH CARE}

\section{Consent form for Managers}

Introduction: Hello, my name is Matilda Aberese Ako. I am a student at the Wageningen University in the Netherlands and I am carrying out a study which is a collaboration between the university and the Ghana health service. I will like to have a discussion with you in connection with the study. The purpose of our discussion is to help me understand and describe factors affecting frontline health worker motivation, morale and attitude in providing maternal and neonatal health care and how and why these factors affect their performance. Description: In this regard, I will discuss with you issues regarding your work, work experience, life history, your views on the health delivery system, organisational issues, administrative issues, managerial issues and client or patient issues.

Risks and Benefits: The risks in this interview are: some of the questions might be uncomfortable and it will take a bit of your time: it will take a duration of 45 minutes to one hour. There are no financial benefits, however, we hope the results of the study will inform policy on frontline worker-client relations, which will go a long way to contribute to interventions aimed at improving worker responsiveness to clients' needs and expectations.

Confidentiality: I will like to assure you that your responses will remain confidential, and will only be used for the purposes of this study. None of the issues that you will discuss with me will be disclosed to your colleagues, superiors, subordinates or any other person; besides the report on this study will not use original names of respondents. Your participation is voluntary and so you have the right to refuse or to participate in this conversation. You have the right to refuse to answer any question, and you can terminate the conversation at any time.

If you have any questions or concerns about this study, you may contact the following: Dr. Daniel Arhinful on 0244573610 or Matilda Aberese Ako on 0248233397 or the Ghana Health Service Ethical Review Committee Administrator Ms. Hannah Frimpong on 0202920651.

Before we proceed you are free to ask me questions.

Consent statement of Participant: "I have read the foregoing information, or it has been read to me. I have had the opportunity to ask questions about it and any question I have asked have been answered to my satisfaction. I consent voluntarily to participate as a subject in this study and understand that I have the right to withdraw from the study at any time" 
Consent: Participate agrees to participate in the study: Yes........1 (continue), No........2 (end interview)

Signature of participant:...................... Date:......

Signature of interviewer:........................ Date:. 


\title{
Appendix 2: Frontline health workers' consent form
}

\author{
STUDY ON FRONTLINE HEALTH WORKER MOTIVATION THE PROVISION OF MATERNAL \\ AND NEONATAL HEALTH CARE
}

Frontline health workers' Consent form

Introduction: Hello, my name is Matilda Aberese Ako. I am a student at the Wageningen University in the Netherlands and I am carrying out a study which is a collaboration between the university and the Ghana Health Service. I will like to have a discussion with you in connection with the study. The purpose of the discussion is to help me understand and describe factors affecting frontline health worker motivation, morale and attitude in providing maternal and neonatal health care and how and why these factors affect your performance. Description: In this regard, I will discuss with you issues regarding your work, work experience, life history, your views on the health delivery system, organisational issues, administrative and managerial issues and client or patient issues.

Risks and Benefits: The risks in this discussion are: some questions might be uncomfortable and it will take a bit of your time, a duration of one hour to one hour thirty minutes. There are no financial benefits, however, we hope the results of the study will inform policy on frontline worker-client relations, which will go a long way to contribute to interventions aimed at improving worker responsiveness to clients' needs and expectations in Ghana.

Confidentiality: I will like to assure you that your responses will remain confidential, and will only be used for the purposes of this study. None of the issues that you will discuss with me will be disclosed to your colleagues, superiors, subordinates, clients or any other person, besides the report of this study will not use original names of respondents. Your participation is voluntary and so you have the right to refuse or agree to participate in this discussion. You have the right to refuse to answer any question, and you can terminate the discussion at any time.

If you have any questions or concerns about this study, you may contact the following: Dr. Daniel Arhinful on 0266177515, Matilda Aberese Ako on 0248233397 or the Ghana Health Service Ethical Review Committee administrator Ms. Hannah Frimpong on 0202920651.

Before we proceed you are free to ask me questions.

Participant consent statement: "I have read the foregoing information, or it has been read to me. I have had the opportunity to ask questions about it and any question I have asked have been answered to my satisfaction. I consent voluntarily to participate as a subject in this study and understand that I have the right to withdraw from the study at any time" 
Consent: Participant agrees to participate in this study: Yes.......1 (continue), No........2 (end interview)

Signature of participant:...................... Date:......

Signature of interviewer:..................... Date:. 


\section{Thesis summary}

The health of mothers and neonates is a concern for many countries, because they form the future of every society. In Ghana efforts have been made to address quality health care in order to accelerate progress in maternal and child health and reduce maternal and neonatal mortality through the implementation of a number of polices including a fee exemption for pregnant women for antenatal, delivery and postnatal care and a national health insurance scheme among others. However these interventions have not led to an improvement in the quality of health care and concerns have been raised whether health workers are sufficiently motivated to provide health care that is responsive to the needs of mothers and children. This study set out to study motivation as an individual quality of the worker, however it became obvious in the analytical phase that motivation is an outcome of interactions between the worker and the work environment. So the research resorted to analyse and understand the various ways in which interpersonal interactions and organisational processes contribute to the motivation of health workers and quality of care in a Ghanaian hospital setting. The research tried to answer the following questions: what are the interpersonal processes that influence health worker motivation; what are the organisational and managerial processes that influence health worker motivation; how does the setup of the Ghana health sector and its associated policies influence health worker motivation and how does health worker motivation influence health worker response to client health needs? The research focused on the quality of interpersonal interaction, such as attitudes, motivation, trust and conflict, on a number of organizational characteristics such as power relations, power being defined as the ability to affect organizational outcomes, uncertainty in decision-making and the provision of resources to deliver quality health care and on wider policy-making that affects the ability of health care institutions to take care of the staff (remuneration, human resource management) and the decision-making space of health facility managers.

In order to investigate health worker motivation in a real life setting ethnographic research was conducted for twenty months in two hospitals; a specialist referral hospital and a district hospital that offer basic maternal and child health services in the greater Accra region in Ghana. Between 2011 and 2013, data was collected in mostly the maternity and new-born units of both hospitals. The researcher interacted with hospital staff including nurses, doctors, anaesthetists, orderlies, 
laboratory technicians, accounts officers and managers and collected data on daily activities and interactions in the hospital environment. The hospitals, which had different characteristics, were not selected for comparative purposes, but to enable a better understanding of how the organizational context influences worker motivation. Conversations were useful in helping the researcher to understand social phenomena. Interviews were conducted to explore social phenomena in depth. Participant observation was also a very important tool in helping the researcher to observe at firsthand how health care is provided in a natural hospital environment. An important source of information consisted of the reactions of hospital staff on the research and the researcher and the researcher's emotional reactions to this, as it helped her to experience motivation, which was very useful in understanding and analysing motivational processes in the hospital environment.

Ethical clearance was obtained from the Ghana Health Service Ethics Review board (approval number GHS-ERC:06/01/12) and the proposal was reviewed by the Wageningen School of Social Sciences board. Written informed consent was obtained from all interview participants. Verbal consent was obtained for conversations and pseudonyms are used for the names of the study hospitals and frontline workers throughout the thesis.

Interpersonal processes including limited interaction and communication between collaborating frontline workers and perceived disrespect from colleagues and managers contributed to poor relations between frontline workers. A high number of frontline workers engaged in locum (private practice) in private hospitals. Such workers came to work late, or left early and some even skipped their official work to engage in locum practice. Workers also believed that some of their colleagues sneaked in their clients from their locum site to the hospital and charged them illegal fees, which they did not share with colleagues. Such practices and perceptions contributed to distrust relations among workers and to a poor organisational climate, which resulted in demotivation of staff, poor collaboration in the provision of health care, and eventually to conflicts. Conflicts contributed to delays in the provision of care and those who were willing to work felt disempowered, as they were unable to marshal their resources with collaborating professionals to respond to clients' needs. They also contributed to angry and bitter workers and negative perceptions of other professional groups. Sometimes cases were postponed and on some occasions clients had to be referred to other facilities. 
Organisational and managerial processes equally influenced health worker motivation in various ways. Health workers perceived distributive, procedural and interactional injustice in organisational and managerial processes as they perceived that managers were not responding to their personal and organisational needs, which compromised their ability to offer quality health care. Health workers perceived distributive injustice in the fact that they worked hard and deserved to be given incentives to offset the stoppage of bonuses that the government initially paid to workers when the fee exemption for maternal health was introduced. Workers felt their managers were not meeting the hospitals' needs for essential medical supplies, equipment and were incapable of putting up appropriate infrastructure to accommodate workers and an overwhelming number of clients. They perceived interactional injustice because of the fact that managers did not communicate with them on decisions that affected them and that managers were out of touch with the needs of workers. They complained that they were not respected by their superiors, who shouted at them when they made mistakes, and suggested that managers and superiors did not treat them with dignity in matters of discipline. Workers further argued that managers did not care whether they had adequate workforce to support them to provide quality health care. Some felt overworked and some felt burn out.

However, managers felt disempowered at their level as well. The setup of the Ghana health sector and its associated policies remains largely centralised, so managers who are expected to meet the needs of frontline health workers and their hospitals, do not have the power to do so. They could not beef up staff numbers, since recruitment and allocation of staff to health facilities is centralised. In addition, managers received little financial support to run their hospitals. Their main source of funding was from reimbursement of funds from the National Health Insurance Authority, but reimbursement usually delayed for up to six months and they did not receive subvention from the Ghana Health Service or the Ministry of Health $(\mathrm{MOH})$ to run their hospitals, so they were always cash strapped. Also the $\mathrm{MOH}$, which is the body responsible for putting up infrastructure, could not meet the infrastructure needs of the hospitals. Additionally managers had to deal with conflicting policies including procurement policies that made decisions on purchasing essential supplies and drugs bureaucratic and slowed managers' response to frontline worker and organisational needs. As a result, managers faced uncertainty in securing human and physical resources. To cope with uncertainties managers had to distribute their funds thinly 
among competing priorities of worker and organisational needs. At times managers had to sacrifice certain needs of workers and their hospitals in order to meet others. Consequently, workers lost trust in managers, which demotivated them in the provision of health care. Also the fee exemption policy made health care accessible to the general populace, but it did not lead to a commensurate increase in salaries, infrastructure development and increase in staff numbers. For that matter managers and frontline workers were overwhelmed with client numbers and had to turn some away. Both hospital managers and frontline workers perceived that policy makers and their superiors were not interested in how they provided care to clients or even their own safety, which demotivated them.

It is important to note that some workers were observed to be intrinsically motivated and responded to the health needs of clients, despite the fact that they faced similar challenges as those who were demotivated. Such workers explained that their sources of motivation included a belief in a supreme being, the desire to maintain work standards and others perceived that clients had a right to quality health care. Also some indicated that they derived inner satisfaction when they were able to provide quality care to clients.

Demotivation contributed to absenteeism, workers reporting to work late and some closing early as strategies to avoid collaborating with colleagues that they did not feel comfortable working with, which further worsened the conflict situation. Some workers also picked and chose to work with particular professionals. Workers exercised power negatively in two ways: 1 . Some workers exhibited negative attitudes towards their colleagues, which contributed to poor interaction and poor communication. It further created gaps in clinical decision making. 2. Workers transferred their frustrations and disappointments to clients by shouting at clients and insulting them, which compromised with the quality of care that clients received. Another important consequence of demotivation was that workers got angry, some felt frustrated, and some reported experiencing high blood pressure. Consequently it affected the wellbeing of health workers who were supposed to cater for clients. Also demotivation became so deeply seated in some workers that they appeared to be beyond redemption. Some even hated the hospital environment that they worked in and others chose to leave the hospital.

For health workers to be able to respond to the health needs of clients who visit the hospital there is the need that their personal needs including demand for better 
terms and conditions of service, incentives and training needs are catered for. Also their organisational needs including demand for essential supplies, equipment, appropriate infrastructure among others need to be addressed. Additionally managers have to be transparent, communicate and interact more frequently with frontline workers to enable them appreciate managers' efforts in meeting workers' personal and organisational needs. Also for managers to be able to meet the needs of frontline workers and their organisations managers must be given the power to make decisions on human and other resources. Also managers should be supported with the necessary funds, so that they can meet the multiple needs of their workers and hospitals.

Health worker motivation in the hospital context is determined by an interaction of interpersonal and organisational processes that are shaped by external and internal influencers, who exercise power in their bid to influence organisational outcomes. Thus this study contributes to theory by propounding that motivation is not an individual quality of the worker, but it is an outcome of interactions between the worker and the work environment. Also power and trust relations within and outside the hospital influence worker motivation and for that matter theories on organisational power and trust relations are central to understanding and analysing worker motivation. 


\section{About the author}

Matilda Aberese-Ako is a health research officer with the Navrongo Health Research Centre under the research and development division of the Ghana Health Service in Ghana. She attended the Tamale Secondary School (Tamasco) for her O' Levels and A' Levels from 1986 to 1993. She proceeded to the University for Development Studies from 1994 to 1998, where she pursued a Bachelor of Arts honours degree in Integrated Development Studies. She did her national service with the World Neighbours and went on to teach social studies at her Alma Mater, Tamasco in 1999 and 2000. Later in 2000 she joined the Navrongo Health Research Centre (NHRC) as an assistant research officer on the female genital mutilation study and later on the adolescent sexual and reproductive health study. In 2003 she was offered a government of Netherlands fellowship to pursue a Master of Arts programme in Women, Gender and Development at the Erasmus University Institute of Social Studies in the Hague. She returned to the NHRC in 2004 to work as a research officer. In 2011 she obtained a WOTRO fellowship to pursue PhD studies in medical and organisational anthropology at Wageningen University.

Her research interests include human rights, gender, sexual and reproductive health and worker motivation. She has co-authored articles on human rights approach to the elimination of female genital mutilation, NGOs right based approaches to development and health worker motivation and attitudes in the provision of health care in Ghana and the rest of Africa. 


\section{Completed Training and Supervision Plan}

Wageningen School of Social Sciences (WASS)

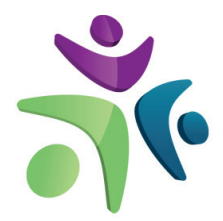

Matilda Aberese Ako

Wageningen School

of Social Sciences

\begin{tabular}{lllr}
\hline Name of the learning activity & Department/Institute & Year & ECTS* $^{*}$ \\
\hline $\begin{array}{l}\text { A) Project related competences } \\
\text { Ceres Orientation Course }\end{array}$ & CERES & 2011 & 10 \\
$\begin{array}{l}\text { Human Resource Management, ECS- } \\
57206\end{array}$ & WUR & 2011 & 6 \\
Time and project management & WGS & 2011 & 1.5 \\
Mobilising your scientific network & WGS & 2011 & 1.0
\end{tabular}

B) General research related competences

Interpretive master class analysis

WASS

2011

Methodology Seminars

CERES

2011

Information literacy including endnote

WGS

2011

0.6

introduction

'Tell them to sue us!": Challenges, Frustrations and their influence on frontline health workers'

Global Maternal Health

2013

motivation in the provision of quality maternal conference

health care in Ghana

'WHATEVER HE TELLS YOU IS A

LIE!':Trust and health worker attitudes in the

provision of maternal and neonatal health care

in Ghana

'Your Health Our Concern, Our Health Whose

Concern?': Perceptions of injustice in

Third International

2014

Organizational relationships and processes and

frontline health worker motivation in Ghana

Conference of the African

Health Economics and

Policy Association

"I used to fight with them but now I have

WASS, PhD Day

stopped!": Conflict and frontline health worker

motivation in the provision of maternal and

neonatal health care in a district hospital

'I don't care, you can take me anywhere, I

SDC research seminar

2015

1 won't take part!' Power, trust and the anthropologist in a biomedical environment 


\section{C) Career related competences/personal development}

The anthropological perspective

Introduction to Medical Anthropology

Research proposal writing

Workshops on accelerate programme
AMMA (Amsterdam
University)

AMMA

2011

7.5

WUR

Accelerate project

*One credit according to ECTS is on average equivalent to 28 hours of study load

Financial support of NWO-WOTRO, through the Global Health Policy and Health Systems programme is gratefully acknowledged. This research was part of the programme 'Accelerating progress towards attainment of MDG 4 and 5 in Ghana through basic health systems function strengthening', grant number W 07.45.102.00 